\title{
Craniofacial Characteristics of Syrian and Hungarian Adolescents with Class II Division 1 Malocclusion
}

\section{PhD Thesis}
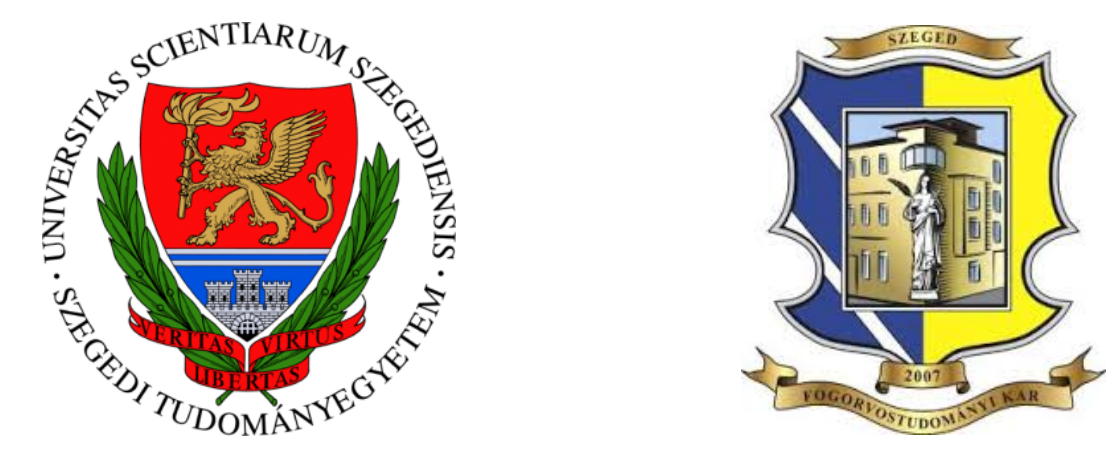

Dr. Alaa Al Ayoubi DMD, PgDip, MSc, SBODO

Department of Orthodontics and Pediatric Dentistry

Faculty of Dentistry

Doctoral School of Clinical Medicine

University of Szeged

Supervisor: Prof. Dr. habil. Melinda Madléna DMD, DSc, MBA

Szeged

2021 


\section{Table of Contents}

\section{Table of Contents}

1 List of publications ............................................................................................4

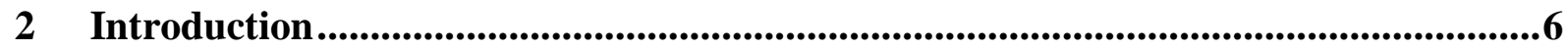

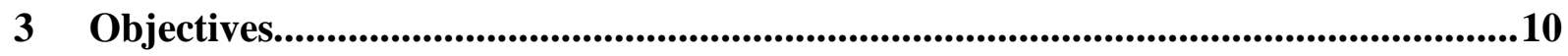

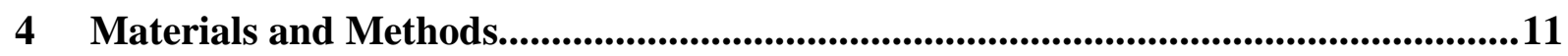

4.1 Subjects and sample size determination .................................................11

4.2 Cephalometric analyses and measurements ...............................................14

4.3 Orthodontic cast analyses and measurements............................................21

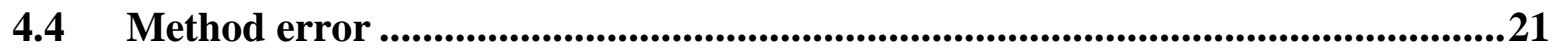

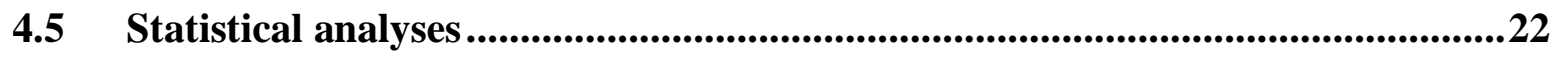

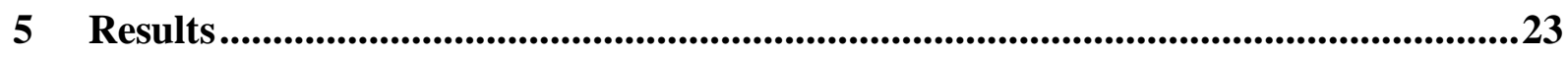

5.1 Cephalometric and tooth-size characteristics of Syrian adolescents with Class

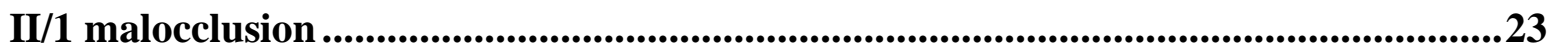

5.1.1 Cephalometric characteristics of Syrian adolescents with Class II/1

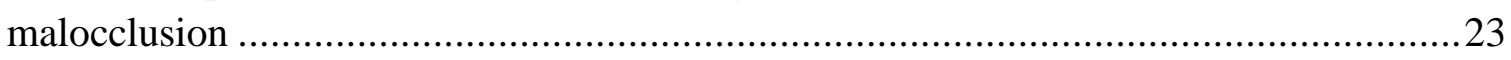

5.1.2 Tooth-size characteristics of Syrian adolescents with Class II/1 malocclusion .24

5.2 Dentoskeletal and tooth-size differences between Syrian and Hungarian adolescents with Class II/1 malocclusion................................................................26

5.2.1 Dentoskeletal cephalometric comparisons between Syrian and Hungarian adolescents with Class II/1 malocclusion ...............................................................2

5.2.2 Tooth-size comparisons between Syrian and Hungarian adolescents with Class

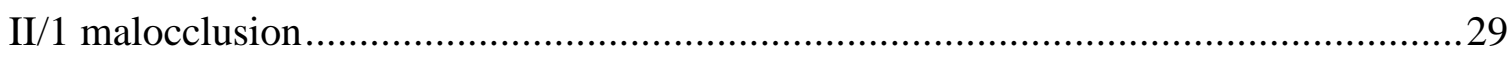

5.3 Upper airway differences between Syrian and Hungarian adolescents with

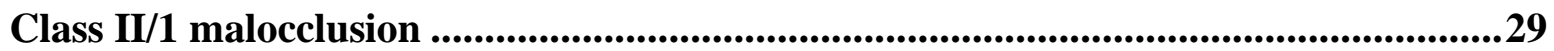

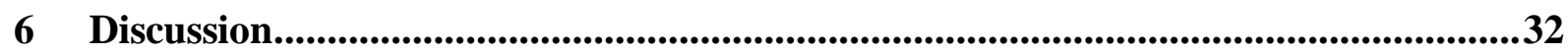

6.1 Cephalometric and tooth-size characteristics of Syrian adolescents with Class

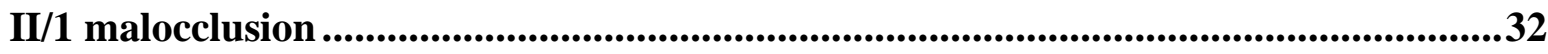

6.1.1 Skeletal components of Syrian adolescents with Class II/1 malocclusion.........32

6.1.2 Dentoalveolar components of Syrian adolescents with Class II/1 malocclusion35

6.1.3 Soft tissue components of Syrian adolescents with Class II/1 malocclusion ......35 
6.1.4 Upper airway dimensions of Syrian adolescents with Class II/1 malocclusion .36

6.1.5 Tooth-size characteristics of Syrian adolescents with Class II/1 malocclusion .37

6.1.6 Limitations and future scope of this investigation ........................................38

\subsection{Dentoskeletal and tooth-size differences between Syrian and Hungarian}

adolescents with Class II/1 malocclusion.....................................................................38

6.2.1 Differences in skeletal components between Syrian and Hungarian adolescents with Class II/1 malocclusion.

6.2.2 Differences in dentoalveolar components and tooth-size characteristics between

Syrian and Hungarian adolescents with Class II/1 malocclusion .................................39

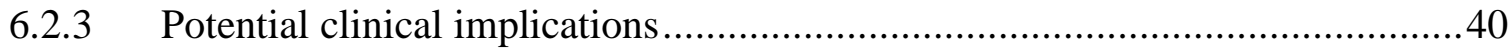

6.2.4 Limitations and future scope of this investigation .........................................41

\subsection{Upper airway differences between Syrian and Hungarian adolescents with}

Class II/1 malocclusion

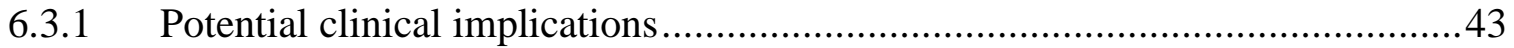

6.3.2 Limitations and future scope of this investigation ........................................ 43

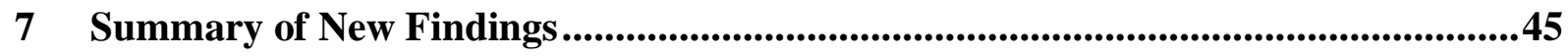

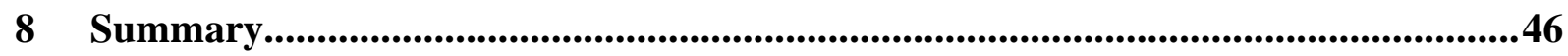

9 Supplementary Information...................................................................................47

$10 \quad$ List of abbreviations …..........................................................................................51

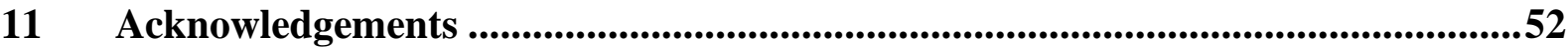

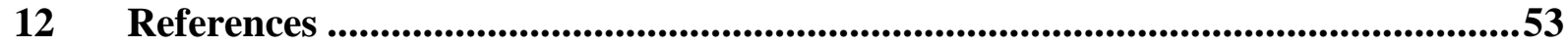

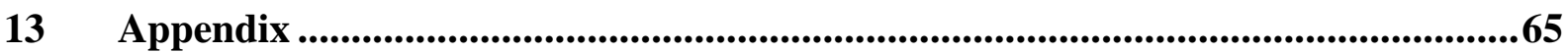




\section{List of publications}

Publications providing the basis of the thesis:

I- Al Ayoubi, Alaa $\square$; Dalla Torre, Daniel; Madléna, Melinda $\square$

Craniofacial characteristics of Syrian adolescents with Class II division 1 malocclusion: a retrospective study. PeerJ 8 Paper: e9545, 18 p. (2020).

Q1

$\mathrm{IF}=\mathbf{2 . 3 7 9}$

Citations: 2 (Independent Citations: 1)

II- Al Ayoubi, Alaa $\square$; Khandan Dezfully, Alireza; Madléna, Melinda $\square$

Dentoskeletal and tooth-size differences between Syrian and Hungarian adolescents with Class II division 1 malocclusion: a retrospective study. BMC Research Notes 13: 1 Paper: 270, 7 p. (2020).

Q2

\section{Citations: 3 (Independent Citations: 2)}

III- Al Ayoubi, Alaa $\square$; Madléna, Melinda $\square$

Upper airway characteristics in young individuals with Class II division 1 malocclusion: A retrospective inter-ethnic cephalometric comparison. (2021). Accepted (In press). Journal of Craniofacial Surgery.

Q2

IF $=0.953$

$\sum \mathrm{IF}=3.332$ 


\section{Publication on another topic:}

1- Roland Wirth, Gergely Maróti, Lídia Lipták, Mónika Mester, Alaa Al Ayoubi, Bernadett Pap, Melinda Madléna, Janos Minarovits, Kornél L. Kovács $\square$

Microbiomes in supragingival biofilms and saliva of adolescents with gingivitis and gingival health. (2021). In review. Oral Diseases.

(Q1

$\mathrm{IF}=\mathbf{2 . 6 1 3 )}$

Cumulative IF $=3.332(+2.613=5.945)$

Citable abstract directly related to the subject of the thesis:

1- Al Ayoubi, Alaa $\square$; Khandan Dezfully, Alireza; Madléna, Melinda. Dentofacial Differences between Syrian and Hungarian Adolescents with Class-II/1 Malocclusion. J Dent Res. 2019;98: 0384. www.iadr.org. https://iadr.abstractarchives.com/abstract/ced-iadr20193198648/dentofacial-differences-between-syrian-and-hungarian-adolescents-with-class-ii1malocclusion

\section{Lectures directly related to the subject of the thesis:}

1- Al Ayoubi, Alaa $\varangle$; Khandan Dezfully, Alireza; Madléna, Melinda. Dentofacial Differences between Syrian and Hungarian Adolescents with Class-II/1 Malocclusion. CEDIADR/NOF. Sept 19-21, 2019. Madrid.

2- Al Ayoubi, Alaa $\varangle$; Khandan Dezfully, Alireza; Madléna, Melinda. Comparison of Dentofacial Characteristics between Syrian and Hungarian Adolescents with Class II division 1 malocclusion. 8th Symposium of Hungarian Society of Orthodontics and Pediatric Dentistry. Nov 7-8, 2019. Siklós.

3- Al Ayoubi, Alaa $\varangle$; Khandan Dezfully, Alireza; Madléna, Melinda. Assessment of dentofacial characteristics in Middle Eastern (Syrian) young orthodontic patients with angle class II division 1 malocclusion. Symposium: "Research in oral cavity - from basic science to clinical use" organized within the framework of conference EFOP-3.6.2-16-2017-00006. Nov 22-23, 2018. Budapest.

4- Al Ayoubi, Alaa $\square$; Khandan Dezfully, Alireza; Madléna, Melinda. Assessment of Dentofacial Characteristics in Middle Eastern (Syrian) Young Orthodontic Patients with Angle Class II Division 1 Malocclusion. 22nd Congress of the Hungarian Association for Cranio-Maxillo-Facial Surgery and Scientific Meeting of Dentists. Sept 27-29, 2018. Szeged. 


\section{Introduction}

In orthodontics, it is essential to understand the complex relationship between skeletal, dental, and soft tissue aberrations in each malocclusion to achieve an accurate diagnosis followed by an optimal treatment plan.

Class II division 1 (Class II/1) malocclusion has been suggested as one of the most frequent pathologies that orthodontists may encounter in their practice. According to epidemiologic studies conducted among different populations, the prevalence of this malocclusion ranges from $12 \%$ to $40 \%$ worldwide (Table 1$)(1-21)$.

Table 1: Distribution of Class II/1 malocclusion in different populations.

\begin{tabular}{|c|c|c|c|c|}
\hline Series & Population & Size (n) & Age (y) & Class II/1 (\%) \\
\hline Bilgic, Gelgor \& Celebi, 2015 (1) & Turkish & 2329 & $12-16$ & 40.0 \\
\hline Onyeaso, 2004 (2) & Nigerian & 636 & $12-17$ & 12.3 \\
\hline $\begin{array}{l}\text { Borzabadi-Farahani, Borzabadi- } \\
\text { Farahani \& Eslamipour, } 2009 \text { (3) }\end{array}$ & Iranian & 502 & $11-14$ & 24.1 \\
\hline Thilander et al., 2001 (4) & Colombian & 4724 & $5-17$ & 14.9 \\
\hline Lew, Foong \& Loh, 1993 (5) & Chinese & 1050 & $12-14$ & 18.8 \\
\hline Foster \& Walpole Day, 1974 (6) & British & 1000 & $11-12$ & 27.2 \\
\hline Perillo et al., 2009 (7) & Italian & $703 * *$ & $12.2^{*}$ & 33.7 \\
\hline Albakri, Ingle \& Assery, 2018 (8) & Saudi & $500 \dagger$ & $12-15$ & 17.4 \\
\hline Tausche, Luck \& Harzer, 2004 (9) & German & 1975 & $6-8$ & 31.4 \\
\hline Silva \& Kang, 2001 (10) & Latin American & 507 & $12-18$ & 20.3 \\
\hline Saleh, 1999 (11) & Lebanese & 851 & $9-15$ & 16.9 \\
\hline Massler \& Frankel, 1951 (12) & American & 2728 & $14-18$ & 16.68 \\
\hline Shyagali et al., 2019 (13) & Indian & 171 & $12-16$ & 21.05 \\
\hline Bugaighis \& Karanth, 2013 (14) & Libyan & 343 & $12-17$ & 21.9 \\
\hline Nadim, Aslam \& Rizwan, 2014 (15) & Pakistani & 718 & $12-15$ & 17.8 \\
\hline El-Mangoury \& Mostafa, 1990 (16) & Egyptian & 501 & $18-24$ & 16.17 \\
\hline Thilander \& Myrberg, 1973 (17) & Swedish & 6398 & $7-13$ & $13.23 * * *$ \\
\hline Singh \& Sharma, 2014 (18) & Nepalese & 2010 & $12-15$ & 29.35 \\
\hline de Souza et al., 2016 (19) & Brazilian & 1014 & $7-11$ & 21 \\
\hline Gábris, Márton \& Madléna, 2006 (20) & )Hungarian & 483 & $16-18$ & 25.9 \\
\hline Alatrach, Saleh \& Osman, 2014 (21) & Syrian & 200 & $8-13$ & 16 \\
\hline
\end{tabular}


Numerous studies have investigated the cephalometric and tooth-size characteristics of patients with Class II/1 malocclusion using various measurements either on cephalometric radiographs or orthodontic casts. However, the significance of these studies is limited by multiple factors, including the conflicting results; some cephalometric studies have reported that a retrognathic mandible is the key factor contributing to Class II/1 malocclusion with a normally positioned maxilla (22-26). In contrast, other studies have indicated that maxillary protrusion is the most common feature of Class II/1 malocclusion with a neutral mandibular position $(27,28)$. Finally, some researchers have described the malpositioning of both the maxilla and mandible in this condition (29-31). Likewise, inconsistent results have been reported regarding the relationship between Class II/1 malocclusion and upper airway dimensions, where some investigators suggested Class II/1 malocclusion may have an influence on the upper airway dimensions (32-34) while other authors did not find significant correlation between upper airway dimensions and Class II/1 malocclusion (35-37). Further, a number of tooth-size studies have investigated Class II/1 malocclusion; their findings were also contradictory, with some results reporting significant differences in tooth-size ratios between Class II/1 malocclusion and Class I malocclusion or normal occlusion (38-40) and others indicating no significant differences in this regard (41-43).

Besides the conflicting results, the value of previous studies on Class II/1 malocclusion is limited due to the following additional factors:

- First, the influence of skeletal age variations on the reliability of the results has been neglected since samples in most previous studies on Class II/1 malocclusion were grouped according to chronological age $(22,23,25,26,29-31,44-51)$ or dental age $(27,52,53)$.

- Second, while most investigations selected the patients with Class II/1 malocclusion on the basis of dental relationships (molar and/or incisor relationships) (25,2731,44,46,47,50-52), the participants might have had either a Class I or Class II skeletal pattern; studies on both skeletal and dental Class II/1 malocclusions are lacking.

- Third, the craniofacial morphology of individuals with Class II/1 malocclusion has been analyzed during childhood $(45,46,50,52)$, adulthood (24) or by including subjects across a wide age range, from early childhood to adulthood $(23,25,29,49)$, whilst the age at which the vast majority of orthodontic patients seek treatment is the 
adolescence, when all treatment options and techniques are still available.

- Fourth, cephalometric and tooth-size measurements in orthodontic investigations have not been the focus of research in recent decades, only one study has included these measurements in the same investigation (54). This combination could provide a comprehensive diagnosis for the examined malocclusion and could help to understand the complex relationship between its components.

- Finally, It is also important to consider that most of the previous studies on Class II/1 malocclusion were performed on radiographs or casts of Caucasians or without mention of the ethnicity of the investigated subjects, ignoring the fact that ethnicity is an important influencing factor in Class II malocclusion $(30,45)$.

It is well established that Class II/1 malocclusion can be caused by a broad range of factors (22-31,46-49,51-53). However, conflicting results, possibly due to ethnic variations, have not allowed the general characterization of this malocclusion $(30,44,45,50)$. Likewise, ethnic differences have been observed in tooth-size ratios and upper airway morphology (55-60). Ethnic differences in cephalometric and tooth-size characteristics have been documented in several studies (54-56,61-69), but only few studies have investigated these differences with respect to Class II/1 malocclusion $(30,44,45,50)$. This malocclusion is one of the most frequently seen orthodontic anomalies in Syrian and Hungarian populations with prevalences of $16 \%$ and $23.5 \%$ in Syrian and Hungarian adolescents, respectively $(20,21)$.

Because of recent wars and conflicts, such as the Syrian conflict, ethnic diversity is increasing worldwide. During the last few years, Syrian refugees and immigrants have occupied the foreground of migration statistics, particularly in Europe (70). Data show that the population of Syrian immigrants reached 8.2 million in 2019 and are considered to be among the fastestgrowing populations of ethnic minorities $(71,72)$. This inflow of Syrian immigrants and refugees into Europe and in many areas worldwide demonstrates the need for updated studies to discover the craniofacial characteristics of these new immigrants. Former studies on Syrian populations aimed to establish cephalometric and tooth-size norms $(73,74)$. Limited data, however, are available for the characteristics of Syrian adolescents with Class II/1 malocclusion.

Such a view of recent trends in migration, especially from the Middle East toward Europe, 
also underscores the need for updated comparisons of cephalometric and tooth-size characteristics between different ethnic groups $(75,76)$. Although some research has considered some cephalometric and tooth-size norms of Syrian populations $(73,74)$, or some cephalometric and tooth-size characteristics of Hungarian populations $(77,78)$, no study has compared the cephalometric and tooth-size characteristics between Syrian and European (Hungarian) adolescents. This comparison would help orthodontists to optimize their treatment planning, considering the ethnic differences between Syrian and Hungarian orthodontic patients regarding their craniofacial and dental characteristics.

Over the past few decades, much attention has been directed toward investigating individuals with sleep-disordered breathing, including obstructive sleep apnea (OSA) (79). To this end, scholars have focused on estimating the underlying relationship between craniofacial structures and pharyngeal morphology in orthodontic populations to anticipate the occurrence of OSA and to enhance treatment effectiveness for OSA patients (80).

Class II/1 subjects with small pharyngeal airways tend to have features typical for OSA patients $(79,81,82)$, including a short and retruded mandible $(34,83-86)$, an anteroposterior discrepancy between the jaws (84,87-89), and a hyperdivergent growth pattern $(85,88,90)$. However, the relative contributions of skeletofacial and upper airway abnormalities may vary between ethnic groups. Inter-ethnic studies provide a good opportunity to identify the role of ethnicity in upper airway morphological variations. However, existing investigations that performed direct inter-ethnic comparisons are somewhat limited in number and are restricted to studies comparing Caucasian subjects with subjects of some ethnicities, particularly Asians (91), Polynesians (92), Hispanics (93), and African-Americans (94). Moreover, several other issues have limited the significance of previous inter-ethnic studies, because, on one hand, the absence of well-matched groups for skeletal age, sex, craniofacial skeletal pattern, and craniocervical angulation. On the other hand, most of these inter-ethnic investigations included only subjects with OSA and have not been able to characterize the full spectrum of variations among ethnic groups (91-93).

Class II/1 malocclusion is noted in a significant proportion of the population in clinical orthodontic practice, presenting a considerable number of features associated with OSA, and these features may vary among ethnicities. However, currently there is limited information 
available on upper airway differences between Middle Eastern (Syrian) and European (Hungarian) adolescents with Class II/1 malocclusion.

\section{Objectives}

- The first objective of this thesis is to elucidate the cephalometric and tooth-size characteristics of Syrian adolescents with skeletal and dental Class II/1 malocclusion and compare the acquired data with those of Syrian population norms.

- The second objective of this thesis is to compare the dentoskeletal and tooth-size characteristics between Middle Eastern (Syrian) and European (Hungarian) adolescents with skeletal and dental Class II/1 malocclusion.

- The third objective of this thesis is to compare the upper airway structures between Middle Eastern (Syrian) and European (Hungarian) adolescents with skeletal and dental Class II/1 malocclusion, and to investigate a number of skeletal and soft tissue parameters that would be associated with the upper airway depths in each ethnic group. 


\section{Materials and Methods}

\subsection{Subjects and sample size determination}

All procedures of the retrospective investigations presented in this thesis were approved by the Human Investigation Review Board at the University of Szeged (151/2018-SZTE) and the investigations were designed in accordance with the Declaration of Helsinki. Written informed consent to participate in these studies was provided by the participants' parent or legal guardian or next of kin.

All sample size calculations were performed on the basis of a significance level of alpha of 0.05 (two-sided) with a power of $80 \%$ using $G^{*}$ Power software version 3.1.9.4 (Heinrich Heine University Düsseldorf, Germany) (95,96), or according to Hulley et al., (2013) (97).

In order to calculate the required sample size to elucidate the characteristics of Syrian adolescents with Class II/1 malocclusion and compare the acquired data with those of Syrian population norms, effect sizes were estimated from previous similar dentofacial, upperairway, and tooth-size studies $(24,32,55)$. The effect size of the Pog-Np distance was estimated at $7.8( \pm 8.1) \mathrm{mm}(24)$, the effect size of the upper-pharyngeal width was estimated at $3.1( \pm 2.6) \mathrm{mm}(32)$, and the effect size of the upper first molar’s width was estimated at 0.2 $( \pm 0.2) \mathrm{mm}$ (55). The sample size was calculated to detect the standardized effect sizes of 0.96 (7.8/8.1 mm), 1.19 (3.1/2.6 mm), and 1 (0.2/0.2 mm) for dentofacial, upper airway, and toothsize comparisons, respectively. Sample size calculations when considering these three types of comparisons showed that 17 patients of each sex were necessary for inclusion in the Class II/1 Syrian group (97), in order to elucidate the characteristics of Syrian adolescents with Class II/1 malocclusion and compare with those of Syrian population norms.

Considering the dentoskeletal and tooth-size inter-ethnic compassions between Syrian and Hungarian adolescents with Class II/1 malocclusion, sample-size planning assumed that a bilateral t-test for independent variables was to be used for assessment. According to the previous similar dentoskeletal and tooth-size studies $(55,98)$, effect sizes were estimated from the SNGoMe angle 5.80 degrees ( \pm 5.78 degrees) (98), and the upper central-incisor width $0.54( \pm 0.52) \mathrm{mm}(55)$, respectively. The required sample size was calculated to detect 
standardized effect sizes of 1.00 (5.80/5.78 degrees) and $1.03(0.54 / 0.52 \mathrm{~mm})$ for dentoskeletal and tooth-size comparisons, respectively. Sample size calculation showed that 17 patients were required for each sex subgroup in each ethnic group (97).

For the upper airway inter-ethnic comparison between Syrian and Hungarian adolescents with Class II/1 malocclusion, sample-size planning was performed using G*Power software version 3.1.9.4 (Heinrich Heine University Düsseldorf, Germany) (95,96), under the assumption that a bilateral t-test for independent variables was to be used for assessment. The effect size of 1.07 (3.47/3.23 mm) was estimated from a previous similar upper airway interethnic study (99), based on the posterior airway space (PAS) measurement (99), and the sample size calculation showed that 15 patients were required for each sex in each ethnic group $(95,96)$. To investigate the correlations between upper airway depths and skeletofacial morphology in each ethnic group, sample-size planning assumed that a correlation coefficient test was to be used for assessment. The effect size of 0.488 was estimated from a previous similar correlation study (100), based on the correlation between uvula length and the minimal posterior airway space between the uvula and the posterior pharyngeal wall (PAS-UP) in the group with mandibular retrognathism (100), and sample size calculation showed that 30 patients were required for each ethnic group $(95,96)$.

As a consequence of the sample size planning, lateral cephalograms and dental casts of 86 untreated patients with skeletal and dental Class II/1 malocclusion were included in the investigations providing the basis of this thesis. The total sample consisted of two groups based on ethnicity: Group 1 ( $n=43$ ) was composed of Syrian patients selected from a private orthodontic office in Damascus, Syria, and group $2(n=43)$ was composed of Hungarian patients selected from the Department of Orthodontics and Pediatric Dentistry, Faculty of Dentistry, University of Szeged, Hungary, including 24 females and 19 males in each ethnic group. Each patient in group 1 was matched with a patient in group 2 by sex and skeletal age. In order to eradicate the bias caused by growth variations, skeletal age was assessed on lateral cephalograms according to the method developed by Baccetti et al. (2002) (101). Since a number of studies have recognized the effect of craniocervical angulation on the pharyngeal airway dimensions (102-105), and since the craniocervical angulation would vary even if the same protocol was used to obtain the cephalograms for each patient in both examined groups (106), the two groups were also compared to ensure compatible craniocervical angulation 
prior to upper airway comparison (OPT/NSL, P > 0.05). Age and sex distributions of the samples that were included in the investigations providing the basis of this thesis are summarized in Table 2.

Table 2. The demographic characteristics of the samples included in the investigations providing the basis of this thesis.

\begin{tabular}{|c|c|c|c|c|c|c|c|}
\hline & \multicolumn{3}{|c|}{ Syrians } & \multicolumn{3}{c|}{ Hungarians } & \multirow{2}{*}{ Total } \\
& Mean age \pm S.D (y) & Age range (y) & Sample size (n) & Mean age \pm S.D (y) & Age range (y) & Sample size (n) & \\
\hline Males & $14.1 \pm 1.7$ & $11.7-17.3$ & 19 & $14.0 \pm 2.0$ & $11.4-17.6$ & 19 & 38 \\
\hline Females & $14.6 \pm 1.4$ & $11.9-17.1$ & 24 & $14.6 \pm 1.8$ & $11.3-17.7$ & 24 & 48 \\
\hline Total & & & 43 & & & 43 & 86 \\
\hline
\end{tabular}

The criteria for inclusion were as follows:

- Age of between 12 and 17 years

- Syrian origin for Syrian group and Hungarian origin for Hungarian group

- Overjet of larger than $4 \mathrm{~mm}$

- Absence of upper incisor retroclination (1U/NA angle $\geq 22$ degrees)

- Permanent dentition

- Bilateral distal occlusion (half-unit or greater)

- ANB angle greater than 4 degrees with a convex facial profile

- Absence of extractions or interproximal caries/restorations or any other condition that affected the mesio-distal diameter of the teeth

The criteria for exclusion were as follows:

- Patients with craniofacial syndromes

- Patients with a history of trauma

- Patients with previous orthodontic treatment

- Patients with cephalograms in which a swallowing action or obvious hyperplasia of tonsils and adenoids was detected.

When cephalometric and tooth-size characteristics of Syrian adolescents with Class II/1 malocclusion were compared with Syrian population norms, the Syrian normative 
cephalometric and tooth-size measurements were obtained from two previous studies used as sources of Syrian normative measurements $(73,74)$. Age and sex distributions in the Syrian normative studies' samples used as sources of Syrian normative measurements are shown in Supplementary Table 1.

\subsection{Cephalometric analyses and measurements}

Pretreatment lateral cephalograms were obtained for each patient in both ethnic groups using the same protocol: head in the natural position and the teeth in maximal intercuspation. A dental radiograph system (PAX 400; Vatech Co., Hawseong, Korea) was used to acquire cephalograms for Class II/1 Syrian Samples. The same X-ray machine was used to acquire cephalograms for the Syrian normative cephalometric sample using the same protocol (73). Another dental radiograph system (Gendex (GXDP-800 ${ }^{\mathrm{TM}}$ ); Hatfield, PA, USA) was used to acquire cephalograms for Class II/1 Hungarian Samples. Because the cephalograms for Class II/1 Syrian samples and Class II/1 Hungarian samples were acquired with two different machines, the magnification was corrected to 1:1 using a special orthodontic software

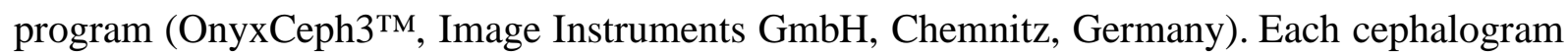
was digitized, calibrated, and analyzed by one investigator using the above-mentioned special orthodontic software program (OnyxCeph3 ${ }^{\mathrm{TM}}$ ).

In order to investigate potential upper airway obstructions in Syrian adolescents with Class II/1 malocclusion, upper-pharyngeal widths were computed for all Class II/1 Syrian subjects whose values were equal to $5 \mathrm{~mm}$ or less according to McNamara (1984) (107).

Definitions of all cephalometric landmarks used in this thesis are presented in Supplementary Table 2.

The cephalometric measurements used to compare the cephalometric characteristics between Syrian adolescents with Class II/1 malocclusion and Syrians with normal occlusion were derived from the analyses developed by McNamara (1984) and McNamara et al. (1992) $(107,108)$, since the same analyses were used by the Syrian normative cephalometric study (73). Table 3 shows the definitions of the cephalometric measurements that were used to compare the cephalometric characteristics between Syrian adolescents with Class II/1 malocclusion and Syrians with normal occlusion. These cephalometric measurements were developed by McNamara (1984) and McNamara et al. (1992) (107,108). Figure 1 illustrates 
reference landmarks and lines that were used to compare the cephalometric characteristics between Syrian adolescents with Class II/1 malocclusion and Syrians with normal occlusion. These reference landmarks and lines obtained from the analyses developed by McNamara (1984) and McNamara et al. (1992) (107,108).

Table 3: Definitions of the cephalometric measurements used to compare between Syrian adolescents with Class II/1 malocclusion and Syrians with normal occlusion.

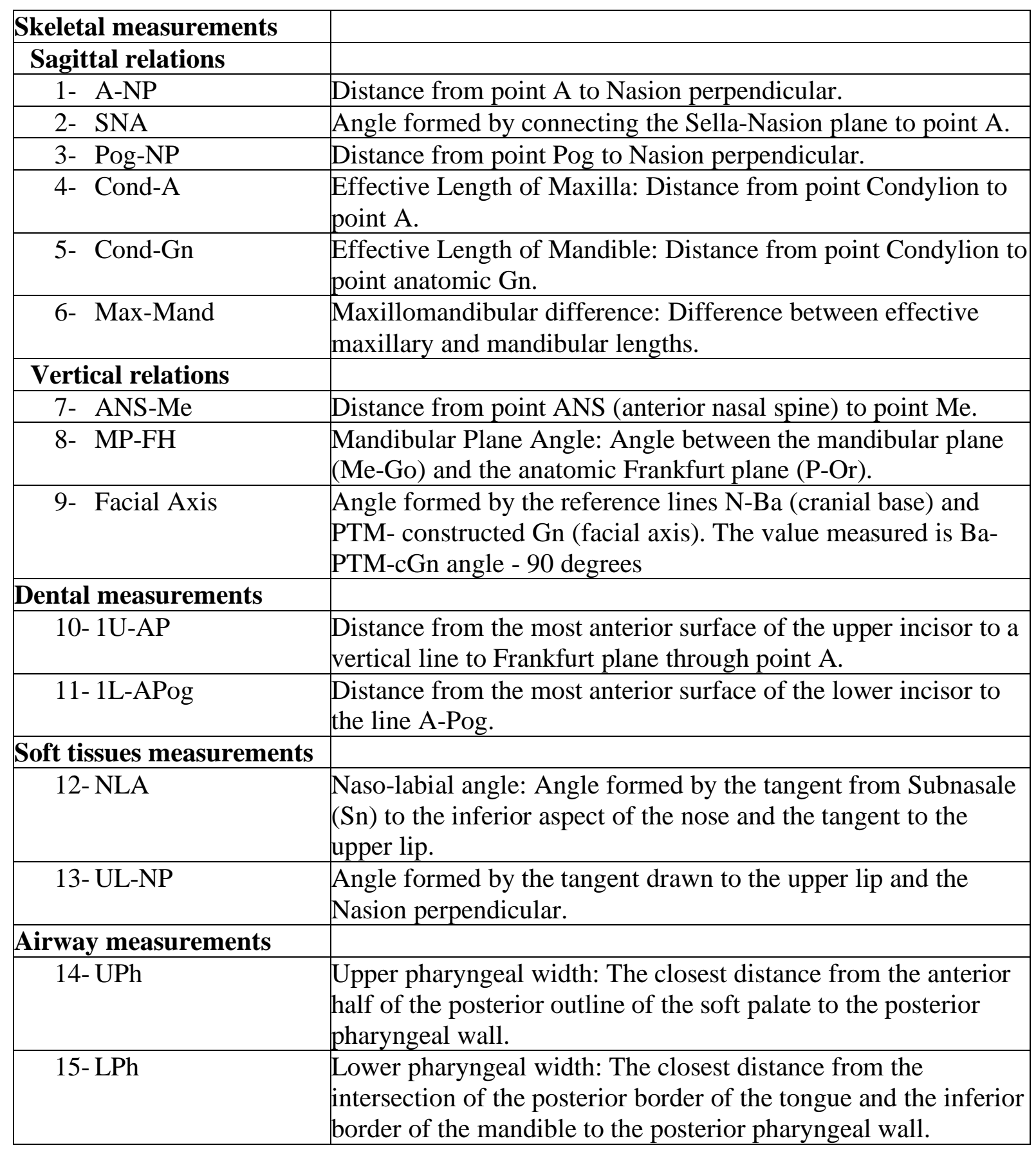


Figure 1. Reference cephalometric landmarks and lines used to compare between Syrian adolescents with Class II/1 malocclusion and Syrians with normal occlusion.

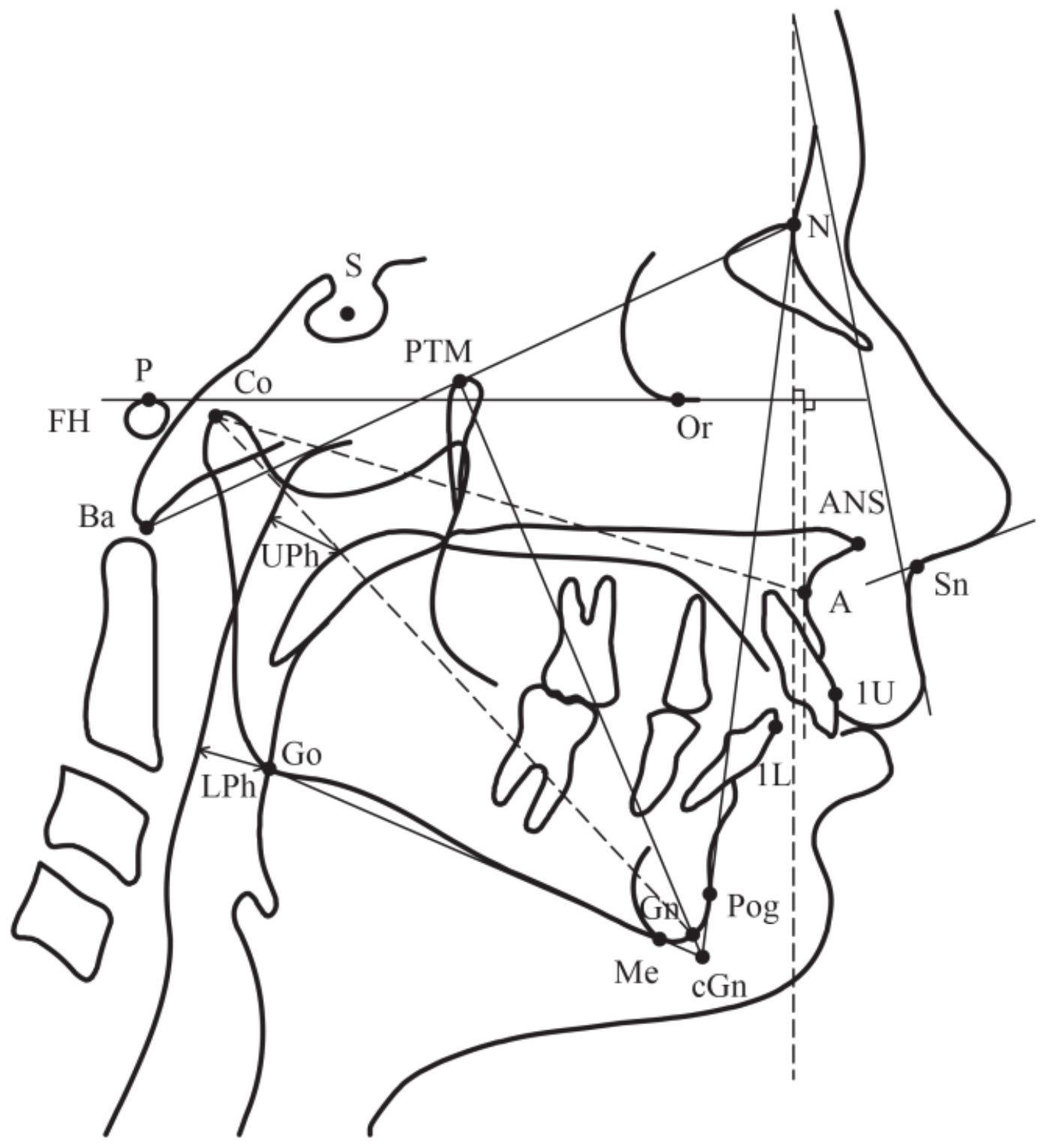

The cephalometric measurements used to compare the dentoskeletal characteristics between Syrian and Hungarian adolescents with Class II/1 malocclusion were derived from the analyses developed by Jarabak (1972), Steiner (1953), and Bathia and Leighton (1993) (University of Bonn analysis) (109-111). Table 4 shows the definitions of the cephalometric 
measurements used to compare the dentoskeletal characteristics between Syrian and Hungarian adolescents with Class II/1 malocclusion. Landmarks and reference lines used to compare the dentoskeletal characteristics between Syrian and Hungarian adolescents with Class II/1 malocclusion are shown in Figure 2.

Table 4. Definitions of the cephalometric measurements used to compare the dentoskeletal characteristics between Syrian and Hungarian adolescents with Class II/1 malocclusion.

\begin{tabular}{|c|c|}
\hline Skeletal measurements & \\
\hline \multicolumn{2}{|l|}{ Sagittal relations } \\
\hline 1- SNA & Angle formed by connecting the S-N plane to A point. \\
\hline 2- SNB & Angle formed by connecting the S-N plane to B point. \\
\hline 3- ANB & Angle formed by subtracting SNB angle from SNA angle. \\
\hline 4- ANS-PNS & $\begin{array}{l}\text { Distance between ANS point (anterior nasal spine) and PNS } \\
\text { point (posterior nasal spine) determining the length of the } \\
\text { maxilla. }\end{array}$ \\
\hline 5- Go-Gn & $\begin{array}{l}\text { Distance from Gn point (Gnathion) to Go point (Gonion) } \\
\text { determining the length of the mandible. }\end{array}$ \\
\hline \multicolumn{2}{|l|}{ Vertical relations } \\
\hline $\begin{array}{l}\text { 6- ArGoMe (Gonial } \\
\text { angle) }\end{array}$ & $\begin{array}{l}\text { Angle between the horizontal and the vertical part of the lower } \\
\text { jaw, formed by the reference lines Ar-Go and Go-Me. }\end{array}$ \\
\hline 7- $\sum$ Bjork & $\begin{array}{l}\text { Sum of the angles NSAr, SArGo and ArGoMe, formed by the } \\
\text { reference lines N-S, S-Ar, Ar-Go and Go-Me. }\end{array}$ \\
\hline 8- Ar-Go & $\begin{array}{l}\text { Distance from Ar point (Artikulare) to Go point determining the } \\
\text { length of the mandibular ramus. }\end{array}$ \\
\hline 9- SNGoMe & $\begin{array}{l}\text { Angle formed by the reference lines S-N and Me-Go, } \\
\text { determines the inclination of the mandibular plane to the } \\
\text { anterior cranial base. }\end{array}$ \\
\hline 10- S-Go:N-Me & $\begin{array}{l}\text { Ratio between anterior facial height (distance from } \mathrm{N} \text { point to } \\
\text { Me point) and posterior facial height (distance from } \mathrm{S} \text { point to } \\
\text { Go point). }\end{array}$ \\
\hline \multicolumn{2}{|l|}{ Dental measurements } \\
\hline 11- U1/NA & $\begin{array}{l}\text { Angle formed by the long axis of the most prominent upper } \\
\text { incisor and the line N-A. }\end{array}$ \\
\hline 12- L1/NB & $\begin{array}{l}\text { Angle formed by the long axis of the most prominent lower } \\
\text { incisor and the line N-B. }\end{array}$ \\
\hline 13- U1-NA & $\begin{array}{l}\text { Distance from the labial outline of the crown of the most } \\
\text { prominent upper incisor to the line N-A. }\end{array}$ \\
\hline 14- L1-NB & $\begin{array}{l}\text { Distance from the labial outline of the crown of the most } \\
\text { prominent lower incisor to the line N-B. }\end{array}$ \\
\hline
\end{tabular}


Figure 2. Landmarks and reference lines used to compare the dentoskeletal characteristics between Syrian and Hungarian adolescents with Class II/1 malocclusion.

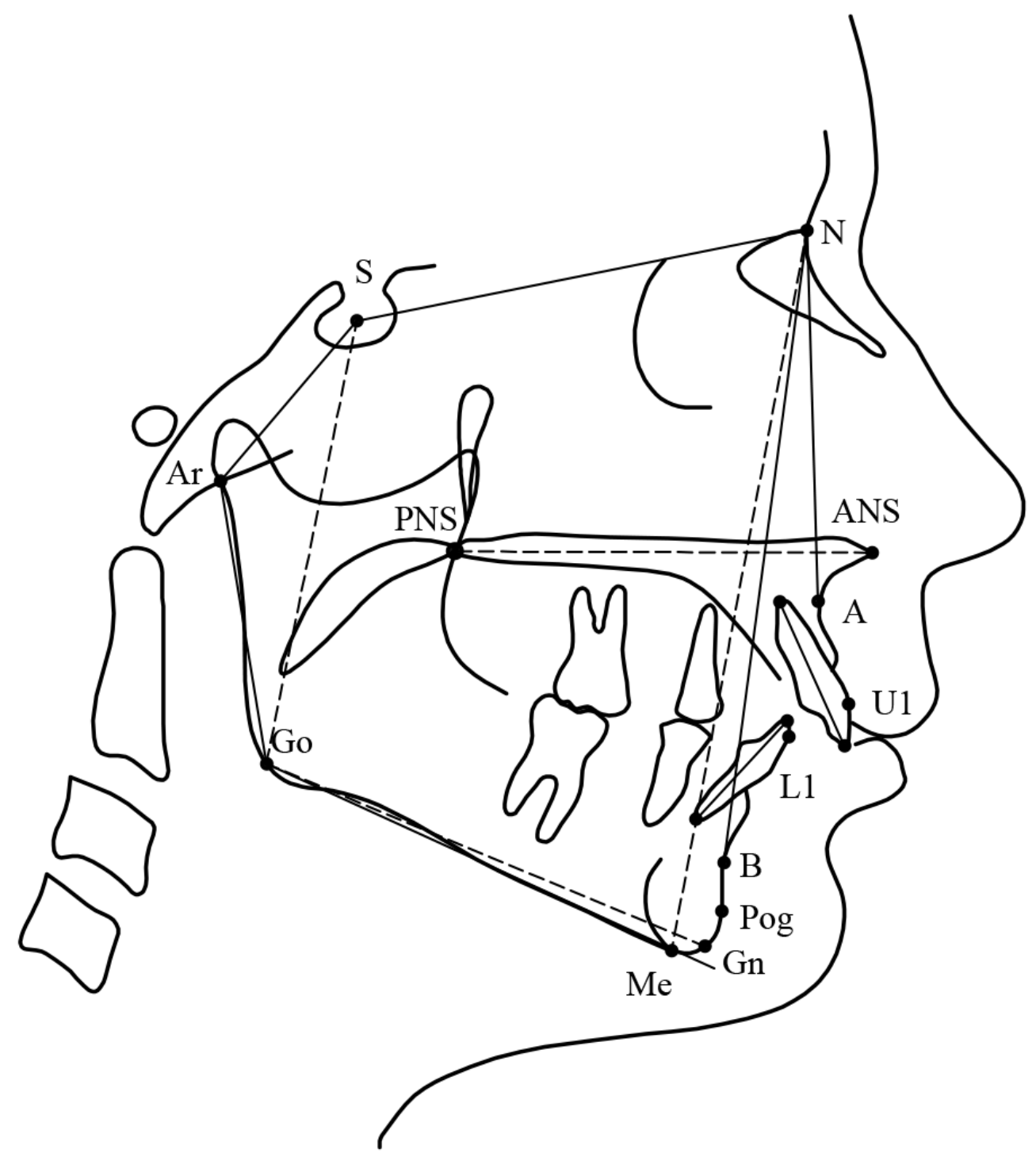

Pharyngeal airway measurements used to compare the upper airway structures between Syrian and Hungarian adolescents with Class II/1 malocclusion were derived from previous upper airway studies $(57,58,80)$. Skeletal and soft tissue measurements used to investigate the potential correlations between the skeletofacial morphology and the upper airway depths in each ethnic group were derived from the analyses reported by Hasund (1973) (112), Clark (1998) (113), and Rakosi (1988) (114). Definitions of the cephalometric measurements used in the upper airway inter-ethnic comparison are shown in Table 5. Landmarks, reference lines, and measurements used in the upper airway inter-ethnic comparison are illustrated in Figure 3. 
Table 5. Definitions of the cephalometric measurements used in the upper airway inter-ethnic comparison.

\begin{tabular}{|c|c|}
\hline Cephalometric measurements & Interpretations \\
\hline \multicolumn{2}{|l|}{ Upper airway measurements } \\
\hline \multicolumn{2}{|l|}{ Upper airway depth } \\
\hline 16- PNS-Ad1 & $\begin{array}{l}\text { Distance between PNS point and Ad1 Point (point of intersection } \\
\text { of posterior pharyngeal wall and line PNS-Ba). }\end{array}$ \\
\hline 17- UPh (Upper pharyngeal width) & $\begin{array}{l}\text { The closest distance from the anterior half of the posterior outline } \\
\text { of the soft palate to the posterior pharyngeal wall. }\end{array}$ \\
\hline $\begin{array}{l}\text { 18- MPh (Middle pharyngeal } \\
\text { width) }\end{array}$ & $\begin{array}{l}\text { Distance between } U \text { point (tip of the uvula) and foot point of } \\
\text { perpendicular line from point } U \text { to posterior pharyngeal wall. }\end{array}$ \\
\hline 19- LPh (Lower pharyngeal width) & $\begin{array}{l}\text { The closest distance from the intersection of the posterior border } \\
\text { of the tongue and the inferior border of the mandible to the } \\
\text { posterior pharyngeal wall. }\end{array}$ \\
\hline \multicolumn{2}{|l|}{ Upper airway length } \\
\hline $\begin{array}{l}\text { 20- PNS-Eb (Vertical airway } \\
\text { length) }\end{array}$ & Distance between PNS point and Eb point (base of epiglottis). \\
\hline \multicolumn{2}{|l|}{ Soft palate } \\
\hline 21- PNS-U (Soft palate length) & Distance between PNS point and U point. \\
\hline 22- SPT (Soft palate thickness) & $\begin{array}{l}\text { Maximum thickness of soft palate measured on line perpendicular } \\
\text { to PNS-U line. }\end{array}$ \\
\hline $\begin{array}{l}\text { 23- ANS-PNS-U (Soft palate } \\
\text { angle) }\end{array}$ & $\begin{array}{l}\text { Angle formed by the lines ANS-PNS and PNS-U, determines the } \\
\text { inclination of the soft palate to the palatal plane. }\end{array}$ \\
\hline \multicolumn{2}{|l|}{ Hyoid bone position } \\
\hline 24- MPH & $\begin{array}{l}\text { Perpendicular distance from hyoid bone (H point) to mandibular } \\
\text { plane (Go-Me line). }\end{array}$ \\
\hline 25- $\mathrm{C} 3 \mathrm{H}$ & Distance between hyoid bone (H point) and $\mathrm{C} 3$ point. \\
\hline \multicolumn{2}{|l|}{ Soft tissue measurements } \\
\hline 1- CL (Cervical Length Gn'-H') & $\begin{array}{l}\text { Distance between the points soft tissue Gnathion (Gn') and neck } \\
\text { point }\left(\mathrm{H}^{\prime}\right) \text { representing the length of the neck. }\end{array}$ \\
\hline 2- LCT (Lip-Chin-Throat Angle) & $\begin{array}{l}\text { Angle between a tangent to the lower lip and the chin and the } \\
\text { throat line. } \\
\text { Formed by the reference lines Li-Gn' and Me'-H'. }\end{array}$ \\
\hline \multicolumn{2}{|l|}{ Skeletal measurements } \\
\hline \multicolumn{2}{|l|}{ Sagittal relations } \\
\hline 1- SNA & Angle formed by connecting the S-N line to A point. \\
\hline 2- SNB & Angle formed by connecting the S-N line to B point. \\
\hline 3- ANB & Angle formed by subtracting SNB angle from SNA angle. \\
\hline 4- A-Ba & $\begin{array}{l}\text { Distance between A point and Ba point, determines the length of } \\
\text { the maxilla. }\end{array}$ \\
\hline 5- Pog-Ba & $\begin{array}{l}\text { Distance between Pog point and Ba point, determines the length of } \\
\text { the mandible. }\end{array}$ \\
\hline \multicolumn{2}{|l|}{ Vertical relations } \\
\hline 6- NL/NSL & $\begin{array}{l}\text { Angle formed by the lines S-N and ANS-PNS, determines the } \\
\text { inclination of the palatal plane to the anterior cranial base. }\end{array}$ \\
\hline 7- ML/NSL & $\begin{array}{l}\text { Angle formed by the lines S-N and Go-Me, determines the } \\
\text { inclination of the mandibular plane to the anterior cranial base. }\end{array}$ \\
\hline 8- NL/ML & $\begin{array}{l}\text { Angle formed by the lines ANS-PNS and Go-Me, determines the } \\
\text { angle between the palatal plane and the mandibular plane. }\end{array}$ \\
\hline \multicolumn{2}{|l|}{ Craniocervical inclination } \\
\hline 1- OPT/NSL & $\begin{array}{l}\text { Angle formed by the lines S-N and odontoid process tangent (line } \\
\text { joining C2s point and C2i point). }\end{array}$ \\
\hline
\end{tabular}


Figure 3. Landmarks, reference lines and measurements used in the upper airway inter-ethnic comparison.

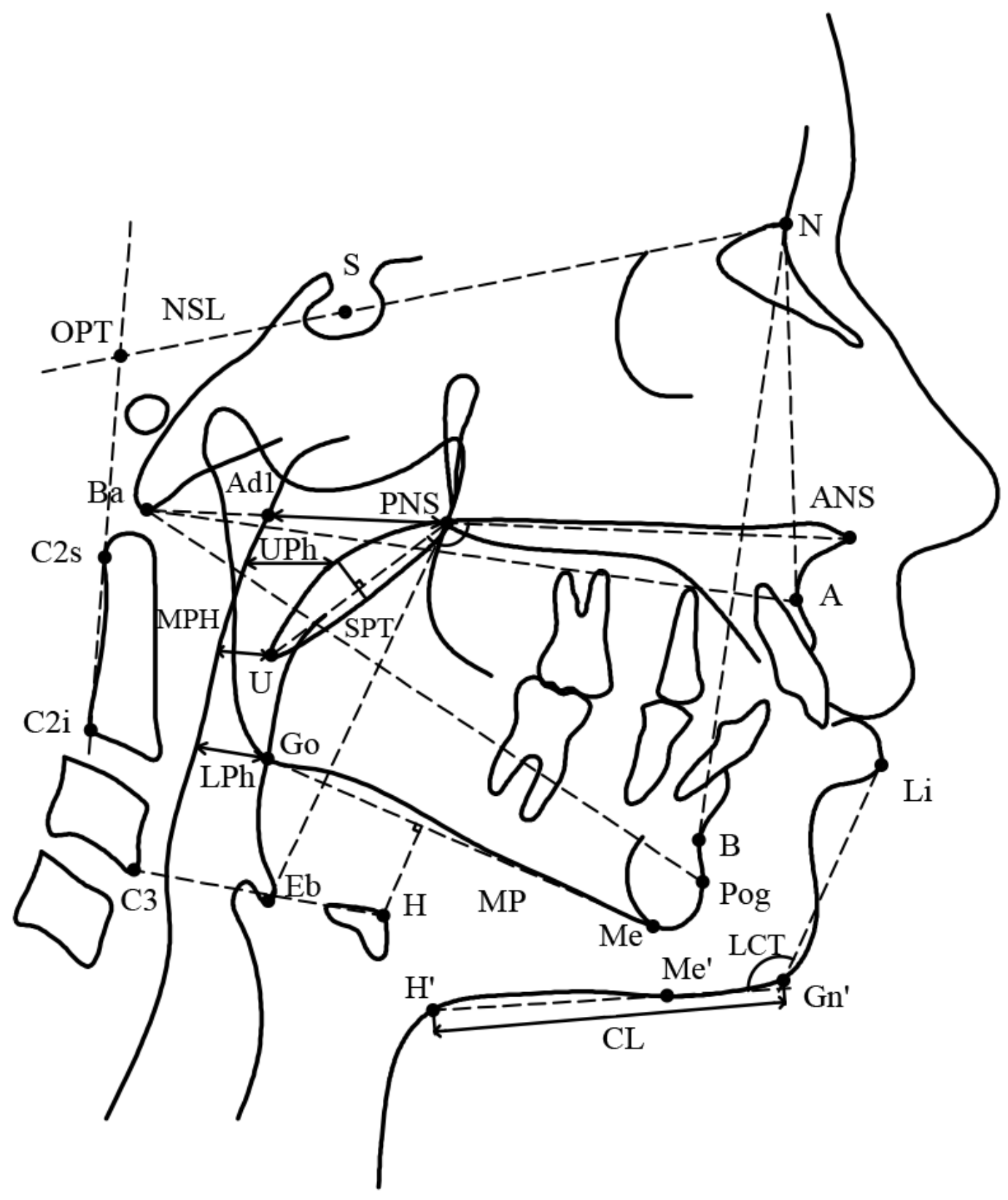




\subsection{Orthodontic cast analyses and measurements}

In Syrian and Hungarian adolescents with Class II/1 malocclusion, the mesiodistal crown diameters of all teeth from the right first permanent molar to the left first permanent molar on each cast were measured to the nearest $0.01 \mathrm{~mm}$ by one investigator using a universal digital caliper (MIB Messzeuge GMBH, Spangenberg, Germany). The measurements were conducted according to the methods described by Seipel (1946) (115) and Moorrees and Reed (1964) (116). The same method was used in the Syrian normative tooth-size study (74). Bolton's overall ratio (sum of mesiodistal widths of 12 mandibular teeth divided by the sum of mesiodistal widths of 12 maxillary teeth multiplied by 100) (117), and Bolton's anterior ratio (sum of mesiodistal widths of six mandibular anterior teeth divided by the sum of mesiodistal widths of six maxillary anterior teeth multiplied by 100) (117) were calculated and used in the statistical analyses.

In order to investigate the clinical significance of the potential deviations from norms in the tooth-size ratios of Class II/1 Syrian subjects, overall and anterior ratios were computed for all Syrian subjects with Class II/1 malocclusion whose values were outside two SDs from Bolton's norms (117) and were also computed for all Syrian subjects with Class II/1 malocclusion whose values were outside two SDs from Syrian population norms (74).

\subsection{Method error}

Three approaches were used to assess the method error. First, Dahlberg's formula (118) was used to establish the random errors. Second, paired sample t-tests were used to assess the systematic error. Third, intraclass correlation coefficients were calculated for all variables.

To assess the intra-examiner reliability, 20 randomly selected lateral cephalograms and orthodontic casts were remeasured several weeks later by the same investigator. Both measurements were compared using the above-mentioned three approaches. First, according to Dahlberg's formula (118), the random errors of the cephalometric variables measured on lateral cephalograms did not exceed $0.45 \mathrm{~mm}$ or 0.64 degrees for linear and angular variables, respectively. The random errors for tooth-size measurements measured on orthodontic casts did not exceed $0.19 \mathrm{~mm}$, and the anterior and overall Bolton’s ratios showed random errors of 
0.62 and 0.39, respectively. Second, no systematic error could be found after the use of paired t-tests for all variables $(\mathrm{P}>0.05)$. Third, the results of the intraclass correlation coefficients were larger than 0.93. The three approaches indicated excellent repeatability of measurements.

To establish inter-examiner reliability, measurements of 20 randomly selected lateral cephalograms and orthodontic casts were replicated again by another investigator. Both measurements were compared using the above-mentioned three approaches. First, according to Dahlberg's formula (118), the random errors of the cephalometric variables measured on lateral cephalograms did not exceed $0.53 \mathrm{~mm}$ or 0.66 degrees for linear and angular variables, respectively. The random errors for tooth-size measurements measured on orthodontic casts did not exceed $0.33 \mathrm{~mm}$, and the anterior and overall Bolton's ratios showed random errors of 0.56 and 0.47 , respectively. Second, no systematic error could be found after the use of paired t-tests for the variables $(\mathrm{P}>0.05)$. Third, the results of the intraclass correlation coefficients were larger than 0.92. The three approaches indicated excellent repeatability of measurements.

\subsection{Statistical analyses}

Statistical analyses were performed using the SPSS software 24.0 (SPSS Inc., Chicago, USA). Descriptive statistics (Mean/Median, Standard Deviation/Interquartile Range and 95\% Confidence Intervals) of all variables were calculated. The data within each examined group were checked using the Shapiro-Wilk test to ensure normal distribution prior to using parametric tests. Comparisons between the two ethnic groups regarding the normally distributed variables were performed using t-test for independent variables (two-tailed) or Welch t-test for independent variables (two-tailed) depending on equality of variance according to F-test. Conversely, Mann-Whitney U-test for independent variables (two-tailed) was used to compare the non-normally distributed variables. In order to investigate correlations in each ethnic group, Spearman's correlation coefficient (with a two-tailed test for significance) was used since the assumptions for Pearson correlation coefficient were not fully met. The level of statistical significance was $\mathrm{P}<0.05$. 


\section{Results}

\subsection{Cephalometric and tooth-size characteristics of Syrian adolescents with Class II/1 malocclusion (119)}

\subsubsection{Cephalometric characteristics of Syrian adolescents with Class II/1 malocclusion}

Data presenting sex-based and general cephalometric characteristics of Syrian adolescents with Class II/1 malocclusion are summarized in Table 6.

Table 6: Cephalometric characteristics of Syrian adolescents with Class II/1 malocclusion.

\begin{tabular}{|c|c|c|c|c|c|c|}
\hline \multirow{2}{*}{$\begin{array}{c}\begin{array}{c}\text { Cephalometric } \\
\text { measurements }\end{array} \\
\text { Variables }\end{array}$} & \multicolumn{2}{|c|}{$\begin{array}{c}\text { Syrian Males with Class II/1 } \\
\text { Malocclusion }(\mathrm{n}=19)\end{array}$} & \multicolumn{2}{|c|}{\begin{tabular}{|c} 
Syrian Females with Class II/1 \\
Malocclusion $(n=24)$ \\
\end{tabular}} & \multicolumn{2}{|c|}{$\begin{array}{c}\text { Syrian adolescents with Class } \\
\text { II/1 Malocclusion }(n=43)\end{array}$} \\
\hline & Mean ( \pm S.D) & \begin{tabular}{|c|}
$95 \%$ CIs for \\
mean \\
Lower, Upper
\end{tabular} & Mean ( \pm S.D) & $\begin{array}{c}95 \% \text { CIs for } \\
\text { mean } \\
\text { Lower, Upper }\end{array}$ & Mean $( \pm$ S.D) & $\begin{array}{c}\text { 95\% CIs for } \\
\text { mean } \\
\text { Lower, Upper }\end{array}$ \\
\hline \multicolumn{7}{|l|}{ Skeletal measurements } \\
\hline \multicolumn{7}{|l|}{ Sagittal values } \\
\hline A-NP (mm) & $-0.64( \pm 2.60)$ & $-1.90,0.61$ & $0.53( \pm 2.00)$ & $-0.31,1.38$ & $0.01( \pm 2.33)$ & $-0.70,0.73$ \\
\hline SNA $\left(^{\circ}\right)$ & $79.70( \pm 2.72)$ & 78.39, 81.01 & $81.06( \pm 2.50)$ & $80.00,82.11$ & $80.46( \pm 2.66)$ & $79.64,81.27$ \\
\hline Pog-NP (mm) & $-10.95( \pm 3.85)$ & $-12.81,-9.10$ & $-11.05( \pm 5.34)$ & $-13.31,-8.80$ & $-11.01( \pm 4.69)$ & $-12.45,-9.57$ \\
\hline Cond-A (mm) & $85.84( \pm 5.31)$ & 83.28, 88.39 & $85.25( \pm 3.79)$ & $83.65,86.85$ & $85.51( \pm 4.48)$ & 84.13, 86.89 \\
\hline Cond-Gn (mm) & $108.47( \pm 5.81)$ & $105.67,111.27$ & $107.59( \pm 5.43)$ & $105.30,109.89$ & $107.98( \pm 5.55)$ & $106.27,109.69$ \\
\hline Max-Mand (mm) & $22.64( \pm 4.26)$ & $20.59,24.69$ & $22.34( \pm 4.59)$ & $20.41,24.28$ & $22.47( \pm 4.39)$ & 21.12, 23.82 \\
\hline \multicolumn{7}{|l|}{ Vertical values } \\
\hline ANS-Me (mm) & $68.65( \pm 5.41)$ & 66.04, 71.26 & $68.01( \pm 4.92)$ & $65.94,70.09$ & $68.30( \pm 5.09)$ & $66.73,69.86$ \\
\hline MP-FH $\left(^{\circ}\right)$ & $28.70( \pm 5.15)$ & 26.21, 31.18 & $30.61( \pm 5.94)$ & 28.11, 33.12 & $29.77( \pm 5.62)$ & 28.04, 31.50 \\
\hline Facial Axis $\left(^{\circ}\right)$ & $-6.35( \pm 5.05)$ & $-8.78,-3.91$ & $-6.18( \pm 4.24)$ & $-7.97,-4.38$ & $-6.25( \pm 4.56)$ & $-7.65,-4.85$ \\
\hline \multicolumn{7}{|l|}{ Dental measurements } \\
\hline 1U-AP (mm) & $5.66( \pm 2.07)$ & $4.66,6.65$ & $6.03( \pm 2.06)$ & $5.16,6.90$ & $5.86( \pm 2.05)$ & $5.23,6.49$ \\
\hline $1 \mathrm{~L}-\mathrm{APog}(\mathrm{mm})$ & $4.33( \pm 1.92)$ & $3.40,5.25$ & $5.27( \pm 1.79)$ & 4.51, 6.02 & $4.85( \pm 1.89)$ & $4.27,5.43$ \\
\hline \multicolumn{7}{|c|}{ Soft tissue measurements } \\
\hline NLA $\left(^{\circ}\right)$ & $104.78( \pm 6.32)$ & 101.73, 107.82 & $103.47( \pm 8.27)$ & 99.98, 106.96 & $104.05( \pm 7.42)$ & $101.77,106.33$ \\
\hline UL-NP $\left(^{\circ}\right)$ & $9.16( \pm 7.51)$ & $5.54,12.78$ & $12.54( \pm 7.49)$ & $9.38,15.70$ & $11.05( \pm 7.60)$ & 8.71, 13.39 \\
\hline \multicolumn{7}{|l|}{ Airway measurements } \\
\hline UPh (mm) & $10.57( \pm 3.17)$ & $9.04,12.10$ & $12.24( \pm 3.00)$ & $10.97,13.51$ & $11.50( \pm 3.15)$ & $10.53,12.47$ \\
\hline $\mathrm{LPh}(\mathrm{mm})$ & $10.44( \pm 2.48)$ & $9.25,11.63$ & $11.41( \pm 3.19)$ & $10.06,12.75$ & $10.98( \pm 2.90)$ & $10.09,11.87$ \\
\hline
\end{tabular}

CIs=confidence intervals, S.D=standard deviation.

Bold values indicate lower and upper bounds of $\mathbf{9 5 \%}$ confidence intervals for mean.

Results regarding the sagittal position of the maxilla were as follows: The linear variable (A$\mathrm{NP})$ showed a value of $0.01( \pm 2.33) \mathrm{mm}$ [mean ( \pm standard deviation)]. The angular variable (SNA) showed a value of $80.46( \pm 2.66)$ degrees. The sagittal mandibular position was 
determined by one linear variable (Pog-NP) with a value of $-11.01( \pm 4.69) \mathrm{mm}$. The effective length of the maxilla (Cond-A) was $85.51( \pm 4.48) \mathrm{mm}$. The effective length of the mandible (Cond-Gn) was $107.98( \pm 5.55) \mathrm{mm}$. The difference between the maxillary length and the mandibular length (Max-Mand) was $22.47( \pm 4.39) \mathrm{mm}$.

Results in the vertical plane were as follows: First, lower anterior facial height (ANS-Me) showed a value of $68.30( \pm 5.09) \mathrm{mm}$. Second, mandibular plane angle (MP-FH) showed a value of $29.77( \pm 5.62)$ degrees. Third, facial axis (facial axis) showed a value of $-6.25( \pm 4.56)$ degrees.

Results regarding the incisors position were as follows: First, maxillary incisors position (1UAP) showed a value of $5.86( \pm 2.05) \mathrm{mm}$. Second, mandibular incisors position (1L-APog) showed a value of $4.85( \pm 1.89) \mathrm{mm}$.

Soft tissue measurements showed an obtuse nasolabial angle (NLA) of $104.05( \pm 7.42)$ degrees. Further, the value of the upper-lip angle (UL-NP) was $11.05( \pm 7.60)$ degrees.

Regarding upper-airway dimensions, upper and lower-pharyngeal widths (UPh, LPh) were assessed. The upper-pharyngeal width (UPh) was $11.50( \pm 3.15) \mathrm{mm}$. The lower-pharyngeal width $(\mathrm{LPh})$ was $10.98( \pm 2.90) \mathrm{mm}$. However, there was no prevalence of upper-pharyngeal obstructions (upper-pharyngeal width $\leq 5 \mathrm{~mm}$ ) in Syrian subjects with Class II/1 malocclusion.

\subsubsection{Tooth-size characteristics of Syrian adolescents with Class II/1 malocclusion}

Data presenting sex-based and general tooth-size characteristics of Syrian adolescents with Class II/1 malocclusion are summarized in Table 7.

Table 7. Tooth-size ratios of Syrian adolescents with Class II/1 malocclusion.

\begin{tabular}{|c|c|c|c|c|c|c|}
\hline \multirow{2}{*}{$\begin{array}{c}\text { Tooth-size ratios } \\
\text { Variables }\end{array}$} & \multicolumn{2}{|c|}{$\begin{array}{c}\text { Syrian Males with Class II/1 } \\
\text { Malocclusion }(\mathrm{n}=19)\end{array}$} & \multicolumn{2}{|c|}{$\begin{array}{l}\text { Syrian Females with Class } \\
\text { II/1 Malocclusion }(n=24)\end{array}$} & \multicolumn{2}{|c|}{$\begin{array}{c}\text { Syrian adolescents with Class } \\
\text { II/1 Malocclusion }(n=43)\end{array}$} \\
\hline & Mean ( \pm S.D) & $\begin{array}{c}\text { 95\% CIs for } \\
\text { means } \\
\text { Lower, Upper }\end{array}$ & Mean ( \pm S.D) & $\begin{array}{l}\text { 95\% CIs for } \\
\text { means } \\
\text { Lower, Upper }\end{array}$ & Mean $( \pm$ S.D) & $\begin{array}{c}\text { 95\% CIs for } \\
\text { means } \\
\text { Lower, Upper }\end{array}$ \\
\hline Anterior ratio (\%) & $80.55( \pm 2.95)$ & 79.12, 81.97 & $80.81( \pm 2.60)$ & 79.71, 81.91 & $80.69( \pm 2.73)$ & 79.85, 81.53 \\
\hline Overall ratio (\%) & $92.74( \pm 1.80)$ & 91.87, 93.61 & $92.92( \pm 1.65)$ & $92.23,93.62$ & $92.84( \pm 1.70)$ & 92.32, 93.37 \\
\hline
\end{tabular}

CIs=confidence intervals, S.D=standard deviation.

Bold values indicate lower and upper bounds of $\mathbf{9 5 \%}$ confidence intervals for mean. 
Bolton tooth-size analysis revealed that the anterior ratio was $80.69( \pm 2.73)$ percent, while the overall ratio was $92.84( \pm 1.70)$ percent.

Table 8 displays the frequencies of tooth-size discrepancies among Class II/1 Syrian subjects outside two SDs from Bolton's norms and the frequencies of tooth-size discrepancies of Class II/1 Syrian subjects outside two SDs from Syrian population norms.

Table 8. Frequencies of tooth-size discrepancies among Class II/1 Syrian subjects outside two SDs from Bolton's norms and frequencies of tooth-size discrepancies among Class II/1 Syrian subjects outside two SDs from Syrian population norms.

\begin{tabular}{|c|c|c|c|c|}
\hline & \multicolumn{4}{|c|}{ Anterior ratio } \\
\hline & \multicolumn{2}{|c|}{ Outside 2 SD from Bolton’s norm (\%) } & \multicolumn{2}{|c|}{ Outside 2 SD from Syrian's norm (\%) } \\
\hline & $<73.9$ & $>80.5$ & $<74.63$ & $>83.35$ \\
\hline \multirow[t]{4}{*}{$\begin{array}{l}\text { Class II/1 Syrian } \\
\text { subjects }(\mathrm{n}=43)\end{array}$} & 0 & 39.54 & 0 & 25.58 \\
\hline & \multicolumn{4}{|c|}{ Overall Ratio } \\
\hline & \multicolumn{2}{|c|}{ Outside 2 SD from Bolton’s norm (\%) } & \multicolumn{2}{|c|}{ Outside 2 SD from Syrian’s norm (\%) } \\
\hline & $<87.5$ & $>95.1$ & $<88.14$ & $>96.38$ \\
\hline $\begin{array}{l}\text { Class II/1 Syrian } \\
\text { subjects }(\mathrm{n}=43)\end{array}$ & 0 & 6.98 & 0 & 0 \\
\hline
\end{tabular}

The percentage of Class II/1 Syrian patients who had anterior ratios greater than two SDs from Bolton’s norm [77.2 ( \pm 1.65$)$ percent] (117) was 39.5\%, whereas the percentage of Class II/1 Syrian patients who had anterior ratios greater than two SDs from Syrian population norm [78.99 ( \pm 2.18$)$ percent] (74) was 25.6\%. The percentage of Class II/1 Syrian patients who had overall ratios greater than two SDs from Bolton’s norm [91.3 $( \pm 1.91)$ percent] (117) was $6.98 \%$, whereas none of Class II/1 Syrian patients had overall ratios greater than two SDs from Syrian population norm [92.26 ( \pm 2.06$)$ percent] (74). Additionally, none of Class II/1 Syrian patients had anterior or overall ratios smaller than two SDs from Bolton's norms (117), and none of Class II/1 Syrian patients had anterior or overall ratios smaller than two SDs from Syrian population norms (74). 


\subsection{Dentoskeletal and tooth-size differences between Syrian and Hungarian adolescents with Class II/1 malocclusion (120)}

Results for overall comparisons between the two ethnic groups are presented in Table 9 and Table 10 for dentoskeletal cephalometric comparisons and tooth-size comparisons, respectively.

Table 9. Overall comparison of dentoskeletal cephalometric measurements between Syrian and Hungarian adolescents with Class II/1 malocclusion.

\begin{tabular}{|c|c|c|c|c|c|}
\hline & \multirow{2}{*}{$\begin{array}{l}\text { Syrian adolescents with } \\
\text { Class II/1 malocclusion } \\
\qquad(n=43)\end{array}$} & \multirow{2}{*}{$\begin{array}{c}\text { Hungarian adolescents with } \\
\text { Class II/1 malocclusion } \\
(\mathrm{n}=43)\end{array}$} & \multicolumn{2}{|c|}{$\begin{array}{c}95 \% \text { CI of } \\
\text { Mean/Median } \\
\text { Difference }\end{array}$} & \multirow[t]{2}{*}{ P-value } \\
\hline & & & $\mathbf{L}$ & $\mathbf{U}$ & \\
\hline \multicolumn{6}{|l|}{\begin{tabular}{|l|} 
Cephalometric measurements \\
\end{tabular}} \\
\hline \multicolumn{6}{|l|}{ Skeletal measurements } \\
\hline \multicolumn{6}{|l|}{ Sagittal values } \\
\hline SNA $\left(^{\circ}\right)($ Mean \pm S.D) $\partial$ & $80.46 \pm 2.66$ & $81.90 \pm 3.45$ & -2.76 & -0.12 & 0.033 \\
\hline SNB $\left({ }^{\circ}\right)($ Mean \pm S.D) $\partial$ & $73.94 \pm 2.86$ & $75.34 \pm 3.49$ & -2.76 & -0.03 & 0.045 \\
\hline ANB $\left(^{\circ}\right)($ Median / IQR $) \dagger$ & $6.48 / 2.45$ & $6.18 / 1.78$ & -0.56 & 0.74 & 0.704 \\
\hline ANS-PNS (mm) (Median / IQR) $\dagger$ & $54.43 / 5.17$ & $54.78 / 5.55$ & -2.08 & 1.33 & 0.749 \\
\hline Go-Gn $(\mathrm{mm})($ Mean \pm S.D) $\partial$ & $72.46 \pm 5.31$ & $69.37 \pm 5.03$ & 0.87 & 5.31 & 0.007 \\
\hline \multicolumn{6}{|l|}{ Vertical values } \\
\hline $\operatorname{ArGoMe}\left({ }^{\circ}\right)($ Mean \pm S.D) $\partial$ & $124.76 \pm 8.81$ & $119.71 \pm 6.44$ & 1.74 & 8.37 & 0.003 \\
\hline$\sum$ Bjork $\left(^{\circ}\right)($ Mean \pm S.D) $\partial$ & $399.34 \pm 6.13$ & $393.48 \pm 6.40$ & 3.17 & 8.55 & $<0.001$ \\
\hline Ar-Go (mm) (Median / IQR) $\dagger$ & $41.48 / 7.77$ & 41.34 / 5.55 & -1.62 & 2.41 & 0.650 \\
\hline SN/GoMe $\left({ }^{\circ}\right)($ Mean \pm S.D) $\partial$ & $39.34 \pm 6.14$ & $33.48 \pm 6.40$ & 3.17 & 8.55 & $<0.001$ \\
\hline S-Go:N-Me (\%) (Mean \pm S.D) $\partial$ & $61.07 \pm 4.41$ & $65.46 \pm 5.11$ & -6.44 & -2.34 & $<0.001$ \\
\hline \multicolumn{6}{|l|}{ Dental measurements } \\
\hline U1/NA $\left(^{\circ}\right)($ Median / IQR) $\dagger$ & $25.96 / 4.61$ & $26.60 / 7.24$ & -0.75 & 2.33 & 0.409 \\
\hline L1/NB $\left(^{\circ}\right)($ Mean \pm S.D) $\partial$ & $32.76 \pm 5.74$ & $28.08 \pm 5.67$ & 2.24 & 7.13 & $<0.001$ \\
\hline U1-NA $(\mathrm{mm})($ Mean \pm S.D) $\partial$ & $6.05 \pm 2.09$ & $5.17 \pm 2.20$ & -0.04 & 1.80 & 0.061 \\
\hline L1-NB (mm) (Mean \pm S.D) $\partial$ & $9.06 \pm 2.11$ & $6.12 \pm 2.06$ & 2.05 & 3.84 & $<0.001$ \\
\hline
\end{tabular}

$\partial t$-tests for independent variables

$\dagger$ Mann-Whitney $U$-test for independent variables

$\mathrm{CI}=$ Confidence interval, $\mathrm{S} . \mathrm{D}=\mathrm{Standard}$ deviation, and $\mathrm{IQR}=$ Interquartile range

Bold values indicate significance of $p$ value $(p<0.05)$ (two-tailed)

$<0.001$ refers to very small values (values below 0.000 ) and it does not refer to another level of significance (this sign $<0.001$ was used in accordance with journals requirements) 
Table 10. Overall comparison of tooth-size ratios between Syrian and Hungarian adolescents with Class II/1 malocclusion.

\begin{tabular}{|l|c|c|c|c|c|}
\hline & $\begin{array}{c}\text { Syrian adolescents with } \\
\text { Class II/1 malocclusion } \\
(\mathbf{n}=\mathbf{4 3 )}\end{array}$ & $\begin{array}{c}\text { Hungarian adolescents with } \\
\text { Class II/1 malocclusion } \\
(\mathbf{n}=\mathbf{4 3 )}\end{array}$ & $\begin{array}{c}\text { 95\% CI of } \\
\text { Mean/Median } \\
\text { Difference }\end{array}$ & \multirow{2}{*}{ P-value } \\
\cline { 3 - 5 } & & & & $\mathbf{U}$ & \\
\hline Tooth-size ratios & & $78.57 \pm 2.38$ & 1.03 & 3.22 & $<\mathbf{0 . 0 0 1}$ \\
\hline Anterior ratio (\%) (Mean \pm S.D) $\partial$ & $80.69 \pm 2.73$ & $92.28 \pm 2.16$ & -0.27 & 1.40 & 0.180 \\
\hline
\end{tabular}

$\partial t$-tests for independent variables

$\mathrm{CI}=$ Confidence interval, $\mathrm{S} . \mathrm{D}=$ Standard deviation

Bold values indicate significance of $p$ value $(p<0.05)$ (two-tailed)

\subsubsection{Dentoskeletal cephalometric comparisons between Syrian and Hungarian adolescents with Class II/1 malocclusion}

Results for sex-based dentoskeletal cephalometric comparisons between the two ethnic groups are presented in Tables 11.

Table 11. Sex-based comparison of dentoskeletal cephalometric measurements between Syrian and Hungarian adolescents with Class II/1 malocclusion.

\begin{tabular}{|c|c|c|c|c|c|c|c|c|c|c|}
\hline & \multicolumn{5}{|c|}{ Males with Class II/1 malocclusion } & \multicolumn{5}{|c|}{ Females with Class II/1 malocclusion } \\
\hline & \multirow{2}{*}{$\begin{array}{c}\text { Syrians } \\
(n=19) \\
\text { Mean } \pm \text { S.D }\end{array}$} & \multirow{2}{*}{$\begin{array}{c}\text { Hungarians } \\
(n=19) \\
\text { Mean+S.D }\end{array}$} & \multicolumn{2}{|c|}{$\begin{array}{l}95 \% \text { CI of } \\
\text { Mean } \\
\text { Difference } \\
\end{array}$} & \multirow[t]{2}{*}{$P$-value } & \multirow{2}{*}{$\begin{array}{c}\text { Syrians } \\
(n=24) \\
\text { Mean } \pm \text { S.D }\end{array}$} & \multirow{2}{*}{$\begin{array}{c}\text { Hungarians } \\
(n=24) \\
\text { Mean } \pm \text { S.D }\end{array}$} & \multicolumn{2}{|c|}{$\begin{array}{l}95 \% \text { CI of } \\
\text { Mean } \\
\text { Difference } \\
\end{array}$} & \multirow[t]{2}{*}{$P$-value } \\
\hline & & & $\mathbf{L}$ & $\mathbf{U}$ & & & & $\mathbf{L}$ & $\mathbf{U}$ & \\
\hline \multicolumn{11}{|l|}{\begin{tabular}{|l|} 
Cephalometric \\
measurements $\partial$
\end{tabular}} \\
\hline \multicolumn{11}{|c|}{ Skeletal measurements } \\
\hline \multicolumn{11}{|l|}{ Sagittal values } \\
\hline SNA $\left(^{\circ}\right)$ & $79.70 \pm 2.72$ & $83.43 \pm 2.79$ & -5.54 & -1.91 & $<0.001$ & $81.06 \pm 2.50$ & $80.69 \pm 3.49$ & -1.40 & 2.13 & 0.679 \\
\hline SNB $\left(^{\circ}\right)$ & $73.81 \pm 2.93$ & $76.73 \pm 2.82$ & -4.81 & -1.03 & 0.003 & $74.05 \pm 2.85$ & $74.24 \pm 3.62$ & -2.09 & 1.70 & 0.840 \\
\hline ANB $\left({ }^{\circ}\right)$ & $5.89 \pm 1.46$ & $6.70 \pm 1.19$ & -1.69 & 0.06 & 0.068 & $7.01 \pm 1.75$ & $6.45 \pm 1.56$ & -0.41 & 1.52 & 0.249 \\
\hline ANS-PNS (mm) & $56.44 \pm 4.95$ & $56.68 \pm 3.12$ & -2.97 & 2.49 & 0.859 & $55.00 \pm 4.04$ & $53.39 \pm 3.15$ & -0.50 & 3.71 & 0.132 \\
\hline Go-Gn (mm) & $73.13 \pm 6.18$ & $71.38 \pm 5.05$ & -1.96 & 5.47 & 0.345 & $71.93 \pm 4.58$ & $67.77 \pm 4.50$ & 1.52 & 6.79 & 0.003 \\
\hline \multicolumn{11}{|l|}{ Vertical values } \\
\hline $\operatorname{ArGoMe~}\left(^{\circ}\right)$ & $124.08 \pm 7.88$ & $119.11 \pm 6.25$ & 0.30 & 9.66 & 0.038 & $125.29 \pm 9.62$ & $120.18 \pm 6.67$ & 0.30 & 9.92 & 0.038 \\
\hline$\sum$ Bjork $\left(^{\circ}\right)$ & $398.33 \pm 5.75$ & $392.16 \pm 5.85$ & 2.35 & 9.99 & 0.002 & $400.14 \pm 6.43$ & $394.53 \pm 6.75$ & 1.78 & 9.44 & 0.005 \\
\hline Ar-Go (mm) & $41.56 \pm 5.11$ & $44.48 \pm 4.70$ & -6.15 & 0.30 & 0.074 & $42.01 \pm 4.81$ & $39.98 \pm 4.17$ & -0.58 & 4.65 & 0.124 \\
\hline SN/GoMe $\left(^{\circ}\right)$ & $38.33 \pm 5.76$ & $32.16 \pm 5.85$ & 2.35 & 9.99 & 0.002 & $40.14 \pm 6.43$ & $34.53 \pm 6.75$ & 1.78 & 9.44 & 0.005 \\
\hline S-Go:N-Me (\%) & $61.64 \pm 4.09$ & $66.71 \pm 4.51$ & -7.90 & -2.24 & 0.001 & $60.62 \pm 4.69$ & $64.47 \pm 5.42$ & -6.80 & -0.90 & 0.012 \\
\hline \multicolumn{11}{|c|}{ Dental measurements } \\
\hline U1/NA $\left({ }^{\circ}\right)$ & $26.97 \pm 4.18$ & $26.98 \pm 3.71$ & -2.62 & 2.58 & 0.989 & $26.44 \pm 2.60$ & $28.16 \pm 4.32$ & -3.81 & 0.36 & 0.102 \\
\hline $\mathrm{L} 1 / \mathrm{NB}\left({ }^{\circ}\right)$ & $29.37 \pm 5.56$ & $28.80 \pm 5.23$ & -2.99 & 4.11 & 0.750 & $35.45 \pm 4.34$ & $27.50 \pm 6.05$ & 4.89 & 11.01 & $<0.001$ \\
\hline U1-NA (mm) & $5.86 \pm 2.06$ & $4.90 \pm 2.11$ & -0.42 & 2.33 & 0.166 & $6.21 \pm 2.15$ & $5.39 \pm 2.29$ & -0.47 & 2.11 & 0.208 \\
\hline L1-NB (mm) & $8.22 \pm 2.03$ & $6.88 \pm 2.08$ & -0.01 & 2.69 & 0.052 & $9.73 \pm 1.96$ & $5.52 \pm 1.88$ & 3.09 & 5.32 & $<\mathbf{0 . 0 0 1}$ \\
\hline
\end{tabular}

$\partial$ t-tests for independent variables

S.D=Standard deviation, $\mathrm{CI}=$ Confidence interval

Bold values indicate significance of $p$ value $(p<0.05)$ (two-tailed) 
Sagittal comparisons revealed that Hungarian males with Class II/1 malocclusion had significantly more protruded maxillae (based on SNA angle) than their Syrian counterparts $(\mathrm{p}<0.001)$, while Syrian males with Class II/1 malocclusion had significantly more retruded mandibles (based on SNB angle) $(p=0.003)$. Additionally, Hungarian females with Class II/1 malocclusion had significantly smaller mandibular lengths (based on Go-Gn distance) than their Syrian counterparts $(p=0.003)$ (Figure 4).

Figure 4. Sex-based dentoskeletal cephalometric comparisons between Syrian and Hungarian adolescents with Class II/1 malocclusion

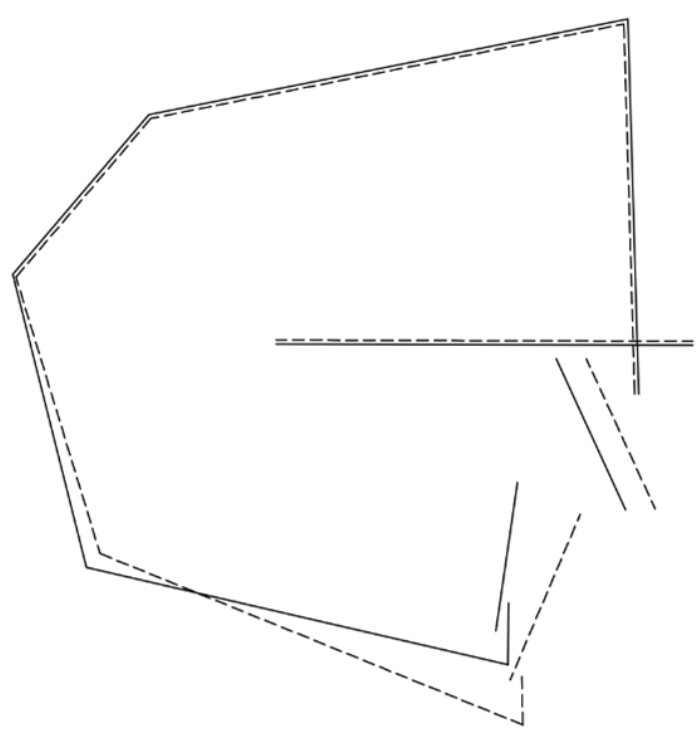

- Class II/1 Hungarian Females ------- Class II/1 Syrian Females

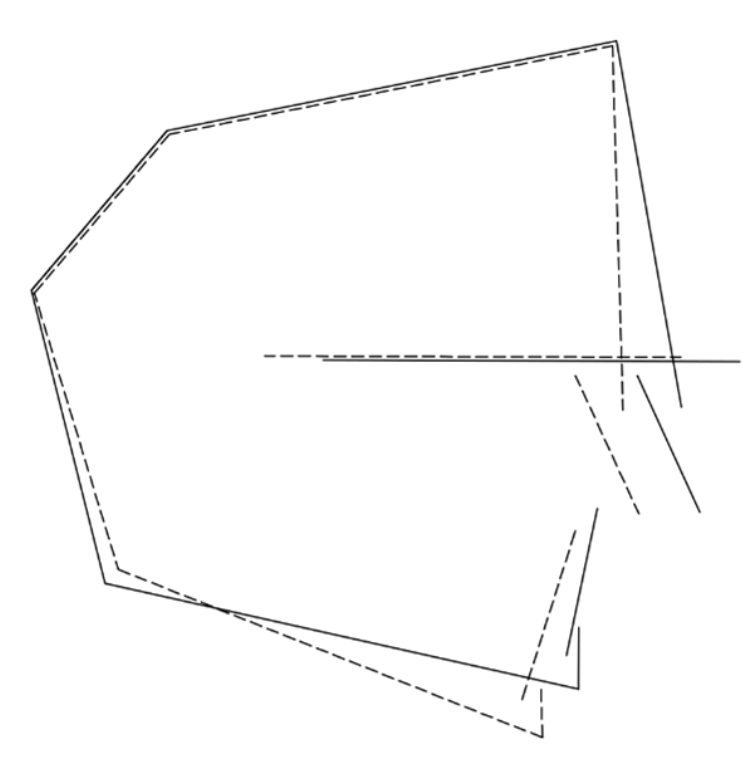

Class II/1 Hungarian Males ------- Class II/1 Syrian Males

Vertical measurements (ArGoMe, $\sum$ Bjork, SN/GoMe, and S-Go:N-Me) showed significant differences ( $\mathrm{p}=0.003, \mathrm{p}<0.001, \mathrm{p}<0.001$ and $\mathrm{p}<0.001$, respectively) between Syrian and Hungarian adolescents with Class II/1 malocclusion, regardless of sex, indicating a hyperdivergent facial pattern in Syrian sample with Class II/1 malocclusion (Table 9).

Dental measurement results revealed that Syrian females with Class II/1 malocclusion had significantly more protruded lower incisors (based on L1/NB and L1-NB values) $(\mathrm{p}<0.001$ ) than Hungarian females with Class II/1 malocclusion. These observations did not extend to the male populations with Class II/1 malocclusion (Table 11). 


\subsubsection{Tooth-size comparisons between Syrian and Hungarian adolescents with Class}

\section{II/1 malocclusion}

Results for sex-based tooth-size comparisons between the two ethnic groups are presented in Tables 12.

Table 12. Sex-based comparison of anterior and overall tooth-size ratios between Syrian and Hungarian adolescents with Class II/1 malocclusion.

\begin{tabular}{|c|c|c|c|c|c|c|c|c|c|c|}
\hline & \multicolumn{5}{|c|}{ Males with Class II/1 malocclusion } & \multicolumn{5}{|c|}{ Females with Class II/1 malocclusion } \\
\hline & \multirow{2}{*}{$\begin{array}{c}\text { Syrians } \\
(n=19) \\
\text { Mean } \pm \text { S.D }\end{array}$} & \multirow{2}{*}{$\begin{array}{c}\text { Hungarians } \\
(n=19) \\
\text { Mean } \pm \text { S.D }\end{array}$} & \multicolumn{2}{|c|}{$\begin{array}{c}95 \% \text { CI of } \\
\text { Mean } \\
\text { Difference } \\
\end{array}$} & \multirow[t]{2}{*}{$P$-value } & \multirow{2}{*}{$\begin{array}{c}\text { Syrians } \\
(n=24) \\
\text { Mean } \pm \text { S.D }\end{array}$} & \multirow{2}{*}{$\begin{array}{c}\text { Hungarians } \\
(n=24) \\
\text { Mean } \pm \text { S.D }\end{array}$} & \multicolumn{2}{|c|}{$\begin{array}{c}95 \% \text { CI of } \\
\text { Mean } \\
\text { Difference } \\
\end{array}$} & \multirow[t]{2}{*}{$P$-value } \\
\hline & & & $\mathbf{L}$ & $\mathbf{U}$ & & & & $\mathbf{L}$ & $\mathbf{U}$ & \\
\hline \multicolumn{11}{|l|}{ Tooth-size ratios $\partial$} \\
\hline Anterior ratio (\%) & $80.55 \pm 2.95$ & $79.42 \pm 2.08$ & -0.57 & 2.81 & 0.186 & $80.81 \pm 2.60$ & $77.89 \pm 2.42$ & 1.46 & 4.38 & $<0.001$ \\
\hline Overall ratio (\%) & $92.74 \pm 1.80$ & $92.79 \pm 2.33$ & -1.42 & 1.32 & 0.941 & $92.92 \pm 1.65$ & $91.87 \pm 1.98$ & 0.00 & 2.11 & 0.051 \\
\hline
\end{tabular}

$\partial$ t-tests for independent variables

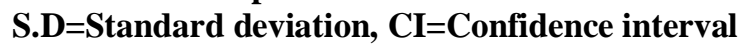

Bold values indicate significance of $p$ value $(p<0.05)$ (two-tailed)

Tooth-size comparisons revealed that Syrian females with Class II/1 malocclusion had significantly greater anterior tooth-size ratios than Hungarian females with Class II/1 malocclusion $(p<0.001)$. Syrian and Hungarian males with Class II/1 malocclusion showed no such difference (Table 12).

\subsection{Upper airway differences between Syrian and Hungarian adolescents with Class II/1 malocclusion (Accepted article/In press, III)}

Comparisons of the upper airway morphology between the two ethnic groups showed that Syrian adolescents with Class II/1 malocclusion had a significantly smaller depth of the upper pharynx (UPh) $(\mathrm{p}=0.007)$ and a significantly larger soft palate angle (ANS-PNS-U) $(\mathrm{p}=$ 0.003) than their Hungarian counterparts, while the hyoid bone was located more posteriorly (based on C3H distance) ( $\mathrm{p}=0.002)$ in Hungarian adolescents with Class II/1 malocclusion than in Syrian adolescents with Class II/1 malocclusion (Table 13).

Additionally, comparisons of the soft tissue variables related to the upper airway showed that the cervical length $(C L)$ was significantly shorter $(p=0.042)$ and the lip-chin-throat angle 
(LCT) was significantly larger $(\mathrm{p}=0.049)$ in Hungarian adolescents with Class II/1 malocclusion than in Syrian adolescents with Class II/1 malocclusion (Table 13) .

Table 13. Comparisons of upper airway and related soft tissue measurements between Syrian and Hungarian adolescents with Class II/1 malocclusion.

\begin{tabular}{|c|c|c|c|c|c|}
\hline & \multirow{2}{*}{$\begin{array}{l}\text { Syrians with } \\
\text { Class II/1 } \\
\text { malocclusion } \\
(\mathrm{n}=43)\end{array}$} & \multirow{2}{*}{$\begin{array}{l}\text { Hungarians with } \\
\text { Class II/1 } \\
\text { malocclusion } \\
(n=43)\end{array}$} & \multicolumn{2}{|c|}{$\begin{array}{c}95 \% \text { CI of } \\
\text { Mean/Median } \\
\text { Difference }\end{array}$} & \multirow[t]{2}{*}{$p$-value } \\
\hline & & & $\mathbf{L}$ & $\mathbf{U}$ & \\
\hline OPT/NSL $\left(^{\circ}\right)($ Mean \pm SD) $\partial$ & $102.88 \pm 9.91$ & $100.33 \pm 10.58$ & -1.85 & 6.95 & 0.252 \\
\hline \multicolumn{6}{|l|}{ Upper airway measurements } \\
\hline \multicolumn{6}{|l|}{ Upper airway depth } \\
\hline PNS-Ad1(mm) (Median \pm IQR) $\dagger$ & $23.12 \pm 8.14$ & $20.52 \pm 6.68$ & -3.33 & 0.82 & 0.232 \\
\hline $\mathrm{UPh}(\mathrm{mm})($ Mean $\pm \mathrm{SD}) \partial$ & $11.50 \pm 3.15$ & $13.28 \pm 2.85$ & -3.07 & -0.49 & 0.007 \\
\hline $\operatorname{MPh}(\mathrm{mm})($ Mean \pm SD) $\partial$ & $10.34 \pm 2.88$ & $9.63 \pm 2.70$ & $\begin{array}{ll}-0.48 \\
\end{array}$ & 1.91 & 0.236 \\
\hline $\mathrm{LPh}(\mathrm{mm})($ Median $\pm \mathrm{IQR}) \dagger$ & $10.65 \pm 4.56$ & $10.44 \pm 5.31$ & -2.02 & 0.61 & 0.316 \\
\hline \multicolumn{6}{|l|}{ Upper airway length } \\
\hline PNS-Eb $(\mathrm{mm})($ Mean \pm SD) $\partial$ & $59.35 \pm 7.20$ & $60.31 \pm 6.68$ & -3.94 & 2.02 & 0.523 \\
\hline \multicolumn{6}{|l|}{ Soft palate } \\
\hline PNS-U (mm) (Median \pm IQR) $\dagger$ & $30.79 \pm 4.08$ & $29.98 \pm 5.14$ & -2.20 & 0.86 & 0.400 \\
\hline SPT $(\mathrm{mm})($ Mean \pm SD) $\partial$ & $9.39 \pm 1.38$ & $9.05 \pm 1.53$ & -0.28 & 0.97 & 0.279 \\
\hline ANS-PNS-U $\left(^{\circ}\right)($ Mean \pm SD) $\partial$ & $131.96 \pm 6.94$ & $127.51 \pm 6.58$ & 1.55 & 7.35 & 0.003 \\
\hline \multicolumn{6}{|l|}{ Hyoid bone position } \\
\hline MPH $(\mathrm{mm})($ Mean $\pm \mathrm{SD}) \partial$ & $12.01 \pm 5.17$ & $13.68 \pm 5.16$ & -3.88 & 0.55 & 0.138 \\
\hline $\mathrm{C} 3 \mathrm{H}(\mathrm{mm})($ Median $\pm \mathrm{IQR}) \dagger$ & $33.36 \pm 4.00$ & $30.77 \pm 7.27$ & -4.62 & -1.12 & 0.002 \\
\hline \multicolumn{6}{|l|}{ Soft tissue measurements } \\
\hline $\mathrm{LCT}\left(^{\circ}\right)($ Mean $\pm \mathrm{SD}) \partial$ & $121.54 \pm 11.76$ & $126.33 \pm 10.46$ & -9.57 & -0.02 & 0.049 \\
\hline CL (mm) (Median \pm IQR) $\dagger$ & $45.29 \pm 11.17$ & $41.97 \pm 8.95$ & -6.95 & -0.12 & 0.042 \\
\hline
\end{tabular}

$\partial$ t-test for independent variables

$\dagger$ Mann-Whitney U-test for independent variables

$\mathrm{CI}=$ Confidence interval, $\mathrm{SD}=$ Standard deviation, and $\mathrm{IQR}=$ Interquartile range

Bold values indicate significance of $p$ value $(p<0.05)$ (two-tailed)

Correlation analyses revealed several statistically significant and moderate correlations (Table 14). Indeed, in Syrian subjects with Class II/1 malocclusion, dimensions at the upper level of the pharynx (PNS-Ad1) tended to decrease with decreasing SNA, SNB angles $(r=0.34$ and $r$ $=0.31$, respectively) $(\mathrm{p}=0.028$ and $\mathrm{p}=0.042$, respectively), decreasing maxillary and mandibular lengths $(r=0.47$ and $r=0.47$, respectively) $(p=0.002$ and $p=0.002$, respectively), and increasing inter-maxillary and mandibular plane angles ( $r=-0.35$ and $r=-$ 0.31 , respectively) ( $\mathrm{p}=0.022$ and $\mathrm{p}=0.047$, respectively). Furthermore, in Syrian subjects with Class II/1 malocclusion, dimensions at the middle level of the pharynx (MPh) tended to 
decrease with a decreasing SNA angle $(r=0.41)(p=0.006)$, decreasing maxillary length $(r=$ $0.32)(p=0.036)$, and increasing inter-maxillary angle $(r=-0.40)(p=0.008)$.

Table 14. Correlations between pharyngeal depths and skeletofacial morphology for Syrian and Hungarian adolescents with Class II/1 malocclusion.

\begin{tabular}{|c|c|c|c|c|c|c|c|c|c|}
\hline \multirow[b]{2}{*}{ Variables } & & \multicolumn{4}{|c|}{ Syrians with Class II/1 malocclusion } & \multicolumn{4}{|c|}{ Hungarians with Class II/1 malocclusion } \\
\hline & & $\begin{array}{c}\text { PNS-Ad1 } \\
\text { (mm) }\end{array}$ & $\begin{array}{c}\text { UPh } \\
(\mathbf{m m})\end{array}$ & $\begin{array}{l}\text { MPh } \\
(\mathbf{m m})\end{array}$ & $\begin{array}{c}\text { LPh } \\
(\mathbf{m m})\end{array}$ & $\begin{array}{c}\text { PNS-Ad1 } \\
\text { (mm) }\end{array}$ & $\begin{array}{c}\text { UPh } \\
(\mathbf{m m})\end{array}$ & $\begin{array}{l}\text { MPh } \\
(\mathbf{m m})\end{array}$ & $\begin{array}{c}\text { LPh } \\
(\mathbf{m m})\end{array}$ \\
\hline \multirow[t]{2}{*}{ SNA $\left(^{\circ}\right)$} & Coefficient & 0.336 & 0.145 & 0.412 & 0.293 & 0.038 & -0.202 & 0.035 & 0.057 \\
\hline & P Value & 0.028 & 0.352 & 0.006 & 0.056 & 0.811 & 0.195 & 0.825 & 0.715 \\
\hline \multirow[t]{2}{*}{ SNB $\left({ }^{\circ}\right)$} & Coefficient & 0.312 & 0.133 & 0.210 & 0.118 & -0.051 & -0.292 & -0.012 & 0.023 \\
\hline & P Value & 0.042 & 0.396 & 0.176 & 0.450 & 0.747 & 0.057 & 0.941 & 0.882 \\
\hline \multirow[t]{2}{*}{ ANB $\left({ }^{\circ}\right)$} & Coefficient & 0.054 & 0.069 & 0.270 & 0.170 & 0.268 & 0.108 & 0.213 & 0.046 \\
\hline & P Value & 0.733 & 0.659 & 0.080 & 0.275 & 0.083 & 0.490 & 0.170 & 0.770 \\
\hline \multirow[t]{2}{*}{ A-Ba (mm) } & Coefficient & 0.465 & 0.238 & 0.320 & 0.137 & 0.248 & -0.116 & 0.140 & 0.080 \\
\hline & $\mathrm{P}$ Value & 0.002 & 0.125 & 0.036 & 0.381 & 0.110 & 0.461 & 0.371 & 0.609 \\
\hline \multirow[t]{2}{*}{ Pog-Ba (mm) } & Coefficient & 0.469 & 0.340 & 0.236 & 0.033 & 0.089 & -0.107 & 0.102 & 0.093 \\
\hline & P Value & 0.002 & 0.026 & 0.128 & 0.836 & 0.570 & 0.494 & 0.515 & 0.554 \\
\hline \multirow[t]{2}{*}{ NL/NSL $\left({ }^{\circ}\right)$} & Coefficient & 0.034 & 0.111 & 0.140 & 0.061 & -0.158 & -0.158 & 0.104 & 0.122 \\
\hline & P Value & 0.831 & 0.479 & 0.371 & 0.698 & 0.313 & 0.311 & 0.509 & 0.436 \\
\hline \multirow[t]{2}{*}{ ML/NSL ( $\left.{ }^{\circ}\right)$} & Coefficient & -0.305 & 0.035 & -0.242 & -0.012 & -0.070 & -0.002 & -0.111 & -0.116 \\
\hline & P Value & 0.047 & 0.822 & 0.118 & 0.937 & 0.654 & 0.987 & 0.477 & 0.459 \\
\hline \multirow[t]{2}{*}{ NL/ML ( $\left.{ }^{\circ}\right)$} & Coefficient & -0.349 & -0.141 & -0.398 & -0.166 & -0.052 & 0.028 & -0.154 & -0.170 \\
\hline & P Value & 0.022 & 0.365 & 0.008 & 0.286 & 0.741 & 0.858 & 0.323 & 0.275 \\
\hline \multirow[t]{2}{*}{ CL (mm) } & Coefficient & 0.073 & -0.062 & 0.222 & 0.260 & 0.136 & -0.095 & 0.297 & 0.459 \\
\hline & P Value & 0.641 & 0.692 & 0.153 & 0.092 & 0.385 & 0.545 & 0.053 & 0.002 \\
\hline \multirow[t]{2}{*}{$\operatorname{LCT}\left({ }^{\circ}\right)$} & Coefficient & -0.225 & 0.039 & -0.202 & -0.198 & -0.190 & -0.241 & -0.266 & -0.479 \\
\hline & P Value & 0.147 & 0.803 & 0.195 & 0.202 & 0.223 & 0.120 & 0.085 & 0.001 \\
\hline \multirow[t]{2}{*}{ PNS-Eb (mm) } & Coefficient & -0.097 & 0.175 & -0.163 & -0.267 & 0.026 & 0.012 & -0.219 & -0.253 \\
\hline & P Value & 0.538 & 0.261 & 0.295 & 0.084 & 0.869 & 0.937 & 0.159 & 0.102 \\
\hline \multirow[t]{2}{*}{ PNS-U (mm) } & Coefficient & 0.234 & 0.107 & -0.072 & -0.282 & 0.232 & -0.042 & -0.285 & 0.030 \\
\hline & P Value & 0.131 & 0.496 & 0.644 & 0.067 & 0.134 & 0.791 & 0.064 & 0.849 \\
\hline \multirow[t]{2}{*}{ SPT (mm) } & Coefficient & -0.051 & -0.203 & -0.063 & -0.189 & 0.166 & -0.196 & -0.294 & -0.206 \\
\hline & P Value & 0.744 & 0.191 & 0.687 & 0.224 & 0.288 & 0.209 & 0.056 & 0.185 \\
\hline \multirow[t]{2}{*}{ ANS-PNS-U $\left(^{\circ}\right)$} & Coefficient & 0.121 & -0.193 & -0.193 & 0.042 & 0.293 & 0.074 & -0.002 & 0.235 \\
\hline & P Value & 0.439 & 0.215 & 0.216 & 0.789 & 0.057 & 0.637 & 0.990 & 0.129 \\
\hline \multirow[t]{2}{*}{ MPH (mm) } & Coefficient & -0.293 & 0.166 & -0.207 & -0.160 & -0.105 & -0.184 & -0.113 & -0.074 \\
\hline & P Value & 0.057 & 0.288 & 0.184 & 0.307 & 0.502 & 0.238 & 0.473 & 0.637 \\
\hline \multirow[t]{2}{*}{ C3H (mm) } & Coefficient & 0.160 & 0.234 & 0.189 & 0.001 & 0.134 & -0.002 & 0.173 & 0.411 \\
\hline & P Value & 0.306 & 0.131 & 0.224 & 0.997 & 0.391 & 0.988 & 0.266 & 0.006 \\
\hline
\end{tabular}

Bold values indicate correlation is significant at the 0.05 level (two-tailed) 
In contrast to Syrian subjects with Class II/1 malocclusion, Hungarian subjects with Class II/1 malocclusion showed no correlations between the depths of the pharynx and sagittal or vertical dimensions. However, dimensions at the lower level of the pharynx (LPh) were significantly correlated with hyoid bone position $(r=0.41)(p=0.006)$, cervical length $(r=$ 0.46) $(\mathrm{p}=0.002)$, and lip-chin-throat angle $(\mathrm{r}=-0.48)(\mathrm{p}=0.001)$ only among the Hungarian subjects with Class II/1 malocclusion (Table 14).

\section{Discussion}

\subsection{Cephalometric and tooth-size characteristics of Syrian adolescents with Class II/1 malocclusion}

Several studies have reported the cephalometric and tooth-size features of individuals of Middle Eastern ethnicity (40,121-124). Although Syrians belong to the Middle Eastern ethnic group, limited data are available pertaining to the craniofacial characteristics of adolescents of Syrian nationality. Therefore, this compound cephalometric and tooth-size investigation was attempted to establish the dentofacial morphology, upper-airway dimensions, and tooth-size characteristics of Syrian adolescents with both skeletal and dental Class II/1 malocclusion. To the best of my knowledge, this is the first comprehensive investigation on this topic.

In addition, 95\% confidence intervals (CIs) for the means of cephalometric and tooth-size variables in the Syrian sample with Class II/1 malocclusion (Table 6) were compared with 95\% CIs for the means of Syrian normative cephalometric and tooth-size variables (Supplementary Table 3) obtained from two previous studies (73,74), and with 95\% CIs for the means of the corresponding variables in previous Middle Eastern studies on Class II/1 malocclusion (Supplementary Table 4) (24,40,121-129).

\subsubsection{Skeletal components of Syrian adolescents with Class II/1 malocclusion}

In this investigation, the maxillary anteroposterior position of Syrian subjects with Class II/1 malocclusion was normal relative to the Syrian normative data, while the mandible was posteriorly positioned (CIs of A-NP, SNA, and Pog-NP in Table 6 vs. their corresponding values in Supplementary Table 3); these findings were in agreement with those of several 
Middle Eastern studies (24,25,51,121,130) (CIs of A-NP, and Pog-NP in Table 6 vs. their corresponding values in Supplementary Table 4). However, other Middle Eastern studies have reported different results $(29,125)$; a possible reason for the divergence in findings could be, on one hand, due to differences in the methods used for the determination of the maxillary and mandibular position (46), while on the other hand, the involvement of different nationalities in the various studies may explain the range of results. Furthermore, previous Middle Eastern studies have suggested that the majority of Class II/1 patients may have abnormal development of the mandible, both in terms of size and in terms of position $(24,121,130)$. In this current investigation, although a shorter absolute mandibular length was observed among Syrian subjects with Class II/1 malocclusion, the absolute maxillary length was also shorter when compared with the Syrian normative data, resulting in a normal maxillomandibular difference (CIs of Cond-A, Cond-Gn, and Max-Mand in Table 6 vs. their corresponding values in Supplementary Table 3). In the interpretation of such data, the difference between maxillary and mandibular lengths should also be considered since a geometric relationship exists between both measurements (107). The normal maxillomandibular difference in this investigation confirms that mandibular length was in proportion to the maxillary length. Therefore, the short mandibular and maxillary lengths do not represent a conclusive feature of Syrian subjects with Class II/1 malocclusion included in this investigation rather than a potential difference between this investigation and the cephalometric control study in estimating the point “condylion.” This point was considered by McNamara (1984) as "often difficult to find" and used as a measure of the lengths of both jaws; therefore, a slight difference in the estimation of condylion will simply affect the absolute lengths of both jaws but will not impact the maxillomandibular difference (107).

A prominent feature of Syrian subjects with Class II/1 malocclusion in the present investigation was the hyperdivergent facial pattern. The retruded mandible appeared to be accompanied by an increased mandibular plane angle and opened facial axis in both sexes and excessive lower anterior facial height that was clear enough in females (CIs of ANS-Me, MPFH and Facial Axis in Table 6 vs. their corresponding values in Supplementary Table 3). A review of the Middle Eastern literature suggests wide agreement with these results $(24,25,29,121,125,130)$ (CIs of MP-FH in Table 6 vs. their corresponding values in Supplementary Table 4). Therefore, the posterior position of the mandible and, consequently, 
the inter-maxillary discrepancy of Syrian subjects with Class II/1 malocclusion in this investigation may be seen as a feature of the hyperdivergent facial pattern, as determined by the increased lower anterior facial height and backward rotation of the mandible (Figure 5).

Figure 5. Comparison between Syrian subjects with Class II/1 malocclusion and Syrian subjects with normal occlusion regarding the skeletal parameters.
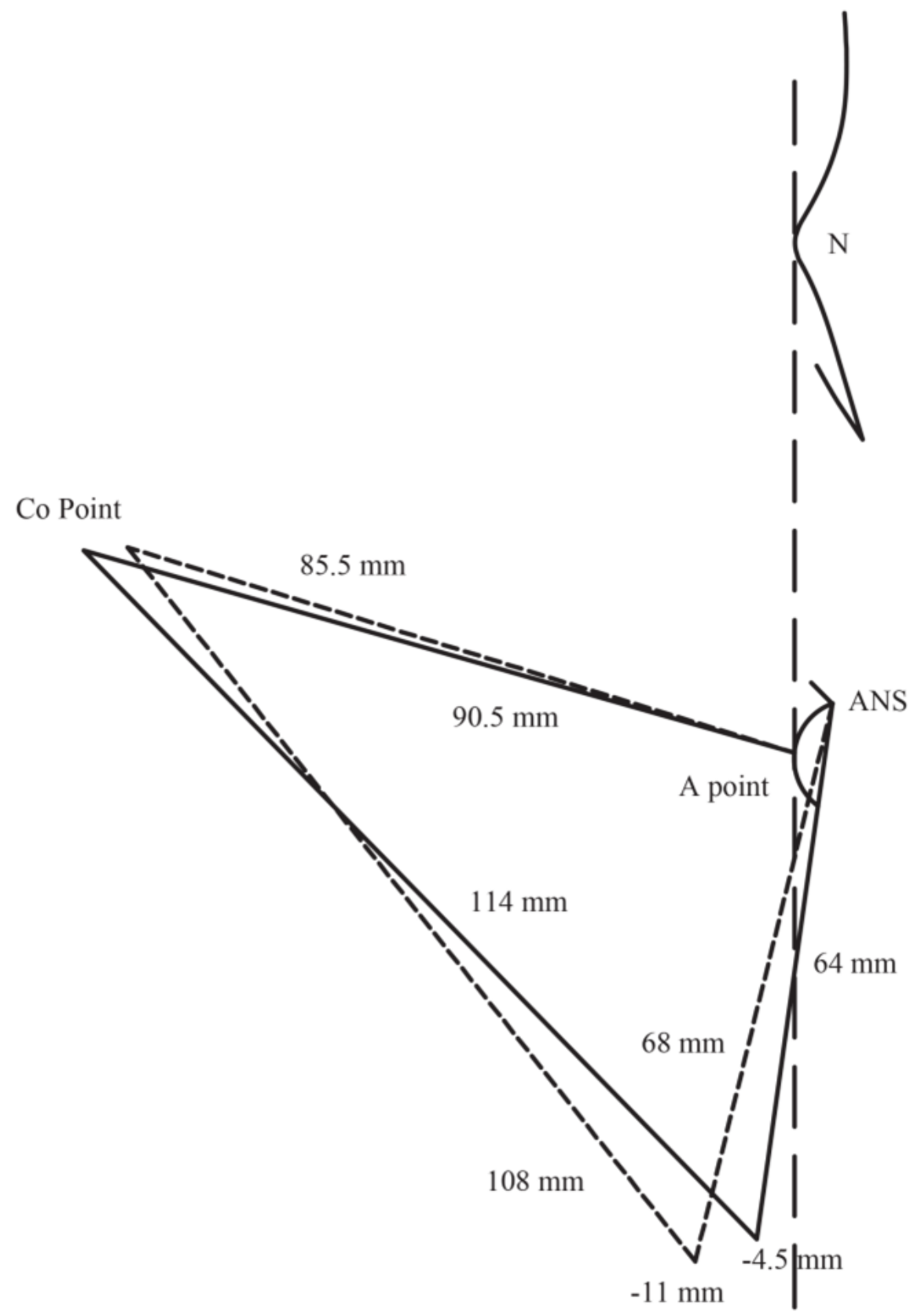

Normal occlusion (Syrian males and females)

Class II/1 (Syrian males and females) 


\subsubsection{Dentoalveolar components of Syrian adolescents with Class II/1 malocclusion}

Dentoalveolar aberrations in Syrian subjects with Class II/1 malocclusion were represented by protrusive mandibular incisors that were clear enough in females, whereas maxillary incisors were normally positioned in both sexes when compared with the Syrian normative data (CIs of 1U-AP and 1L-APog in Table 6 vs. their corresponding values in Supplementary Table 3). These findings contradicted those of certain Middle Eastern studies $(51,125)$. However, other Middle Eastern studies confirmed normally positioned maxillary incisors (24) and more protrusive mandibular incisors existed in Class II/1 malocclusion $(29,121,130)$ (CIs of 1U-AP and 1L-APog in Table 6 vs. their corresponding values in Supplementary Table 4). The inconsistent findings between this investigation and other previous studies might be owing to the use of different reference lines for the determination of the incisors position or might be attributed to the variations in the nationality background of the studied samples.

In the present investigation, the protrusion of mandibular incisors in Syrian subjects with Class II/1 malocclusion (especially in females) might be attributed to the dentoalveolar compensatory mechanism in response to the underlying skeletal discrepancy attempting to maintain relatively normal relationships between the dental arches, in accordance with the previously published study by Solow (1980) (131). Another explanation might be the relative tooth-size excess observed in the mandibular anterior segment of the Syrian subjects with Class II/1 malocclusion (see below: 6.1.5 Tooth-size characteristics of Syrian adolescents with Class II/1 malocclusion), since the protrusion of mandibular incisors could occur because of space limitations.

\subsubsection{Soft tissue components of Syrian adolescents with Class II/1 malocclusion}

The soft tissue parameters of Syrian subjects with Class II/1 malocclusion, when compared with the Syrian normative data, showed a more obtuse nasolabial angle (CIs of NLA in Table 6 vs. their corresponding values in Supplementary Table 3). A previous Middle Eastern study found that Class II subjects had a greater value of the nasolabial angle than those with Class I; however, the difference was not significant (127). Conversely, other Middle Eastern studies suggested different results $(126,132)$ (CIs of NLA in Table 6 vs. their corresponding values in Supplementary Table 4). A possible reason for this variability among outcomes might be the 
differences in the methods used to determine the nasolabial angle (133). Moreover, nationality differences may be a possible reason for such variability in soft tissue results.

Since there was no difference in the upper-lip angulation between Syrian subjects with Class II/1 malocclusion and Syrian normative data (CIs of UL-NP in Table 6 vs. their corresponding values in Supplementary Table 3), the findings of this investigation suggest that the angulation of the lower border of the nose may be a reason for the more obtuse nasolabial angle in Syrian subjects with Class II/1 malocclusion. In this investigation, it was not possible to investigate the slope of the lower nasal border because there was no Syrian normative data available on this variable. Fitzgerald et al. (1992) established a reliable method of constructing the nasolabial angle to determine the interrelationship between the nose and the upper lip (134). Further investigations that consider using this method are needed to validate these results.

\subsubsection{Upper airway dimensions of Syrian adolescents with Class II/1 malocclusion}

In this investigation, upper-pharyngeal widths were smaller in Syrian subjects with Class II/1 malocclusion when compared with the Syrian normative data, and lower-pharyngeal widths showed smaller widths that were clear enough in males (CIs of UPh and LPh in Table 6 vs. their corresponding values in Supplementary Table 3). These findings support the results of previous Middle Eastern studies $(125,128,135)$ (CIs of UPh and LPh in Table 6 vs. their corresponding values in Supplementary Table 4). In contrast, some Middle Eastern studies denied that a relationship exists between Class II/1 malocclusion and airway dimensions $(136,137)$. An explanation for the contrasting results might be an overlap between etiologic factors, including abnormal skeletal morphology and abnormal upper-airway soft tissue structures (138). In this investigation, the observed smaller pharyngeal widths might be attributable to the hyperdivergent facial pattern associated with Class II/1 Syrian subjects; this corroborates the previous results found in the Middle Eastern literature (135).

McNamara (1984) emphasized that an upper-pharyngeal width of $5 \mathrm{~mm}$ or less can be used as an indicator of possible airway obstruction, whereas lower pharyngeal measurements smaller than average values are not remarkable (107). According to this indicator, there was no 
prevalence of pharyngeal obstructions in Syrian subjects with Class II/1 malocclusion. However, a more accurate diagnosis can be made only by an otorhinolaryngologist (107).

\subsubsection{Tooth-size characteristics of Syrian adolescents with Class II/1 malocclusion}

Former Middle Eastern studies have indicated that tooth-size disharmonies exist among different groups of malocclusion $(38,40)$. In accordance with the results of this investigation on tooth-size ratios (CIs of anterior ratio and overall ratio in Table 7 vs. their corresponding values in Supplementary Table 3), some Middle Eastern studies did not find differences in overall ratios between Class II/1 subjects and the normative data (129), whereas other Middle Eastern studies described an overall ratio for Class II/1 subjects that was smaller $(40,139)$ or larger (140) compared to that of subjects with normal occlusion. Similarly, variability can be found in the Middle Eastern literature regarding the anterior ratio, whereas a smaller ratio (38) or no differences were detected $(129,140)$ (CIs of anterior ratio and overall ratio in Table 7 vs. their corresponding values in Supplementary Table 4). Such divergence in findings may be explained by differences in the nationality backgrounds of the samples.

Several studies confirmed that a tooth-size disharmony greater than two SDs, as compared with Bolton's norms, could create clinical difficulties, particularly in the finishing phase of treatment $(39,41)$. In contrast, one study suggested that Bolton's SDs may not be a valuable index to use to determine the clinical significance of tooth-size disharmony because of their relatively modest values (141). Therefore, the frequencies of tooth-size discrepancy outside two SDs from Bolton's norms as well as the frequencies of tooth-size discrepancy outside two SDs from Syrian population norms were calculated in this investigation among Syrian subjects with Class II/1 malocclusion. The percentage of Class II/1 Syrian subjects with anterior ratios greater than two SDs from Bolton's norm was 39.5\%, while the percentage of Class II/1 Syrian subjects who had anterior ratios greater than two SDs from Syrian population norm was $25.6 \%$, representing a relative tooth-size excess in the mandibular anterior segment that was sufficient to warrant clinical concern. These relatively high percentages of Class II/1 Syrian subjects with an anterior ratio exceeding two SDs from Bolton's norm and Syrian population norm may be explained by the association of a higher percentage of tooth-size disharmonies and sufficiently remarkable malocclusions such as 
Class II/1. These disharmonies are particularly evident in the anterior segment, since the anterior teeth, especially the incisors, have the greatest incidence of tooth-size variations (38).

\subsubsection{Limitations and future scope of this investigation}

As far as limitations of the current investigation were concerned, consideration must be given to the sample size. Although the sample size estimation showed sufficient sample size for each sex group, it was small; therefore, the results should be interpreted with caution and further studies with larger sample size would be needed. Such studies should also include adolescents from several orthodontic centers, since the data in the present investigation were recruited from only one private orthodontic practice in Syria. Additionally, there was no concurrent control group in this investigation. The inclusion of a matched control group in this investigation would have been desirable for a better comparison, although, in case of normative cephalometric data, requiring the exposure of patients with well-balanced dentofacial relationships to X-ray radiation constitutes an ethical issue. As an alternative, already established Syrian cephalometric and tooth-size normative data were used as sources of Syrian normative measurements $(73,74)$. Although age could not be a confounding factor in tooth-size analysis, a wider age range was used in the Syrian normative cephalometric study than in this investigation which could be a confounding factor in the cephalometric analysis. As no other cephalometric data have been published on Syrian adolescent norms, these published data were used as sources of Syrian normative measurements.

\subsection{Dentoskeletal and tooth-size differences between Syrian and Hungarian adolescents with Class II/1 malocclusion}

This investigation evaluated the effects of ethnic variations on dentoskeletal and tooth-size characteristics of Syrians and Hungarians adolescents with Class II/1 malocclusion. As most dentoskeletal variations can be ascribed to sex, age (maturity stage), and ethnicity (44), and most tooth-size variations can be ascribed to sex and ethnicity $(55,65)$, this investigation compared sex- and skeletal age-matched individuals to yield clear conclusions on the impact of ethnicity on dentoskeletal and tooth-size characteristics. 


\subsubsection{Differences in skeletal components between Syrian and Hungarian adolescents with Class II/1 malocclusion}

Skeletal comparisons showed that sagittal measurements significantly differed in the two groups. Hungarian males with Class II/1 malocclusion had more protruded maxillae compared to Syrian males with Class II/1 malocclusion, while Hungarian females with Class II/1 malocclusion had significantly shorter mandibles than Syrian females with Class II/1 malocclusion (Figure 4). These observations in Class II/1 Hungarian adolescents support those of a previous investigation (49), which found Class II/1 Caucasian males with maxillary protrusion and Class II/1 Caucasian females with shorter than average mandibular length. Although Class II/1 Syrian adolescents had relatively normal maxillary position and mandibular length as compared with Class II/1 Hungarian adolescents, their mandibles were posteriorly positioned. This was evident in Class II/1 Syrian males with significantly smaller SNB angles than Class II/1 Hungarian males who had relatively normal mandibular position (Table 11). In contrast, Class II/1 Syrian females also had restricted mandibles; however, the diminished mandibular sizes of Class II/1 Hungarian females were pronounced enough to cause a non-significant difference in SNB measurements between the two female populations (Table 11). Non-Caucasian studies reported similar findings of normal maxillary position and retruded mandible in Class II/1 Syrian subjects (24-26,51). Contrarily, some Caucasian studies reported varying findings with normally positioned mandibles and protruded maxillae $(27,28)$. The involvement of different ethnicities across various studies may explain the inconsistent findings $(30,44,45,50)$.

Many authors have recognized the importance of excessive vertical development in the determination of mandibular position $(24,25,45)$. Thus, retruded mandibles of Class II/1 Syrian adolescents in this investigation can be explained with respect to the vertical plane: Class II/1 Syrian adolescents, in comparison to Class II/1 Hungarian adolescents, regardless of sex, had hyperdivergent facial patterns (Figure 4). This finding agrees with those of other studies that compared non-Caucasian and Caucasian Class II patients $(44,45,98)$.

\subsubsection{Differences in dentoalveolar components and tooth-size characteristics between Syrian and Hungarian adolescents with Class II/1 malocclusion}

The position of dentition, relative to the skeletal structure, is another important aspect of Class 
II/1 malocclusion. The only significant difference in the dental position found in this investigation was related to the lower incisors and was evident among females (Table 11). Class II/1 Syrian females had more protrusive lower incisors than Class II/1 Hungarian females. Status on the position of lower incisors in patients with Class II/1 malocclusion remains unclear. Most non-Caucasian studies have reported protruded lower incisors (24$26,29)$, and two comparative studies $(44,45)$ support ethnic variations in lower incisor position between non-Caucasian and Caucasian populations. Since a tooth-size excess with space limitation might cause incisor protrusion, the larger anterior tooth-size ratios of Class II/1 Syrian females relative to Class II/1 Hungarian females might further account for their lower incisor protrusion. This would be a possible explanation since the large anterior tooth-size ratios of Class II/1 Syrian females reflect a relative tooth-size excess in the lower anterior region. The significant difference in anterior tooth-size ratio between Syrian and Hungarian females with Class II/1 malocclusion can be attributed to ethnic variations, in accordance with previous studies in the literature $(55,65)$.

\subsubsection{Potential clinical implications}

According to our observations in this investigation, as Class II/1 malocclusion in Hungarian adolescents represents sagittal discrepancy (protruded maxillae in males; short mandibles in females), treatment strategies should aim to inhibit maxillary growth using extra-oral forces in Class II/1 Hungarian males and enhance mandibular growth using functional appliances in Class II/1 Hungarian females. Moreover, since Class II/1 Syrian adolescents had considerable vertical tendencies and in case of treatment of this anomaly most orthodontic treatment mechanics tend to open the bite, greater care should be exercised to control the vertical dimension when treating Class II/1 Syrian adolescents compared with Class II/1 Hungarian adolescents. Treatment strategies for Class II/1 Syrian adolescents should aim to alter the extent and direction of vertical facial growth and prevent posterior mandibular rotation. Finally, Class II/1 Syrian females exhibited more protrusive lower incisors with relative toothsize excess in the lower anterior segment, which affects treatment objectives regarding the optimal final position of these teeth. Therefore, a more interproximal reduction might be a better treatment option for Class II/1 Syrian females than Class II/1 Hungarian females, if the treatment decision is to decrease protrusion. Contrarily, protruded lower incisors, more than 
the standard levels, might be acceptable outcomes in Class II/1 Syrian females.

\subsubsection{Limitations and future scope of this investigation}

Although sample size estimation showed sufficient numbers of participants, there were relatively small groups. This was the major drawback of the present investigation; therefore, the results should be interpreted with caution, and additional studies with larger sample sizes would be needed.

\subsection{Upper airway differences between Syrian and Hungarian adolescents with Class II/1 malocclusion}

This investigation is the first one to compare upper airway structures of untreated Middle Eastern (Syrian) and European (Hungarian) patients with Class II/1 malocclusion. Moreover, no previous investigation of racial differences has compared upper airway structures by matching skeletal age, sex, skeletal type and craniocervical inclination. The present investigation highlights the importance of matching subjects for skeletal age to prevent any maturity-related morphological changes from confounding the results, while previous studies typically comparing samples based on chronological age only $(57,80,85,86,90,142)$. Other strengths of the present investigation are the exclusion of the influence of swallowing and hyperplasia of tonsil or adenoid and minimization of the influence of craniocervical inclination on the examined variables.

The results indicate that Class II/1 Syrian adolescents had smaller upper pharynx dimensions than Class II/1 Hungarian adolescents (Table 13). This can be attributed, on one hand, to the vertical growth patterns observed in Class II/1 Syrian adolescents when compared with Class II/1 Hungarian adolescents, since Class II subjects with vertical growth patterns showed significantly narrower upper pharyngeal airways than those with normal growth patterns $(80,142)$. On the other hand, it can also be attributed to the larger soft palate angle of Class II/1 Syrian adolescents in comparison with Class II/1 Hungarian adolescents, as observed in the present investigation (Table 13), since a large soft palate angle could predispose the individual to smaller upper airway dimensions (100). 
Comparisons between the two populations revealed that Class II/1 Hungarian adolescents had a more posterior hyoid position than Class II/1 Syrian adolescents (Table 13), which can be explained by the observation that Class II/1 Hungarian adolescents had a shorter mandible than their Syrian counterparts, since a shorter mandible may result in a more posterior hyoid position.

This investigation indicates that a number of skeletal variables are related to airway dimensions in Class II/1 Syrian subjects. A small upper pharynx was associated with a restricted maxilla, a restricted mandible, and long faces (Table 14). Moreover, a small middle pharynx was associated with a restricted maxilla and a large inter-maxillary angle (Table 14). On the other hand, no direct correlations between skeletal variables and airway dimensions were noted in Class II/1 Hungarian subjects (Table 14). This is consistent with previous results in the literature since skeletal restriction was found more frequently in Asian individuals with OSA than in Caucasian subjects with OSA (58-60). In patients with a restricted maxilla and mandible and those with long faces where the mandible is positioned downward and backward, the entire facial complex is placed closer to the cervical spine, thereby leading to a more posterior tongue position (79). Such displacement of the tongue can push the soft palate dorsally and contribute to a reduction of the space available for the airway in the upper and middle pharynx (143).

The present investigation found a significant correlation between the position of the hyoid bone and the depth of lower pharynx only in Class II/1 Hungarian subjects. The hyoid bone position has received much attention owing to the attachments of the lingual musculature. In this investigation, a reduced lower pharynx was associated with posteriorly placed hyoid bone in Class II/1 Hungarian subjects (Table 14). In such cases, the hyoid would tend to attract the tongue backward, further reducing the lower pharyngeal airway $(144,145)$. To this regard, it is important to underline that oral appliances used to treat Class II malocclusion by mandibular repositioning and, consequently, hyoid bone repositioning, have been found to improve the lower pharyngeal airway in both growing and adult OSA European patients (146-148).

Interestingly, Class II/1 Hungarian adolescents had a significantly shorter cervical length and larger lip-chin-throat angle than Class II/1 Syrian adolescents (Table 13). Further, lower pharyngeal dimensions were associated with the cervical length and lip-chin-throat angle only 
in the Hungarian group (Table 14). With a shorter cervical length and larger lip-chin-throat angle, lower pharyngeal dimensions tended to be more reduced in Class II/1 Hungarian subjects. According to the literature, a short cervical length is associated with OSA (149). To my knowledge, the association of the lip-chin-throat angle with upper airway morphology has not been investigated previously. I chose to determine the lip-chin-throat angle in order to obtain an objective measurement of this feature of the facial profile in accordance with the aim of the present investigation. I believe that this angle reflects the characteristics of both the mental soft tissue profile and the submental adipose tissue. A retrusive chin and/or an accumulation of adipose tissue in the submental region will result in a large lip-chin-throat angle and short cervical length. To this regard, it is important to underline that Caucasian patients with OSA had these features in comparison with normal controls or OSA Asian patients $(150,151)$.

\subsubsection{Potential clinical implications}

The two groups in this investigation presented with different pharyngeal airway features and different kinds of associations between their upper airway depths and their skeletofacial morphology. Therefore, it might be reasonable to formulate treatment options for these two distinct ethnic groups based on different considerations.

If orthognathic surgery is to be considered, Syrian subjects with Class II/1 malocclusion might be considered more appropriate than similar Hungarians for bimaxillary advancement surgery and for reducing vertical dimension by surgical maxillary intrusion. In contrast, special consideration might be given to the final hyoid bone position after orthognathic surgery in Class II/1 Hungarian subjects (152). On the other hand, if functional appliances are being used in Class II/1 Syrian subjects, it might be reasonable to design the mandibular repositioning to be more horizontal than vertical when compared with Class II/1 Hungarian subjects in order to prevent a negative effect on the pharyngeal airway due to a backward mandibular rotation.

\subsubsection{Limitations and future scope of this investigation}

The use of lateral cephalogram as a two-dimensional (2D) representation of the threedimensional (3D) airway structure can be considered as a limitation of this investigation. Nevertheless, a recent systematic review and meta-analysis revealed that the $2 \mathrm{D}$ 
cephalometric analysis is a valid method not only to evaluate upper airway anatomy, but also to influence treatment choices (153). Moreover, in the last few years, lateral cephalograms have been used in upper airway evaluation by a considerable number of similar studies $(86,88,154-157)$, because of advantages such as low costs, low radiation dose, and easy access. Cephalograms also provide standardization of measures with high reproducibility (158). Furthermore, the 2D cephalometric method when compared with the cone-beam computed tomography (CBCT) showed reliable airway measurements (159) that were strongly correlated with those of the CBCT (160).

Considering the retrospective nature of this investigation, it was not possible to recruit and match patients based on strict criteria from two orthodontic centers in two different countries using a 3D imaging method (CBCT) because of the following ethical and technical considerations:

- The increasing concerns about cancer risks from dental CBCT, especially in young individuals $(161,162)$, because of the high amount of radiation accompanying the CBCT compared with the 2D cephalometric method $(163,164)$,

- The CBCT is not a routine imaging method in orthodontic practice and its usage is limited to specific justified orthodontic cases (165-170), which do not include the routine investigation of the upper airway morphology of orthodontic patients (165169) (as in this investigation). Therefore, the availability of such 3D images is very low and cannot be compared to that of 2D cephalometric images,

- The CBCT is not quite popular in Syria due to the high cost and limited public cognition. 


\section{Summary of New Findings}

- A hyperdivergent facial pattern was the main cause of the inter-maxillary discrepancy in Syrian adolescents with Class II/1 malocclusion.

- The observed small pharyngeal widths in Class II/1 Syrian sample were not clinically significant.

- $39.5 \%$ of Class II/1 Syrian samples had anterior tooth-size ratios exceeding two SDs of Bolton’s norm and 25.6\% of Class II/1 Syrian samples had anterior tooth-size ratios exceeding two SDs of Syrian population norm, which may be considered as clinically relevant.

- Class II/1 treatment strategies for Hungarian adolescents are not applicable to Syrian adolescents, because.

1. Class II/1 malocclusion reflects sagittal discrepancy in Hungarian adolescents (protruded maxillae in males; short mandibles in females), while it was caused by excessive vertical growth among Syrian adolescents, regardless of sex.

2. Class II/1 Syrian females have more protrusive lower incisors with a relative toothsize excess in the lower anterior region compared with Class II/1 Hungarian females.

- Ethnic differences were found in upper airway structures between Syrian and Hungarian subjects with Class II/1 malocclusion. Class II/1 Syrian adolescents had a significantly smaller depth of the upper pharynx and a larger soft palate angle than their Hungarian counterparts, while the hyoid bone was located more posteriorly in Class II/1 Hungarian adolescents than in Class II/1 Syrian adolescents.

- An influence of skeletal restriction and vertical growth pattern on the upper and middle pharyngeal airway depths existed in Syrian patients with Class II/1 malocclusion. In contrast, the depths of the pharynx were generally quite independent of the skeletal parameters in Hungarian subjects with Class II/1 malocclusion.

- The hyoid bone position and soft tissue morphology of the neck and chin regions had an influence on the lower pharyngeal airway depth only among Hungarians with Class II/1 malocclusion. 


\section{Summary}

It is well established that Class II/1 malocclusion can be caused by a broad range of factors. However, conflicting results, possibly due to ethnic variations, have not allowed the general characterization of this malocclusion. Ethnic differences in cephalometric and tooth-size characteristics have been documented in several studies, but only few studies have investigated these differences with respect to Class II/1 malocclusion. This malocclusion is one of the most frequently seen orthodontic anomalies in Syrian and Hungarian populations with prevalences of $16 \%$ and $23.5 \%$ in Syrian and Hungarian adolescents, respectively. Because of recent wars and conflicts, such as the Syrian conflict, ethnic diversity is increasing worldwide. During the last few years, Syrian refugees and immigrants have occupied the foreground of migration statistics, particularly in Europe. Such a view of recent trends in migration, especially from the Middle East toward Europe, underscores the need for updated studies to discover the craniofacial characteristics of these new immigrants and compare the cephalometric and tooth-size characteristics between different ethnic groups.

The investigations described in the thesis attempt: A) To elucidate the cephalometric and tooth-size characteristics of Syrian adolescents with skeletal and dental Class II/1 malocclusion and compare the acquired data with those of Syrian population norms. B) To compare the dentoskeletal and tooth-size characteristics of Middle Eastern (Syrian) and European (Hungarian) adolescents with skeletal and dental Class II/1 malocclusion. C) To compare the upper airway structures between Middle Eastern (Syrian) and European (Hungarian) adolescents with skeletal and dental Class II/1 malocclusion and to investigate a number of skeletal and soft tissue parameters that would be associated with the upper airway depths in each ethnic group. The retrospectively collected data in this thesis consisted of lateral cephalograms and orthodontic casts that were analyzed by special orthodontic software (OnyxCeph3 ${ }^{\mathrm{TM}}$ ) and a universal digital caliper, respectively.

Results of this thesis showed that a hyperdivergent facial pattern was the main cause of the intermaxillary discrepancy in Syrian adolescents with Class II/1 malocclusion, and the observed small pharyngeal widths in Class II/1 Syrian sample were not clinically significant. Additionally, 39.5\% of Class II/1 Syrian samples had anterior tooth-size ratios exceeding two SDs of Bolton's norm and $25.6 \%$ of Class II/1 Syrian samples had anterior tooth-size ratios exceeding two SDs of Syrian population norm, which may be considered as clinically relevant. Results also revealed that Class II/1 treatment strategies for Hungarian adolescents are not applicable to Syrian adolescents, because: First, Class II/1 malocclusion reflects sagittal discrepancy in Hungarian adolescents (protruded maxillae in males; short mandibles in females), while it was caused by excessive vertical growth among Syrian adolescents, regardless of sex. Second, Class II/1 Syrian females have more protrusive lower incisors with a relative tooth-size excess in the lower anterior region compared with Class II/1 Hungarian females. Moreover, ethnic differences were found in upper airway structures between Syrian and Hungarian subjects with Class II/1 malocclusion. Class II/1 Syrian adolescents had a significantly smaller depth of the upper pharynx and a larger soft palate angle than those of their Hungarian counterparts, while the hyoid bone was located more posteriorly in Class II/1 Hungarian adolescents than in Class II/1 Syrian adolescents. Furthermore, an influence of skeletal restriction and vertical growth pattern on the upper and middle pharyngeal airway depths existed in Syrian patients with Class II/1 malocclusion. In contrast, the depths of the pharynx were generally quite independent of the skeletal parameters in Hungarian subjects with Class II/1 malocclusion. Finally, the hyoid bone position and soft tissue morphology of the neck and chin regions had an influence on the lower pharyngeal airway depth only among Hungarians with Class II/1 malocclusion. In conclusion, determining the craniofacial characteristics of Class II/1 malocclusion in the young Syrian and Hungarian populations could help orthodontists to establish an effective protocol for long-term stable treatment outcome in Syrian and Hungarian orthodontic patients. The findings of this thesis may also have potential implications for optimizing the effects of orthognathic/orthodontic treatments on the airway structures in Syrian and Hungarian orthodontic patients. 


\section{Supplementary Information}

Supplementary Table 1. The demographic characteristics of the Syrian normative studies' samples used as sources of Syrian normative measurements $(73,74)$.

\begin{tabular}{|l|c|c|c|}
\hline & Sample size (n) & Mean age \pm S.D (y) & Age range (y) \\
\hline Syrian normative tooth-size sample & & & \\
\hline Females & 20 & ND & ND \\
\hline Males & 35 & ND & ND \\
\hline Total & 55 & ND & $11-22$ \\
\hline Syrian normative cephalometric sample & & & \\
\hline Females & 50 & $16.4 \pm 2.1$ & ND \\
\hline Males & 50 & $16.7 \pm 1.7$ & ND \\
\hline Total & 100 & $16.6 \pm 1.9$ & $13.5-20$ \\
\hline
\end{tabular}

ND indicates not declared. 
Supplementary Table 2. Definitions of the cephalometric landmarks used in this thesis.

\begin{tabular}{|c|c|}
\hline Cephalometric Landmarks & Interpretations \\
\hline $\mathbf{S}$ (sella) & The center of sella turcica \\
\hline $\mathbf{N}$ (nasion) & Anterior point at frontonasal suture \\
\hline $\mathbf{P}$ (porion) & The superior aspect of the external auditory meatus \\
\hline Or (orbitale) & The lower border of the orbit of the eye \\
\hline PTM & The posterosuperior aspect of the pterygomaxillary fissure \\
\hline Co (condylion) & The most posterosuperior point on the outline of the mandibular condyle \\
\hline Ba (basion) & Most inferior point on anterior foramen magnum \\
\hline ANS (anterior nasal spine) & Most anterior point of anterior nasal spine \\
\hline PNS (posterior nasal spine) & Most posterior point of hard palate \\
\hline Sn (subnasale) & $\begin{array}{l}\text { The point at which the columella merges with the upper lip in the midsagittal } \\
\text { plane }\end{array}$ \\
\hline A & Deepest anterior point in concavity of anterior maxilla \\
\hline B & Deepest anterior point in concavity of anterior mandible \\
\hline 1U/U1 & The most anterior surface of the upper incisor \\
\hline $1 \mathrm{~L} / \mathrm{L1}$ & The most anterior surface of the lower incisor \\
\hline Pog (pogonion) & Most anterior point of bony chin \\
\hline Gn (anatomic gnathion) & The most anteroinferior aspect of the mandibular symphysis \\
\hline cGn (constructed gnathion) & The intersection of the facial plane and the mandibular plane \\
\hline Me (menton) & Most inferior point of bony chin \\
\hline Go (gonion) & $\begin{array}{l}\text { A mid-plane point at the gonial angle located by bisecting the posterior and } \\
\text { inferior borders of the mandible }\end{array}$ \\
\hline Ar (articulare) & $\begin{array}{l}\text { A mid-plane point at the intersection of posterior ramus with inferior cranial } \\
\text { base }\end{array}$ \\
\hline OPT & $\begin{array}{l}\text { Point of intersection of odontoid process tangent (line joining C2s point and } \\
\text { C2i point) and line NS }\end{array}$ \\
\hline C2s & $\begin{array}{l}\text { Tangent point at the superior, posterior extremity of the odontoid process of } \\
\text { the second cervical vertebra }\end{array}$ \\
\hline $\mathbf{C} 2 \mathbf{i}$ & Most inferoposterior point on the body of the second cervical vertebra \\
\hline Adi & Point of intersection of posterior pharyngeal wall and line PNS-Ba \\
\hline U (uvula) & The tip of the uvula \\
\hline Eb (base of epiglottis) & The intersection of the epiglottis and the base of the tongue \\
\hline C3 & Most anteroinferior point on the body of the third cervical vertebra \\
\hline H (hyoid point) & Most anterosuperior point of hyoid \\
\hline $\mathbf{H}^{\prime}$ (neck point) & The intersection between the submental area and the tangent line of the neck \\
\hline Me' (soft tissue menton) & The most inferior point on the soft tissue chin \\
\hline Gn' (soft tissue gnathion) & The most anteroinferior aspect of the soft tissue chin \\
\hline Li (labrale inferius) & The most anterior point on the lower lip \\
\hline
\end{tabular}


Supplementary Table 3. Syrian normative cephalometric measurements and tooth-size ratios $(73,74)$.

\begin{tabular}{|c|c|c|c|c|c|c|}
\hline \multirow{2}{*}{\begin{tabular}{|c|}
$\begin{array}{c}\text { Cephalometric } \\
\text { measurements }\end{array}$ \\
Variables
\end{tabular}} & \multicolumn{2}{|c|}{$\begin{array}{c}\text { Syrian Males with Normal } \\
\text { Occlusion }(n=50)\end{array}$} & \multicolumn{2}{|c|}{$\begin{array}{c}\text { Syrian Females with Normal } \\
\text { Occlusion }(\mathrm{n}=\mathbf{5 0})\end{array}$} & \multicolumn{2}{|c|}{$\begin{array}{c}\text { Syrian adolescents with } \\
\text { Normal Occlusion }(n=100)\end{array}$} \\
\hline & Mean $( \pm$ S.D $)$ & $\begin{array}{c}\text { 95\% CIs for } \\
\text { mean } \\
\text { Lower, Upper }\end{array}$ & Mean $( \pm$ S.D $)$ & $\begin{array}{c}95 \% \text { CIs for } \\
\text { mean } \\
\text { Lower, Upper }\end{array}$ & Mean ( \pm S.D) & $\begin{array}{c}\text { 95\% CIs for } \\
\text { mean } \\
\text { Lower, Upper }\end{array}$ \\
\hline \multicolumn{7}{|l|}{ Skeletal measurements } \\
\hline \multicolumn{7}{|l|}{ Sagittal values } \\
\hline A-NP (mm) & $-1.14( \pm 1.28)$ & $-1.51,-0.77$ & $-0.04( \pm 1.34)$ & $-0.42,0.34$ & $-0.58( \pm 0.96)$ & $-0.77,-0.39$ \\
\hline SNA $\left(^{\circ}\right)$ & $80.26( \pm 2.72)$ & 79.48, 81.04 & $80.87( \pm 2.49)$ & $80.16,81.58$ & $80.58( \pm 1.63)$ & $80.25,80.91$ \\
\hline Pog-NP (mm) & $-4.72( \pm 5.77)$ & $-6.37,-3.07$ & $-4.12( \pm 5.62)$ & $-5.73,-2.51$ & $-4.41( \pm 2.09)$ & $-4.83,-3.99$ \\
\hline Cond-A (mm) & $90.76( \pm 3.61)$ & 89.73, 91.79 & $90.34( \pm 3.72)$ & 89.28, 91.40 & $90.61( \pm 2.14)$ & $90.18,91.04$ \\
\hline Cond-Gn (mm) & $114.77( \pm 4.65)$ & $113.44,116.10$ & $113.16( \pm 4.88)$ & $\begin{array}{l}111.77, \\
114.55 \\
\end{array}$ & $113.98( \pm 1.98)$ & $113.58,114.38$ \\
\hline Max-Mand (mm) & $24.01( \pm 3.77)$ & 22.93, 25.09 & $22.72( \pm 3.18)$ & 21.81, 23.63 & $23.38( \pm 2.16)$ & 22.95, 23.81 \\
\hline \multicolumn{7}{|l|}{ Vertical values } \\
\hline ANS-Me (mm) & $65.04( \pm 4.82)$ & 63.66, 66.42 & $62.57( \pm 4.80)$ & $61.20,63.94$ & $63.82( \pm 2.50)$ & 63.32, 64.32 \\
\hline $\mathrm{MP}-\mathrm{FH}\left({ }^{\circ}\right)$ & $23.01( \pm 4.48)$ & $21.73,24.29$ & $22.19( \pm 5.11)$ & $20.73,23.65$ & $22.61( \pm 2.16)$ & $22.18,23.04$ \\
\hline Facial Axis $\left({ }^{\circ}\right)$ & $1.17( \pm 3.34)$ & $0.22,2.12$ & $0.46( \pm 4.09)$ & $-0.71,1.63$ & $0.83( \pm 2.26)$ & $0.38,1.28$ \\
\hline \multicolumn{7}{|l|}{ Dental measurements } \\
\hline 1U-AP (mm) & $5.82( \pm 2.36)$ & 97.55, 99.17 & $5.26( \pm 2.52)$ & $4.54,5.98$ & $5.55( \pm 1.20)$ & $5.31,5.79$ \\
\hline 1L-APog (mm) & $3.13( \pm 2.28)$ & $2.48,3.78$ & $2.53( \pm 2.36)$ & $1.86,3.20$ & $2.84( \pm 1.31)$ & $2.58,3.10$ \\
\hline \multicolumn{7}{|l|}{ Soft tissue measurements } \\
\hline $\operatorname{NLA}\left({ }^{\circ}\right)$ & $98.36( \pm 2.85)$ & 97.55, 99.17 & $97.14( \pm 2.21)$ & 96.51, 97.77 & $97.76( \pm 1.69)$ & $97.42,98.10$ \\
\hline UL-NP $\left({ }^{\circ}\right)$ & $9.02( \pm 3.28)$ & $8.08,9.96$ & $13.53( \pm 3.85)$ & $12.43,14.63$ & $11.29( \pm 0.84)$ & 11.12, 11.46 \\
\hline \multicolumn{7}{|l|}{ Airway measurements } \\
\hline $\mathrm{UPh}(\mathrm{mm})$ & $17.65( \pm 3.11)$ & $16.76,18.54$ & $16.96( \pm 2.87)$ & $16.14,17.78$ & $17.32( \pm 1.36)$ & $17.05,17.59$ \\
\hline $\mathrm{LPh}(\mathrm{mm})$ & $13.44( \pm 2.56)$ & 12.71, 14.17 & $13.01( \pm 2.25)$ & $12.37,13.65$ & $13.24( \pm 1.21)$ & 13.00, 13.48 \\
\hline Tooth-size ratios & \multicolumn{2}{|c|}{$\begin{array}{c}\text { Syrian Males with Normal } \\
\text { Occlusion }(n=35)\end{array}$} & \multicolumn{2}{|c|}{$\begin{array}{c}\text { Syrian Females with Normal } \\
\text { Occlusion }(\mathbf{n}=\mathbf{2 0})\end{array}$} & \multicolumn{2}{|c|}{$\begin{array}{c}\text { Syrian adolescents with } \\
\text { Normal Occlusion }(n=55)\end{array}$} \\
\hline Variables & Mean $( \pm$ S.D $)$ & $\begin{array}{c}\text { 95\% CIs for } \\
\text { means } \\
\text { Lower, Upper }\end{array}$ & Mean $( \pm$ S.D) & $\begin{array}{c}\text { 95\% CIs for } \\
\text { means } \\
\text { Lower, Upper }\end{array}$ & Mean $( \pm$ S.D) & $\begin{array}{c}\text { 95\% CIs for } \\
\text { means } \\
\text { Lower, Upper }\end{array}$ \\
\hline Anterior ratio (\%) & $78.90( \pm 2.29)$ & 78.11, 79.69 & $79.20( \pm 2.02)$ & $78.25,80.15$ & $78.99( \pm 2.18)$ & $78.40,79.58$ \\
\hline Overall ratio (\%) & $92.40( \pm 2.06)$ & $91.69,93.11$ & $91.90( \pm 2.08)$ & $90.93,92.87$ & $92.26( \pm 2.06)$ & $91.70,92.82$ \\
\hline
\end{tabular}

CIs=confidence intervals, S.D=standard deviation.

Bold values indicate lower and upper bounds of $\mathbf{9 5 \%}$ confidence intervals for mean. 
Supplementary Table 4. Corresponding cephalometric measurements and tooth-size ratios in previous Middle Eastern studies on Class II/1 malocclusion.

\begin{tabular}{|c|c|c|c|c|c|c|c|c|c|}
\hline \multirow{2}{*}{\multicolumn{2}{|c|}{\begin{tabular}{|c|}
$\begin{array}{c}\text { Cephalometric } \\
\text { measurements }\end{array}$ \\
$\begin{array}{c}\text { Nationality \& } \\
\text { Series / Variables }\end{array}$
\end{tabular}}} & \multicolumn{8}{|c|}{ Means (95\% CIs for means) } \\
\hline & & $\begin{array}{l}\text { A-NP } \\
\text { (mm) }\end{array}$ & $\begin{array}{c}\text { Pog-NP } \\
\text { (mm) }\end{array}$ & MP-FH $\left(^{\circ}\right)$ & $\begin{array}{l}\text { 1U-AP } \\
(\mathrm{mm})\end{array}$ & $\begin{array}{l}\text { 1L-APog } \\
\text { (mm) }\end{array}$ & $\operatorname{NLA}\left({ }^{\circ}\right)$ & UPh (mm) & LPh (mm) \\
\hline \begin{tabular}{|c|} 
Turkish \\
(Sayın \& \\
Türkkahraman, \\
2005) (24) \\
\end{tabular} & $\mathrm{F}$ & $\begin{array}{c}0.9 \\
(-0.2,2.0)\end{array}$ & $\begin{array}{c}-10.6 \\
(-13.2,-8.0)\end{array}$ & $\begin{array}{c}28.3 \\
(25.9,30.7)\end{array}$ & $\begin{array}{c}5.9 \\
(5.1,6.7)\end{array}$ & $\begin{array}{c}2.2 \\
(1.3,3.1)\end{array}$ & - & - & - \\
\hline \multirow{2}{*}{$\begin{array}{l}\text { Iraqi (Ali, } \\
\text { 2014) (125) }\end{array}$} & M & $\begin{array}{c}2.2 \\
(2.0,2.5) \\
\end{array}$ & $\begin{array}{c}-7.4 \\
(-8.1,-6.6) \\
\end{array}$ & $\begin{array}{c}34.0 \\
(33.0,34.9) \\
\end{array}$ & $\begin{array}{c}8.5 \\
(7.9,9.0) \\
\end{array}$ & $\begin{array}{c}2.8 \\
(2.4,3.2) \\
\end{array}$ & - & $\begin{array}{c}13.4 \\
(12.6,14.2) \\
\end{array}$ & $\begin{array}{c}9.8 \\
(9.2,10.4) \\
\end{array}$ \\
\hline & $\mathrm{F}$ & $\begin{array}{c}2.7 \\
(2.5,2.9) \\
\end{array}$ & $\begin{array}{c}-8.7 \\
(-9.5,-7.8) \\
\end{array}$ & $\begin{array}{c}34.6 \\
(32.9,36.3) \\
\end{array}$ & $\begin{array}{c}7.6 \\
(6.9,8.4) \\
\end{array}$ & $\begin{array}{c}2.8 \\
(2.5,3.1) \\
\end{array}$ & - & $\begin{array}{c}13.2 \\
(12.5,13.9) \\
\end{array}$ & $\begin{array}{c}8.4 \\
(7.8,9.0) \\
\end{array}$ \\
\hline $\begin{array}{c}\text { Egyptian } \\
\text { (ElAbbasy, } \\
\text { 2019) (124) } \\
\end{array}$ & $\mathrm{F}$ & $\begin{array}{c}0.7 \\
(-1.3,2.7)\end{array}$ & $\begin{array}{c}-5.5 \\
(-8.9,-2.1)\end{array}$ & - & - & - & - & - & - \\
\hline \multirow{2}{*}{\begin{tabular}{|c|} 
Saudi (Al \\
Jundi \& Riba, \\
2014) (121)
\end{tabular}} & M & - & - & - & - & $\begin{array}{c}3.4 \\
(2.9,3.8) \\
\end{array}$ & - & - & - \\
\hline & $\mathrm{F}$ & - & - & - & - & $\begin{array}{c}3.5 \\
(3.1,3.8) \\
\end{array}$ & - & - & - \\
\hline \begin{tabular}{|c|} 
Egyptian \\
(Fouda, Hafez \\
\& Al-Awdi, \\
2017) (123) \\
\end{tabular} & $\begin{array}{l}\mathrm{M} \\
+ \\
\mathrm{F}\end{array}$ & - & - & - & - & - & $\mid \begin{array}{c}123.8 \\
(118.9,128.6)\end{array}$ & - & - \\
\hline \multirow{2}{*}{$\begin{array}{c}\text { Iraqi* } \\
\text { (Mohammed, } \\
\text { Nissan \& } \\
\text { Taha, 2013) } \\
(126) \\
\end{array}$} & M & - & - & - & - & - & $\begin{array}{c}105.1 \\
(104.2,105.9) \\
\end{array}$ & - & - \\
\hline & $\mathrm{F}$ & - & - & - & - & - & $\mid \begin{array}{c}110.6 \\
(109.6,111.6)\end{array}$ & - & - \\
\hline \begin{tabular}{|c|} 
Turkish* \\
(Gulsen et al., \\
2006) (127) \\
\end{tabular} & $\begin{array}{c}\mathrm{M} \\
+ \\
\mathrm{F} \\
\end{array}$ & - & - & - & - & - & $\mid \begin{array}{c}108.5 \\
(105.3,111.7)\end{array}$ & - & - \\
\hline \begin{tabular}{|c|} 
Iranian* \\
(Gholinia, \\
Habibi \& \\
Amrollahi \\
Boyouki, \\
2019) (128) \\
\end{tabular} & $\begin{array}{c}\mathrm{M} \\
+ \\
\mathrm{F}\end{array}$ & - & - & - & - & - & - & - & $\begin{array}{c}9.6 \\
(8.4,10.9)\end{array}$ \\
\hline \multicolumn{2}{|c|}{ Tooth-size ratios } & \multicolumn{8}{|c|}{ Means (95\% CIs for means) } \\
\hline \multicolumn{2}{|c|}{\begin{tabular}{|c|} 
Nationality \& \\
Series / Variables \\
\end{tabular}} & \multicolumn{4}{|c|}{ Anterior ratio } & \multicolumn{4}{|c|}{ Overall ratio } \\
\hline \multirow{2}{*}{\begin{tabular}{|c|} 
Egyptian* \\
(Ali, El- \\
Shorbagy \& \\
Elliathy, 2016) \\
(122) \\
\end{tabular}} & $\mathrm{M}$ & \multicolumn{4}{|c|}{$\begin{array}{c}78.7 \\
(77.7,79.7) \\
\end{array}$} & \multicolumn{4}{|c|}{$\begin{array}{c}92.5 \\
(91.9,93.1) \\
\end{array}$} \\
\hline & $\mathrm{F}$ & \multicolumn{4}{|c|}{$\begin{array}{c}78.4 \\
(77.6,79.1)\end{array}$} & \multicolumn{4}{|c|}{$\begin{array}{c}91.9 \\
(91.2,92.6)\end{array}$} \\
\hline \multirow{2}{*}{$\begin{array}{c}\text { Saudi (Asiry } \\
\text { \& Hashim, } \\
\text { 2012) (129) }\end{array}$} & M & \multicolumn{4}{|c|}{$\begin{array}{c}77.9 \\
(77.1,78.7) \\
\end{array}$} & \multicolumn{4}{|c|}{$\begin{array}{c}92.1 \\
(91.3,92.8) \\
\end{array}$} \\
\hline & $\mathrm{F}$ & \multicolumn{4}{|c|}{$\begin{array}{c}77.4 \\
(76.2,78.6) \\
\end{array}$} & \multicolumn{4}{|c|}{$\begin{array}{c}91.8 \\
(91.0,92.6) \\
\end{array}$} \\
\hline \begin{tabular}{|c|} 
Iranian \\
(Mollabashi et \\
al., 2019) (40) \\
\end{tabular} & $\begin{array}{l}\mathrm{M} \\
+ \\
\mathrm{F}\end{array}$ & \multicolumn{4}{|c|}{$\begin{array}{c}78.5 \\
(77.8,79.3) \\
\end{array}$} & \multicolumn{4}{|c|}{$\begin{array}{c}91.6 \\
(91.0,92.2)\end{array}$} \\
\hline
\end{tabular}

CIs=confidence intervals, $M=$ males, $F=$ females

*Class II malocclusion 


\section{List of abbreviations}

PgDip: Postgraduate Diploma

SBODO: Syrian Board (certificate of speciality) in Orthodontics and Dentofacial Orthopedics

Class II/1: Class II division 1 (orthodontic anomaly by Angle’s classification and skeletal classification)

OSA: Obstructive sleep apnea

2D: Two-dimensional

3D: Three-dimensional

CBCT: Cone-beam computed tomography

CIs: Confidence intervals

S.D: Standard deviation

IQR: Interquartile range

n: Sample size

y: Years

r: Correlation coefficient

mm: Millimeters

ND: Not declared 


\section{Acknowledgements}

The goal of this thesis would not have been realized without the inspiration and support of a number of distinguished scientists and wonderful individuals. My thanks and appreciation to all of them for being part of this journey and making this thesis possible.

I owe my deepest gratitude and appreciation to my supervisor Professor Dr. Melinda Madléna, former head of the Department of Orthodontics and Pediatric Dentistry, for her invaluable contribution to my every success through my PhD years. She convincingly guided and encouraged me to do the right thing, even when the road got tough. This thesis would not have been possible without her extraordinary guidance and advice.

I wish to express my sincere gratitude and appreciation to Professor Dr. Lajos Kemény, head of Clinical Medicine Doctoral School, for his generous help and persistent support. It is whole-heartedly appreciated that his wise advice helped me a lot to succeed and pass through the most challenging times.

I am deeply grateful to Professor Dr. János Minárovits for his consistent support and great help and for giving me an opportunity to work with scientists from other research areas.

I gratefully acknowledge present and former leaders of the Faculty of Dentistry, my coauthors, staff of the Department of Orthodontics and Pediatric Dentistry, staff and the administrative coordinator of Clinical Medicine Doctoral School, staff and administrative coordinators of the PhD student office, staff of the Faculty of Dentistry, and staff of the University of Szeged for their kind assistance.

I am indebted to the Hungarian Government, Tempus Public Foundation, my host University (University of Szeged), and my home University (Damascus University) for giving me the opportunity to study my $\mathrm{PhD}$ in Hungary in the frame of Stipendium Hungaricum scholarship. Finally, I wish to acknowledge the support and great love of my family: my father, my mother, my wife, my brothers, and my stepmother. They kept me going on and this thesis would not have been possible without their input. 


\section{References}

1. Bilgic F, Gelgor IE, Celebi AA. Malocclusion prevalence and orthodontic treatment need in central Anatolian adolescents compared to European and other nations' adolescents. Dent Press J Orthod. 2015;20(6):75-81.

2. Onyeaso CO. Prevalence of malocclusion among adolescents in Ibadan, Nigeria. Am J Orthod Dentofacial Orthop. 2004;126(5):604-7.

3. Borzabadi-Farahani A, Borzabadi-Farahani A, Eslamipour F. Malocclusion and occlusal traits in an urban Iranian population. An epidemiological study of 11-to 14-year-old children. Eur J Orthod. 2009;31(5):477-84.

4. Thilander B, Pena L, Infante C, Parada SS, de Mayorga C. Prevalence of malocclusion and orthodontic treatment need in children and adolescents in Bogota, Colombia. An epidemiological study related to different stages of dental development. Eur J Orthod. 2001;23(2):153-68.

5. Lew KK, Foong WC, Loh E. Malocclusion prevalence in an ethnic Chinese population. Aust Dent J. 1993;38(6):442-9.

6. Foster TD, Walpole Day AJ. A survey of malocclusion and the need for orthodontic treatment in a Shropshire school population. Br J Orthod. 1974;1(3):73-8.

7. Perillo L, Masucci C, Ferro F, Apicella D, Baccetti T. Prevalence of orthodontic treatment need in southern Italian schoolchildren. Eur J Orthod. 2009;32(1):49-53.

8. Albakri FM, Ingle N, Assery MK. Prevalence of Malocclusion among Male School Children in Riyadh City. Open Access Maced J Med Sci. 2018;6(7):1296-9.

9. Tausche $\mathrm{E}$, Luck $\mathrm{O}$, Harzer W. Prevalence of malocclusions in the early mixed dentition and orthodontic treatment need. Eur J Orthod. 2004;26(3):237-44.

10. Silva RG, Kang DS. Prevalence of malocclusion among Latino adolescents. Am J Orthod Dentofacial Orthop. 2001;119(3):313-5.

11. Saleh FK. Prevalence of malocclusion in a sample of Lebanese schoolchildren: an epidemiological study. East Mediterr Health J. 1999;5(2):337-43.

12. Massler M, Frankel JM. Prevalence of malocclusion in children aged 14 to 18 years. Am J Orthod. 1951;37(10):751-68.

13. Shyagali TR, Singh M, Joshi R, Gupta A, Kshirsagar P, Jha R. Prevalence of Angle's malocclusion in sensory-deprived and normal school children of age group of 12-16 years in India: A study conducted in 2016-2018. J Oral Health Oral Epidemiol. 2019;8(2):74-80.

14. Bugaighis I, Karanth D. The prevalence of malocclusion in urban Libyan schoolchildren. J Orthod Sci. 2013;2(1):1-6. 
15. Nadim R, Aslam K, Rizwan S. Frequency of malocclusion among 12-15 years old school children in three sectors of Karachi. Pak Oral Dent J. 2014;34(3):510-4.

16. El-Mangoury NH, Mostafa YA. Epidemiologic panorama of dental occlusion. Angle Orthod. 1990;60(3):207-14.

17. Thilander B, Myrberg N. The prevalence of malocclusion in Swedish schoolchildren. Eur J Oral Sci. 1973;81(1):12-20.

18. Singh VP, Sharma A. Epidemiology of malocclusion and assessment of orthodontic treatment need for nepalese children. Int Sch Res Not. 2014;2014:1-4.

19. de Souza RA, de Araújo Magnani MBB, Nouer DF, Romano FL, Passos MR. Prevalence of malocclusion in a Brazilian schoolchildren population and its relationship with early tooth loss. Braz J Oral Sci. 2016;7(25):1566-70.

20. Gábris K, Márton S, Madléna M. Prevalence of malocclusions in Hungarian adolescents. Eur J Orthod. 2006;28(5):467-70.

21. Alatrach AB, Saleh FK, Osman E. The prevalence of malocclusion and orthodontic treatment need in a sample of Syrian children. Eur Sci J. 2014;10(30):230-47.

22. Riedel RA. The relation of maxillary structures to cranium in malocclusion and in normal occlusion. Angle Orthod. 1952;22(3):142-5.

23. Hitchcock HP. A cephalometric description of Class II, Division 1 malocclusion. Am J Orthod Dentofacial Orthop. 1973;63(4):414-23.

24. Sayın Mö, Türkkahraman H. Cephalometric evaluation of nongrowing females with skeletal and dental Class II, division 1 malocclusion. Angle Orthod. 2005;75(4):656-60.

25. Isik F, Nalbantgil D, Sayinsu K, Arun T. A comparative study of cephalometric and arch width characteristics of Class II division 1 and division 2 malocclusions. Eur J Orthod. 2006;28(2):17983.

26. Freitas MR de, Santos MAC dos, Freitas KMS de, Janson G, Freitas DS de, Henriques JFC. Cephalometric characterization of skeletal Class II, division 1 malocclusion in white Brazilian subjects. J Appl Oral Sci. 2005;13(2):198-203.

27. Altemus LA. Horizontal and vertical dentofacial relationships in normal and Class II division I malocclusion in girls 11-15 years. Angle Orthod. 1955;25(3):120-37.

28. Rothstein T, Yoon-Tarlie C. Dental and facial skeletal characteristics and growth of males and females with Class II, Division 1 malocclusion between the ages of 10 and 14 (revisited)-Part I: Characteristics of size, form, and position. Am J Orthod Dentofacial Orthop. 2000;117(3):32032.

29. Al-Khateeb EA, Al-Khateeb SN. Anteroposterior and vertical components of Class II division 1 and division 2 malocclusion. Angle Orthod. 2009;79(5):859-66. 
30. Lau JWP, Hägg U. Cephalometric morphology of Chinese with Class II Division 1 malocclusion. $\mathrm{Br}$ Dent J. 1999;186(4):188-90.

31. Drelich RC. A Cephalometric Study of Untreated Class II, Division 1 Malocclusion1. Angle Orthod. 1948;18(3):70-5.

32. Mergen DC, Jacobs RM. The size of nasopharynx associated with normal occlusion and Class II malocclusion. Angle Orthod. 1970;40(4):342-6.

33. Silva NN e, Lacerda RHW, Silva AWC, Ramos TB. Assessment of upper airways measurements in patients with mandibular skeletal Class II malocclusion. Dent Press J Orthod. 2015;20(5):86-93.

34. Soni J, Shyagali TR, Bhayya DP, Shah R. Evaluation of Pharyngeal Space in Different Combinations of Class II Skeletal Malocclusion. Acta Inform Medica. 2015;23(5):285-9.

35. Sosa FA, Graber TM, Muller TP. Postpharyngeal lymphoid tissue in Angle Class I and Class II malocclusions. Am J Orthod. 1982;81(4):299-309.

36. Ceylan I, Oktay H. A study on the pharyngeal size in different skeletal patterns. Am J Orthod Dentofacial Orthop. 1995;108(1):69-75.

37. Bollhalder J, Hänggi MP, Schätzle M, Markic G, Roos M, Peltomäki TA. Dentofacial and upper airway characteristics of mild and severe class II division 1 subjects. Eur J Orthod. 2013;35(4):447-53.

38. Fattahi HR, Pakshir HR, Hedayati Z. Comparison of tooth size discrepancies among different malocclusion groups. Eur J Orthod. 2006;28(5):491-5.

39. Wędrychowska-Szulc B, Janiszewska-Olszowska J, Stepień P. Overall and anterior Bolton ratio in Class I, II, and III orthodontic patients. Eur J Orthod. 2010;32(3):313-8.

40. Mollabashi V, Soltani MK, Moslemian N, Akhlaghian M, Akbarzadeh M, Samavat $\mathrm{H}$, et al. Comparison of Bolton ratio in normal occlusion and different malocclusion groups in Iranian population. Int Orthod. 2019;17(1):143-50.

41. Crosby DR, Alexander CG. The occurrence of tooth size discrepancies among different malocclusion groups. Am J Orthod Dentofacial Orthop. 1989;95(6):457-61.

42. Oktay H, Ulukaya E. Intermaxillary tooth size discrepancies among different malocclusion groups. Eur J Orthod. 2010;32(3):307-12.

43. Machado V, Botelho J, Pereira D, Vasques M, Fernandes-Retto $P$, Proença L, et al. Bolton ratios in Portuguese subjects among different malocclusion groups. J Clin Exp Dent. 2018;10(9):e8648.

44. Phelan T, Buschang PH, Behrents RG, Wintergerst AM, Ceen RF, Hernandez A. Variation in Class II malocclusion: comparison of Mexican mestizos and American whites. Am J Orthod Dentofacial Orthop. 2004;125(4):418-25. 
45. Ishii N, Deguchi T, Hunt NP. Morphological differences in the craniofacial structure between Japanese and Caucasian girls with Class II Division 1 malocclusions. Eur J Orthod. 2002;24(1):617.

46. Pancherz H, Zieber K, Hoyer B. Cephalometric characteristics of Class II division 1 and Class II division 2 malocclusions: a comparative study in children. Angle Orthod. 1997;67(2):111-20.

47. Henry RG. A classification of Class II, division I malocclusion. Angle Orthod. 1957;27(2):83-92.

48. Craig CE. The skeletal patterns characteristic of Class I and Class II, Division I malocclusions in norma lateralis. Angle Orthod. 1951;21(1):44-56.

49. Elsasser WA, Wylie WL. The craniofacial morphology of mandibular retrusion. Am J Phys Anthropol. 1948;6(4):461-74.

50. Rana N, Qu YY, Wei Y, Liu L. Comparison of Cephalometric Hard and Soft Tissues of Adolescents with Angle Class II Division 1 Malocclusion between Northern Chinese Population and Northern Indian Population. Chin J Dent Res Off J Sci Sect Chin Stomatol Assoc CSA. 2017;20(1):33-42.

51. Demir A, Uysal T, Basciftci FA. Determination of Skeletal and Dental Characteristics of Class II Malocclusion. Turk J Orthod. 2005;18(3):205-14.

52. Bishara SE, Jakobsen JR, Vorhies B, Bayati P. Changes in dentofacial structures in untreated Class II division 1 and normal subjects: a longitudinal study. Angle Orthod. 1997;67(1):55-66.

53. Ishii N, Deguchi T, Hunt NP. Craniofacial morphology of Japanese girls with Class II division 1 malocclusion. J Orthod. 2001;28(3):211-6.

54. Vela E, Taylor RW, Campbell PM, Buschang PH. Differences in craniofacial and dental characteristics of adolescent Mexican Americans and European Americans. Am J Orthod Dentofacial Orthop. 2011;140(6):839-47.

55. Lavelle CLB. Maxillary and mandibular tooth size in different racial groups and in different occlusal categories. Am J Orthod. 1972;61(1):29-37.

56. Smith SS, Buschang PH, Watanabe E. Interarch tooth size relationships of 3 populations:"Does Bolton's analysis apply?" Am J Orthod Dentofacial Orthop. 2000;117(2):169-74.

57. GU M, McGrath CP, Wong RW, Hägg U, Yang Y. Cephalometric norms for the upper airway of 12-year-old Chinese children. Head Face Med. 2014;10(1):38.

58. Liu Y, Lowe AA, Zeng X, Fu M, Fleetham JA. Cephalometric comparisons between Chinese and Caucasian patients with obstructive sleep apnea. Am J Orthod Dentofacial Orthop. 2000;117(4):479-85.

59. Lee RWW, Vasudavan S, Hui DS, Prvan T, Petocz P, Darendeliler MA, et al. Differences in Craniofacial Structures and Obesity in Caucasian and Chinese Patients with Obstructive Sleep Apnea. Sleep. 2010;33(8):1075-80. 
60. Sutherland K, Lee RWW, Cistulli PA. Obesity and craniofacial structure as risk factors for obstructive sleep apnoea: Impact of ethnicity. Respirology. 2012;17(2):213-22.

61. Ioi H, Nakata S, Nakasima A, Counts AL. Comparison of cephalometric norms between Japanese and Caucasian adults in antero-posterior and vertical dimension. Eur J Orthod. 2007;29(5):4939.

62. Hwang H-S, Kim W-S, McNamara Jr JA. Ethnic differences in the soft tissue profile of Korean and European-American adults with normal occlusions and well-balanced faces. Angle Orthod. 2002;72(1):72-80.

63. Abbassy MA, Abushal A. Differences in dentofacial characteristics of Class I malocclusion between Saudi and Japanese adult females. J Orthod Sci. 2015;4(3):86-91.

64. Afifi A, Taha M, Nassar E. Saudian norms of Mc Namara's cephalometric analysis. Egypt Orthod J. 2008;33:41-9.

65. Kumar TP, Chitra P. Determination of Bolton Norms for Indian Population Sample. Orthod J Nepal. 2017;7(1):33-6.

66. Al Taki A, Abuhijleh E, Haider K. Dentofacial Cephalometric Values for Emirati Adults with Normal Occlusion and Well-Balanced Faces. Smile Dent J. 2010;5(4):6-10.

67. Abbassy MA, Horiuchi M, Harouny NE, Kanno Z, Ono T. Comparative cephalometric study of Class I malocclusion in Egyptian and Japanese adult females. Orthod Waves. 2012;71(2):59-65.

68. Trivedi K, Singh S, Shivamurthy DM, Doshi J, Shyagali T, Patel B. Analysis of cephalometrics for orthognathic surgery: Determination of norms applicable to Rajasthani population. Natl J Maxillofac Surg. 2010;1(2):102-7.

69. Uysal T, Yagci A, Aldrees AM, Ekizer E. Ethnic differences in dentofacial relationships of Turkish and Saudi young adults with normal occlusions and well-balanced faces. Saudi Dent J. 2011;23(4):183-90.

70. Eurostat Database [Internet]. 2019 [cited 2019 Mar 7]. Available from: https://ec.europa.eu/eurostat/data/database

71. United Nations Population Division. International migrant stock 2019, graph: Twenty countries or areas of origin with the largest diaspora populations (millions) [Internet]. 2019 [cited 2019 Sep 27]. Available from: https://www.un.org/en/development/desa/population/migration/data/estimates2/estimatesg raphs.asp?3g3

72. DESTATIS. Geburtenanstieg setzte sich 2016 fort [Internet]. Statistisches Bundesamt. 2018 [cited 2019 Sep 11]. Available from: https://www.destatis.de/DE/Presse/Pressemitteilungen/2018/03/PD18_115_122.html

73. Al Sabbagh R. Syrian norms of McNamara cephalometric analysis. Int Arab J Dent. 2014;5(3):95101. 
74. Nourallah AW, Splieth CH, Schwahn C, Khurdaji M. Standardizing interarch tooth-size harmony in a Syrian population. Angle Orthod. 2005;75(6):996-9.

75. Haskell BS, Segal ES. Ethnic and ethical challenges in treatment planning: dealing with diversity in the 21st century. Angle Orthod. 2014;84(2):380-2.

76. Abuhijleh E, Al Taki A, Rahhal A. The Cephalometric Norms of Various Ethnicities and their Significance. Acta Sci Dent Sci. 2019;3(8):21-2.

77. Csiki I, Jianu R, Stratul S-I, Vegh A. Are the Ricketts Norms Adequate for Middle European Adolescents? Timisoara Med J. 2008;58(1-2):74-7.

78. Gurdán Z, Marada G, Herényi G, Nagy Á. Examining Tooth-size Discrepancies in Regard to Treatment, Treatment Planning and Completion. Open J Dent Oral Med. 2014;2(3):43-6.

79. Kandasamy S, Goonewardene M. Class II malocclusion and sleep-disordered breathing. Semin Orthod. 2014;20(4):316-23.

80. Zhong Z, Tang Z, Gao X, Zeng X-L. A Comparison Study of Upper Airway among Different Skeletal Craniofacial Patterns in Nonsnoring Chinese Children. Angle Orthod. 2009;80(2):267-74.

81. Bollhalder J, Hänggi MP, Schätzle M, Markic G, Roos M, Peltomäki TA. Dentofacial and upper airway characteristics of mild and severe class II division 1 subjects. Eur J Orthod. 2013;35(4):447-53.

82. Flores-Mir C, Korayem M, Heo G, Witmans M, Major MP, Major PW. Craniofacial morphological characteristics in children with obstructive sleep apnea syndrome: A systematic review and meta-analysis. J Am Dent Assoc. 2013;144(3):269-77.

83. Battagel JM, Johal A, Kotecha B. A cephalometric comparison of subjects with snoring and obstructive sleep apnoea. Eur J Orthod. 2000;22(4):353-65.

84. Lowe AA, Fleetham JA, Adachi S, Ryan CF. Cephalometric and computed tomographic predictors of obstructive sleep apnea severity. Am J Orthod Dentofacial Orthop. 1995;107(6):589-95.

85. Deng J, Gao X. A case-control study of craniofacial features of children with obstructed sleep apnea. Sleep Breath. 2012;16(4):1219-27.

86. Ardehali MM, Zarch VV, Joibari M-E, Kouhi A. Cephalometric Assessment of Upper Airway Effects on Craniofacial Morphology. J Craniofac Surg. 2016;27(2):361-4.

87. Cozza P, Polimeni A, Ballanti F. A modified monobloc for the treatment of obstructive sleep apnoea in paediatric patients. Eur J Orthod. 2004;26(5):523-30.

88. Galeotti A, Festa P, Viarani V, Pavone M, Sitzia E, Piga S, et al. Correlation between cephalometric variables and obstructive sleep apnoea severity in children. Eur J Paediatr Dent. 2019;20(1):43-7.

89. Galeotti A, Festa P, Viarani V, D’Antò V, Sitzia E, Piga S, et al. Prevalence of malocclusion in children with obstructive sleep apnoea. Orthod Craniofac Res. 2018;21(4):242-7. 
90. Kawashima S, Niikuni N, Chia-hung L, Takahasi Y, Kohno M, Nakajima I, et al. Cephalometric Comparisons of Craniofacial and Upper Airway Structures in Young Children with Obstructive Sleep Apnea Syndrome. Ear Nose Throat J. 2000;79(7):499-506.

91. Li KK, Powell NB, Kushida C, Riley RW, Adornato B, Guilleminault C. A Comparison of Asian and White Patients With Obstructive Sleep Apnea Syndrome. The Laryngoscope. 1999;109(12):1937-40.

92. Coltman R, Taylor D, Whyte K, Harkness M. Craniofacial Form and Obstructive Sleep Apnea in Polynesian and Caucasian Men. Sleep. 2000;23(7):1-10.

93. Will MJ, Ester MS, Ramirez SG, Tiner BD, McAnear JT, Epstein L. Comparison of Cephalometric Analysis With Ethnicity in Obstructive Sleep Apnea Syndrome. Sleep. 1995;18(10):873-5.

94. Cakirer B, Hans MG, Graham G, Aylor J, Tishler PV, Redline S. The Relationship Between Craniofacial Morphology and Obstructive Sleep Apnea in Whites and in African-Americans. Am J Respir Crit Care Med. 2001;163(4):947-50.

95. Faul F, Erdfelder E, Lang A-G, Buchner A. G*Power 3: A flexible statistical power analysis program for the social, behavioral, and biomedical sciences. Behav Res Methods. 2007;39(2):175-91.

96. Faul F, Erdfelder E, Buchner A, Lang A-G. Statistical power analyses using G*Power 3.1: Tests for correlation and regression analyses. Behav Res Methods. 2009;41(4):1149-60.

97. Hulley SB, Cummings SR, Browner WS, Grady DG, Newman TB. Designing clinical research. Wolters Kluwer Health, Philadelphia; 2013.

98. Oh E, Ahn S-J, Sonnesen L. Ethnic differences in craniofacial and upper spine morphology in children with skeletal Class II malocclusion. Angle Orthod. 2018;88(3):283-91.

99. Lee JJ, Ramirez SG, Will MJ. Gender and Racial Variations in Cephalometric Analysis. Otolaryngol Neck Surg. 1997;117(4):326-9.

100. Muto T, Yamazaki A, Takeda S. A cephalometric evaluation of the pharyngeal airway space in patients with mandibular retrognathia and prognathia, and normal subjects. Int J Oral Maxillofac Surg. 2008;37(3):228-31.

101. Baccetti T, Franchi L, McNamara JA. An Improved Version of the Cervical Vertebral Maturation (CVM) Method for the Assessment of Mandibular Growth. Angle Orthod. 2002;72(4):316-23.

102. Hellsing E. Changes in the pharyngeal airway in relation to extension of the head. Eur J Orthod. 1989;11(4):359-65.

103. Solow B, Tallgren A. Head posture and craniofacial morphology. Am J Phys Anthropol. 1976;44(3):417-35.

104. Muto T, Takeda S, Kanazawa M, Yamazaki A, Fujiwara Y, Mizoguchi I. The effect of head posture on the pharyngeal airway space (PAS). Int J Oral Maxillofac Surg. 2002;31(6):579-83. 
105. Anegawa E, Tsuyama $\mathrm{H}$, Kusukawa J. Lateral cephalometric analysis of the pharyngeal airway space affected by head posture. Int J Oral Maxillofac Surg. 2008;37(9):805-9.

106. Muto T, Yamazaki A, Takeda S, Kawakami J, Tsuji Y, Shibata T, et al. Relationship between the pharyngeal airway space and craniofacial morphology, taking into account head posture. Int J Oral Maxillofac Surg. 2006;35(2):132-6.

107. McNamara Jr JA. A method of cephalometric evaluation. Am J Orthod. 1984;86(6):449-69.

108. McNamara Jr JA, Brust EW, Riolo ML. Soft tissue evaluation of individuals with an ideal occlusion and a well-balanced face. In: McNamara JA Jr, ed. Esthetics and the Treatment of Facial Form. Ann Arbor, Mich: Center for Human Growth and Development, The University of Michigan; 1992. p. 115-46.

109. Jarabak JR, Fizzell JA. Technique and treatment with light-wire edgewise appliances, ed. 2 . The C.V. Mosby Company, St. Louis; 1972.

110. Steiner CC. Cephalometrics for you and me. Am J Orthod. 1953;39(10):729-55.

111. Bhatia SN, Leighton BC. Manual of facial growth: a computer analysis of longitudinal cephalometric growth data. Oxford University Press, Inc., Oxford; 1993.

112. Hasund A. Klinische Kephalometrie fiir die Bergen-Technik. Selbstverlag (Self-publishing), Bergen; 1973.

113. Clark WJ. Die funktionelle Therapie mit dem Twinblock. Hüthig, Heidelberg; 1998.

114. Rakosi T. Atlas und Anleitung zur praktischen Fernröntgenanalyse. Hanser, München; 1988.

115. Seipel CM. Variation in tooth positon, A metric study of variation and adaptation in the deciduous and permanent dentitions. Sven Tandlakare Tidskr. 1946;39:26-9.

116. Moorrees CFA, Reed RB. Correlations among crown diameters of human teeth. Arch Oral Biol. 1964;9(6):685-97.

117. Bolton WA. Disharmony in tooth size and its relation to the analysis and treatment of malocclusion. Angle Orthod. 1958;28(3):113-30.

118. Dahlberg G. Statistical methods for medical and biological students. George Alien and Unwin, Ltd., London; 1940.

119. Al Ayoubi A, Dalla Torre D, Madléna M. Craniofacial characteristics of Syrian adolescents with Class II division 1 malocclusion: a retrospective study. PeerJ. 2020;8:e9545.

120. Al Ayoubi A, Khandan Dezfully A, Madléna M. Dentoskeletal and tooth-size differences between Syrian and Hungarian adolescents with Class II division 1 malocclusion: a retrospective study. BMC Res Notes. 2020;13(1):270.

121. Al Jundi A, Riba H. Characteristics of Craniofacial Complex for Class II Division 1 Malocclusion in Saudi subjects with permanent dentition. Glob J Med Res. 2014;14(6). 
122. Ali RSE-D, El-Shorbagy EM, Elliathy MM. Relationship of Interarch Tooth-size Discrepancy to Occlusion. Egypt Dent J. 2016;62(3):2979-88.

123. Fouda M, Hafez A, Al-Awdi M. Soft tissue profile changes in growing patients having Class II Division 1 Malocclusion treated by Modified Activator with lip bumper. Indian J Orthod Dentofac Res. 2017;3(2):103-6.

124. ElAbbasy DO. Evaluation of the therapeutic effects of Sabbagh Universal Spring compared to Class II elastics in the treatment of Class II division 1 patients. Egypt Dent J. 2019;65(4):3053-67.

125. Ali Al. Mcnamara's cephalometric analysis for Iraqi population in Mosul city. Int J Enhanc Res Cience Technol Eng. 2014;3(4):287-99.

126. Mohammed SA, Nissan LMK, Taha SS. Soft Tissue Facial Profile Analysis of Adult Iraqis with Different Classes of Malocclusion. J Baghdad Coll Dent. 2013;325(2209):1-9.

127. Gulsen A, Okay C, Aslan BI, Uner O, Yavuzer R. The relationship between craniofacial structures and the nose in Anatolian Turkish adults: A cephalometric evaluation. Am J Orthod Dentofacial Orthop. 2006;130(2):131.e15-132.e25.

128. Gholinia F, Habibi L, Amrollahi Boyouki M. Cephalometric Evaluation of the Upper Airway in Different Skeletal Classifications of Jaws. J Craniofac Surg. 2019;30(5):e469.

129. Asiry M, Hashim H. Tooth size ratios in Saudi subjects with Class II, Division 1 malocclusion. J Int Oral Health. 2012;4(2):29-34.

130. Mortazavi M, Salehi P, Ansari G. Mandibular Size and Position in a Group of 13-15 Years Old Iranian Children with Class II Division 1 Malocclusion. Res J Biol Sci. 2009;4(4):531-6.

131. Solow $\mathrm{B}$. The dentoalveolar compensatory mechanism: background and clinical implications. $\mathrm{Br}$ J Orthod. 1980;7(3):145-61.

132. Al-Saleem NR. Comparison of Lip Analyses in Skeletal Class I Normal Occlusion and Class II Division 1 Malocclusion. Al-Rafidain Dent J. 2013;13(2):192-201.

133. Hwang H-S, Kim W-S, McNamara JA. A comparative study of two methods of quantifying the soft tissue profile. Angle Orthod. 2000;70(3):200-7.

134. Fitzgerald JP, Nanda RS, Currier GF. An evaluation of the nasolabial angle and the relative inclinations of the nose and upper lip. Am J Orthod Dentofacial Orthop. 1992;102(4):328-34.

135. Elwareth Abd Elrazik Yousif AA. Evaluation of upper and lower pharyngeal airway in hypo and hyper divergent Class I, II and III malocclusions in a group of Egyptian patients. Tanta Dent J. 2015;12(4):265-76.

136. Abu Allhaija ES, Al-Khateeb SN. Uvulo-Glosso-Pharyngeal Dimensions in Different Anteroposterior Skeletal Patterns. Angle Orthod. 2005;75(6):1012-8.

137. Uslu-Akcam O. Pharyngeal airway dimensions in skeletal class II: A cephalometric growth study. Imaging Sci Dent. 2017;47(1):1-9. 
138. Ferguson KA, Ono T, Lowe AA, Ryan CF, Fleetham JA. The relationship between obesity and craniofacial structure in obstructive sleep apnea. Chest. 1995;108(2):375-81.

139. Shamaa MS. Comparison between Class II Division 1 and 2 Malocclusions and Normal Occlusion regarding Tooth Size Discrepancy and Arch Dimensions using Digital Models. Egypt Dent J. 2019;65(2):899-908.

140. Uysal T, Sari Z, Basciftci FA, Memili B. Intermaxillary tooth size discrepancy and malocclusion: is there a relation? Angle Orthod. 2005;75(2):208-13.

141. Othman SA, Harradine NWT. Tooth-size discrepancy and Bolton's ratios: a literature review. J Orthod. 2006;33(1):45-51.

142. de Freitas MR, Alcazar NMPV, Janson G, de Freitas KMS, Henriques JFC. Upper and lower pharyngeal airways in subjects with Class I and Class II malocclusions and different growth patterns. Am J Orthod Dentofacial Orthop. 2006;130(6):742-5.

143. Isono S, Remmers JE, Tanaka A, Sho Y, Sato J, Nishino T. Anatomy of pharynx in patients with obstructive sleep apnea and in normal subjects. J Appl Physiol. 1997;82(4):1319-26.

144. Johal A, Patel SI, Battagel JM. The relationship between craniofacial anatomy and obstructive sleep apnoea: a case-controlled study. J Sleep Res. 2007;16(3):319-26.

145. Riha RL, Brander P, Vennelle M, Douglas NJ. A Cephalometric Comparison of Patients With the Sleep Apnea/Hypopnea Syndrome and Their Siblings. Sleep. 2005;28(3):315-20.

146. Maspero C, Giannini L, Galbiati G, Kairyte L, Farronato G. Upper airway obstuction in class II patients. Effects of Andresen activator on the anatomy of pharingeal airway passage. Cone beam evalution. Stomatologija. 2015;17(4):124-30.

147. Cossellu G, Biagi R, Sarcina M, Mortellaro C, Farronato G. Three-Dimensional Evaluation of Upper Airway in Patients With Obstructive Sleep Apnea Syndrome During Oral Appliance Therapy. J Craniofac Surg. 2015;26(3):745-8.

148. Galeotti A, Festa P, Pavone M, De Vincentiis GC. Effects of simultaneous palatal expansion and mandibular advancement in a child suffering from OSA. Acta Otorhinolaryngol Ital. 2016;36(4):328-32.

149. Mehra P, Wolford LM. Surgical Management of Obstructive Sleep Apnea. Bayl Univ Med Cent Proc. 2000;13(4):338-42.

150. Lam B, Ip MSM, Tench E, Ryan CF. Craniofacial profile in Asian and white subjects with obstructive sleep apnoea. Thorax. 2005;60(6):504-10.

151. Ferguson KA, Ono T, Lowe AA, Ryan CF, Fleetham JA. The Relationship Between Obesity and Craniofacial Structure in Obstructive Sleep Apnea. Chest. 1995;108(2):375-81.

152. Guilleminault C, Riley R, Powell N. Obstructive Sleep Apnea and Abnormal Cephalometric Measurements: Implications for Treatment. Chest. 1984;86(5):793-4. 
153. Neelapu BC, Kharbanda OP, Sardana HK, Balachandran R, Sardana V, Kapoor P, et al. Craniofacial and upper airway morphology in adult obstructive sleep apnea patients: A systematic review and meta-analysis of cephalometric studies. Sleep Med Rev. 2017;31:79-90.

154. Gholinia F, Habibi L, Amrollahi Boyouki M. Cephalometric Evaluation of the Upper Airway in Different Skeletal Classifications of Jaws. J Craniofac Surg. 2019;30(5):e469-74.

155. Bayat M, Shariati M, Rakhshan V, Abbasi M, Fateh A, Sobouti F, et al. Cephalometric risk factors of obstructive sleep apnea. Cranio J Craniomandib Pract. 2017;35(5):321-6.

156. Sprenger R, Martins LAC, dos Santos JCB, de Menezes CC, Venezian GC, Degan VV. A retrospective cephalometric study on upper airway spaces in different facial types. Prog Orthod. 2017;18(1):25.

157. Bilici S, Yigit O, Celebi OO, Yasak AG, Yardimci AH. Relations Between Hyoid-Related Cephalometric Measurements and Severity of Obstructive Sleep Apnea. J Craniofac Surg. 2018;29(5):1276-81.

158. Malkoc S, Usumez S, Nur M, Donaghy CE. Reproducibility of airway dimensions and tongue and hyoid positions on lateral cephalograms. Am J Orthod Dentofacial Orthop. 2005;128(4):513-6.

159. Vizzotto MB, Liedke GS, Delamare EL, Silveira HD, Dutra V, Silveira HE. A comparative study of lateral cephalograms and cone-beam computed tomographic images in upper airway assessment. Eur J Orthod. 2012;34(3):390-3.

160. Bronoosh P, Khojastepour L. Analysis of Pharyngeal Airway Using Lateral Cephalogram vs CBCT Images: A Cross-sectional Retrospective Study. Open Dent J. 2015;9:263-6.

161. Yeh J-K, Chen C-H. Estimated radiation risk of cancer from dental cone-beam computed tomography imaging in orthodontics patients. BMC Oral Health. 2018;18(1):131.

162. Hujoel P, Hollender L, Bollen A-M, Young JD, McGee M, Grosso A. Head-and-neck organ doses from an episode of orthodontic care. Am J Orthod Dentofacial Orthop. 2008;133(2):210-7.

163. Silva MAG, Wolf U, Heinicke F, Bumann A, Visser H, Hirsch E. Cone-beam computed tomography for routine orthodontic treatment planning: A radiation dose evaluation. Am J Orthod Dentofacial Orthop. 2008;133(5):640.e1-640.e5.

164. Wrzesień M, Olszewski J. Absorbed doses for patients undergoing panoramic radiography, cephalometric radiography and CBCT. Int J Occup Med Environ Health. 2017;30(5):705-13.

165. Garib DG, Calil LR, Leal CR, Janson G, Garib DG, Calil LR, et al. Is there a consensus for CBCT use in Orthodontics? Dent Press J Orthod. 2014;19(5):136-49.

166. Hodges RJ, Atchison KA, White SC. Impact of cone-beam computed tomography on orthodontic diagnosis and treatment planning. Am J Orthod Dentofacial Orthop. 2013;143(5):665-74.

167. De Grauwe A, Ayaz I, Shujaat S, Dimitrov S, Gbadegbegnon L, Vande Vannet B, et al. CBCT in orthodontics: a systematic review on justification of $C B C T$ in a paediatric population prior to orthodontic treatment. Eur J Orthod. 2019;41(4):381-9. 
168. Oenning AC, Jacobs R, Pauwels R, Stratis A, Hedesiu M, Salmon B, et al. Cone-beam CT in paediatric dentistry: DIMITRA project position statement. Pediatr Radiol. 2018;48(3):308-16.

169. Radiation Protection No. 172: Cone Beam CT for dental and maxillofacial radiology (evidencebased guidelines) [Internet]. Luxembourg: European Commission; 2012 [cited 2020 Nov 20] p. 154. (Radiation Protection). Report No.: 172. Available from:

https://ec.europa.eu/energy/sites/ener/files/documents/172.pdf

170. Halazonetis DJ. Cone-beam computed tomography is not the imaging technique of choice for comprehensive orthodontic assessment. Am J Orthod Dentofacial Orthop. 2012;141(4):411. 


\section{Appendix}

Copies of the publications providing the basis of the thesis. 
I 


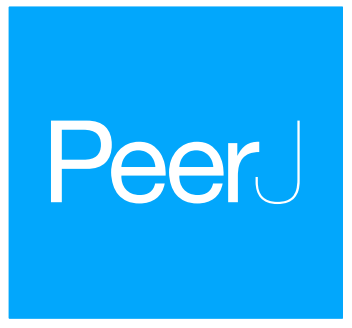

Submitted 22 January 2020

Accepted 24 June 2020

Published 15 July 2020

Corresponding authors

Alaa Al Ayoubi,

alaa.alayoubi@outlook.com

Melinda Madléna,

madlenamelinda784@gmail.com

Academic editor

Maha El Tantawi

Additional Information and

Declarations can be found on page 13

DOI 10.7717/peerj.9545

(c) Copyright

2020 Al Ayoubi et al.

Distributed under

Creative Commons CC-BY 4.0

\section{Craniofacial characteristics of Syrian adolescents with Class II division 1 malocclusion: a retrospective study}

\author{
Alaa Al Ayoubi ${ }^{1}$, Daniel Dalla Torre ${ }^{2}$ and Melinda Madléna ${ }^{1}$ \\ ${ }^{1}$ Department of Orthodontics and Pediatric Dentistry, Faculty of Dentistry, University of Szeged, \\ Szeged, Hungary \\ ${ }^{2}$ University Clinic of Craniomaxillofacial Surgery, Medical University Innsbruck, Innsbruck, \\ Austria
}

\section{ABSTRACT}

Background: Malocclusion characteristics vary across different ethnic groups and populations. Limited data are available regarding the characteristics of Syrian adolescents with Class II division 1 (Class II-1) malocclusion, and the recent inflow of Syrian refugees and immigrants into Europe and many areas worldwide demonstrate the need for updated studies to discover the craniofacial characteristics of these new immigrants.

Objectives: The present compound cephalometric and tooth-size study sought to assess the dentofacial morphology, upper-airway dimensions, and tooth-size characteristics of Syrian adolescents with Class II-1 malocclusion and compare the results with established Syrian population norms.

Materials and Methods: The study sample consisted of 43 Syrian patients including 24 females and 19 males with Class II-1 malocclusion (age: $14.3( \pm 1.5)$ years, mean $( \pm \mathrm{SD})$ ). Cephalometric radiographs and orthodontic casts were analyzed using special orthodontic software (OnyxCeph $3^{\mathrm{TM}}$ ) and a universal digital caliper, respectively. Statistics were calculated using the SPSS software.

Results: In Syrian adolescents with Class II-1 malocclusion, the position of the mandible relative to the nasion perpendicular (mean (95\% confidence interval)) was $-11.01(-12.45,-9.57) \mathrm{mm}$. Facial axis angle showed a negative value: $-6.25(-7.65,-4.85)$ degrees. An obtuse nasolabial angle was observed: 104.05 $(101.77,106.33)$ degrees. The average width of the upper pharynx was 11.50 $(10.53,12.47) \mathrm{mm}$; however, there was no prevalence of an upper-pharyngeal width of $5 \mathrm{~mm}$ or less. The average value of the anterior tooth-size ratio was 80.69 $(79.85,81.53)$ percent. In total, $39.5 \%$ of the investigated subjects had anterior ratios outside two standard deviations from Bolton's norm, while $25.6 \%$ of the investigated subjects had anterior ratios outside two standard deviations from Syrian population norm.

Conclusions: In this study, the inter-maxillary discrepancy of Class II-1 Syrian adolescents was a consequence of their hyperdivergent facial pattern. The observed small pharyngeal widths were not clinically significant, while the anterior tooth-size discrepancy might be clinically relevant. 
Subjects Anatomy and Physiology, Dentistry, Evidence Based Medicine, Radiology and Medical Imaging

Keywords Dentofacial morphology, Upper airway, Tooth size, Class II division 1 malocclusion, Syrian adolescents

\section{INTRODUCTION}

In orthodontics, it is essential to understand the complex relationship between skeletal, dental and facial aberrations in each malocclusion to achieve an accurate diagnosis followed by an optimal treatment plan. Class II division 1 (Class II-1) malocclusion has been suggested as the most frequent pathology that orthodontists may encounter in their practice. According to epidemiologic studies conducted among different populations, the prevalence of this malocclusion ranges from 12 to $40 \%$ worldwide (Table S1) (Massler \& Frankel, 1951; Thilander \& Myrberg, 1973; Foster \& Walpole Day, 1974; El-Mangoury \& Mostafa, 1990; Lew, Foong \& Loh, 1993; Saleh, 1999; Silva \& Kang, 2001; Thilander et al., 2001; Onyeaso, 2004; Tausche, Luck \& Harzer, 2004; Gábris, Márton \& Madléna, 2006; Borzabadi-Farahani, Borzabadi-Farahani \& Eslamipour, 2009; Perillo et al., 2009; Bugaighis \& Karanth, 2013; Alatrach, Saleh \& Osman, 2014; Nadim, Aslam \& Rizwan, 2014; Singh \& Sharma, 2014; Bilgic, Gelgor \& Celebi, 2015; De Souza et al., 2016; Albakri, Ingle \& Assery, 2018; Shyagali et al., 2019).

Numerous studies have investigated the cephalometric and tooth-size characteristics of patients with Class II-1 malocclusion using various measurements either on cephalometric radiographs or orthodontic casts. However, the significance of these studies is limited by multiple factors, including the conflicting results; some cephalometric studies have reported that a retrognathic mandible is the key factor contributing to Class II-1 malocclusion with a normally positioned maxilla (Riedel, 1952; Hitchcock, 1973; Freitas et al., 2005; Sayın \& Türkkahraman, 2005; Isik et al., 2006). In contrast, other studies have indicated that maxillary protrusion is the most common feature of Class II-1 malocclusion with a neutral mandibular position (Altemus, 1955; Rothstein \& Yoon-Tarlie, 2000). Finally, some researchers have described the malpositioning of both the maxilla and mandible in this condition (Drelich, 1948; Lau \& Hägg, 1999; Al-Khateeb \& Al-Khateeb, 2009). Likewise, inconsistent results have been reported regarding the relationship between Class II-1 malocclusion and upper-airway dimensions, where some investigators suggested Class II-1 malocclusion may have an influence on the upper-airway dimensions (Mergen \& Jacobs, 1970; Silva et al., 2015; Soni et al., 2015) while other authors did not find a significant correlation between the two (Sosa, Graber \& Muller, 1982; Ceylan \& Oktay, 1995; Bollhalder et al., 2013). Further, a number of tooth-size studies have investigated Class II-1 malocclusion; their results were also contradictory, with some reporting significant differences in tooth-size ratios between Class II-1 malocclusion and Class I malocclusion or normal occlusion (Fattahi, Pakshir \& Hedayati, 2006; Wędrychowska-Szulc, Janiszewska-Olszowska \& Stepień, 2010; Mollabashi et al., 2019) and others indicating no significant differences in this regard (Crosby \& Alexander, 1989; Oktay \& Ulukaya, 2010; Machado et al., 2018). 
It is also important to consider that most of these previous studies were performed on radiographs or casts of Caucasians or without mention of the ethnicity of the investigated subjects, ignoring the fact that ethnicity is an important etiologic factor in Class II malocclusion (Lau \& Hägg, 1999; Ishii, Deguchi \& Hunt, 2002). Because of recent wars and conflicts, such as the Syrian conflict, ethnic diversity is increasing worldwide. During the last few years, Syrian refugees and immigrants have occupied the foreground of migration statistics, particularly in Europe (Eurostat Database, 2019). Data show that the population of Syrian immigrants has reached 8.2 million in 2019 and is considered to be among the fastest-growing populations of ethnic minorities (DESTATIS, 2018; United Nations Population Division, 2019). This inflow of Syrian refugees and immigrants into Europe and in many areas worldwide demonstrate the need for updated studies to discover the craniofacial characteristics of these new immigrants. Former studies on the Syrian population aimed to establish cephalometric and tooth-size norms (Nourallah et al., 2005; Al Sabbagh, 2014). However, limited data are available on the characteristics of Syrian adolescents with Class II-1 malocclusion.

The objective of this study was to elucidate the cephalometric and tooth-size characteristics of Syrian adolescents with Class II-1 malocclusion and compare the acquired data with those of Syrian population norms.

\section{MATERIALS AND METHODS}

\section{Subjects}

Ethical approval for the present retrospective study was obtained from the Human Investigation Review Board at the University of Szeged (151/2018-SZTE). Written informed consent to participate in this study was provided by the participants' guardians/ parents.

According to previous dentofacial, upper-airway, and tooth-size studies, effect sizes were estimated from the Pog-Np distance 7.8 ( \pm 8.1$) \mathrm{mm}$ (Sayın \& Türkkahraman, 2005), the upper-pharyngeal width $3.1( \pm 2.6) \mathrm{mm}$ (Mergen \& Jacobs, 1970), and the upper first molar's width $0.2( \pm 0.2) \mathrm{mm}$ (Lavelle, 1972). On the basis of a significance level of alpha of 0.05 (two-sided) with a power of $80 \%$, the sample size was calculated to detect the standardized effect sizes of $0.96(7.8 / 8.1 \mathrm{~mm}), 1.19(3.1 / 2.6 \mathrm{~mm})$ and $1(0.2 / 0.2 \mathrm{~mm})$ for dentofacial, upper-airway and tooth-size comparisons, respectively. Sample size calculations when considering these three types of comparisons showed that 17 patients of each gender were necessary for inclusion in the present study (Hulley et al., 2013). As a consequence, cephalometric radiographs and orthodontic casts of 43 untreated patients with skeletal and dental Class II-1 malocclusion (24 females and 19 males, age: $14.3( \pm 1.5)$ years, mean ( \pm standard deviation)) were selected from a private orthodontic practice in Damascus, Syria, based on the following inclusion criteria:

- Adolescents of Syrian origin aged between 12 and 17 years

- Overjet of more than $4 \mathrm{~mm}$ with an absence of retroclination of the upper incisors (1U/NA angle $\geq 22$ degrees)

- Permanent dentition with bilateral distal occlusion (half-unit or greater) 
- ANB angle of more than 4 degrees with a convex facial profile

- Absence of extractions or interproximal caries/restorations or any other condition that affects the dental mesiodistal distance

Patients with craniofacial syndromes or a history of trauma as well as previous orthodontic treatment were excluded from this study. Additionally, we excluded patients with cephalograms in which a swallowing action or obvious hyperplasia of tonsils and adenoids was detected.

Two previous studies on the Syrian population were used as sources of normative cephalometric and tooth-size measurements (Nourallah et al., 2005; Al Sabbagh, 2014) (Table S2).

Age and gender distributions in the present study sample and normative studies' samples used as sources of normative measurements are shown in Table S3.

\section{Cephalometric measurements}

Pretreatment lateral cephalometric radiographs were taken for each patient with the head in the natural position using a dental radiograph system (PAX 400; Vatech Co., Hawseong, Korea). The same $X$-ray machine was used to acquire cephalograms in the normative cephalometric study using the same protocol (Al Sabbagh, 2014). The cephalometric measurements used in this study were derived from the analyses developed by McNamara (1984) and McNamara, Brust \& Riolo (1992). Reference landmarks and lines are illustrated in Fig. 1. Definitions of the cephalometric measurements are shown in Table S4. Each radiograph was digitized and analyzed by one investigator (A. A.) using a special orthodontic software program (OnyxCeph $3^{\mathrm{TM}}$, Image Instruments $\mathrm{GmbH}$, Chemnitz, Germany). Additionally, upper-pharyngeal widths were computed for all Class II-1 subjects whose values were equal to $5 \mathrm{~mm}$ or less (McNamara, 1984).

\section{Orthodontic cast measurements}

The mesiodistal crown diameters of all teeth from the right first permanent molar to the left first permanent molar on each cast were measured to the nearest $0.01 \mathrm{~mm}$ by one investigator (A. A.) using a universal digital caliper (MIB Messzeuge GMBH, Spangenberg, Germany). The measurements were conducted according to the methods described by Seipel (1946) and Moorrees \& Reed (1964). The same method was used in the normative tooth-size study (Nourallah et al., 2005). Bolton's overall ratio (sum of mesiodistal widths of 12 mandibular teeth divided by the sum of mesiodistal widths of 12 maxillary teeth multiplied by 100) and Bolton's anterior ratio (sum of mesiodistal widths of six mandibular anterior teeth divided by the sum of mesiodistal widths of six maxillary anterior teeth multiplied by 100) were calculated and used in the statistical analysis (Bolton, 1958). Overall and anterior ratios were computed for all Class II-1 subjects whose values were outside two SDs from Bolton's norms (Bolton, 1958) and were also computed for all Class II-1 subjects whose values were outside two SDs from Syrian population norms (Nourallah et al., 2005). 


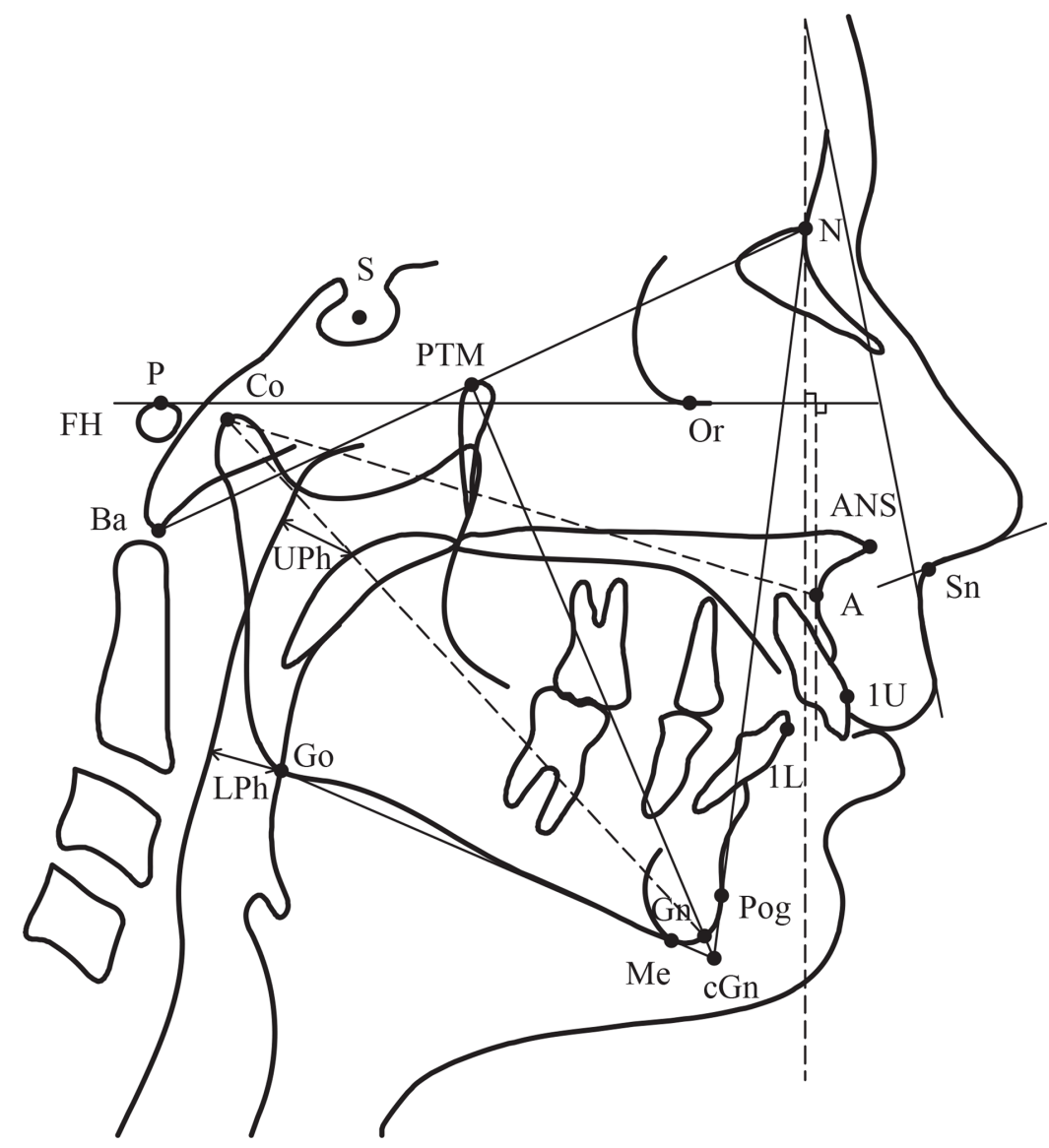

Figure 1 Reference cephalometric landmarks and lines used in this study.

Full-size DOI: $10.7717 /$ peerj.9545/fig-1

\section{Method error}

Following a random selection of 10 patients, all measurements on their cephalometric radiographs and orthodontic casts were retaken 2 months later by the same investigator. To evaluate the method error, both measurements were compared using three approaches.

First, the random method error was established according to Dahlberg's formula (Dahlberg, 1940). The method errors for angular and linear measurements on cephalometric radiographs were within 0.64 degrees and $0.42 \mathrm{~mm}$, respectively, while the method error for tooth-size measurements on orthodontic casts did not exceed $0.19 \mathrm{~mm}$, and the errors of anterior and overall tooth-size ratios were 0.62 and 0.39 , respectively. Second, the systematic error was investigated by paired sample $t$-tests; results showed that no systematic error could be found $(p>0.05)$. Finally, intraclass correlation coefficients were calculated for all variables; results ranged from 0.935 to 0.999 .

Inter-examiner reliability was established to investigate the potential investigator bias. Measurements of 10 randomly selected cephalograms and casts were replicated for a second time by another investigator. Random errors were within $0.53 \mathrm{~mm}$ and 0.61 degrees for linear and angular cephalometric variables, respectively, and within $0.28 \mathrm{~mm}$ for tooth-size measurements. Random errors of anterior and overall tooth-size ratios were 
0.56 and 0.47 , respectively. Systematic error was absent $(p>0.05)$ and intraclass correlation coefficients were above 0.92 .

\section{Statistical analysis}

Descriptive statistics (Means, SDs and 95\% CIs) of all variables were calculated with the use of the SPSS software 24.0 (SPSS Inc., Chicago, IL, USA). All variables in the total group (43 Syrian adolescents with Class II-1 malocclusion) and within each gender group (24 Syrian females and 19 Syrian males) were normally distributed according to Shapiro-Wilk test.

\section{RESULTS}

Data presenting gender-based and general characteristics of Syrian adolescents with Class II-1 malocclusion are summarized in Table 1.

Two variables (A-NP, SNA) were used to assess the sagittal position of the maxilla. The linear variable $(\mathrm{A}-\mathrm{NP})$ showed a value of $0.01( \pm 2.33) \mathrm{mm}$. The angular variable (SNA) showed a value of $80.46( \pm 2.66)$ degrees. The sagittal mandibular position was determined by one linear variable (Pog-NP) with a value of $-11.01( \pm 4.69) \mathrm{mm}$. The effective length of the maxilla (Cond-A) was $85.51( \pm 4.48) \mathrm{mm}$. The effective length of the mandible (Cond-Gn) was $107.98( \pm 5.55) \mathrm{mm}$. The difference between the maxillary length and the mandibular length (Max-Mand) was $22.47( \pm 4.39) \mathrm{mm}$.

Results in the vertical plane were as follows: First, lower anterior facial height (ANS-Me) showed a value of $68.30( \pm 5.09) \mathrm{mm}$. Second, mandibular plane angle $(\mathrm{MP}-\mathrm{FH})$ showed a value of $29.77( \pm 5.62)$ degrees. Third, facial axis (facial axis) showed a value of -6.25 $( \pm 4.56)$ degrees.

For incisors position determination, two linear variables were used: First, maxillary incisors position (1U-AP) showed a value of $5.86( \pm 2.05) \mathrm{mm}$. Second, mandibular incisors position (1L-APog) showed a value of $4.85( \pm 1.89) \mathrm{mm}$.

Soft tissue measurements showed an obtuse nasolabial angle (NLA) of $104.05( \pm 7.42)$ degrees. Further, the value of the upper-lip angle (UL-NP) was $11.05( \pm 7.60)$ degrees.

Regarding upper-airway dimensions, upper and lower-pharyngeal widths (UPh, $\mathrm{LPh}$ ) were assessed. The upper-pharyngeal width $(\mathrm{UPh})$ was $11.50( \pm 3.15) \mathrm{mm}$. The lower-pharyngeal width $(\mathrm{LPh})$ was $10.98( \pm 2.90) \mathrm{mm}$. However, there was no prevalence of upper-pharyngeal obstructions (upper-pharyngeal width $\leq 5 \mathrm{~mm}$ ) in the subjects of this study.

Bolton tooth-size analysis revealed that the anterior ratio was $80.69( \pm 2.73)$ percent, while the overall ratio was $92.84( \pm 1.70)$ percent.

The percentage of Class II-1 patients who had anterior ratios greater than two SDs from Bolton's norm (77.2 ( \pm 1.65$)$ percent) (Bolton, 1958) was 39.5\%, whereas the percentage of Class II-1 patients who had anterior ratios greater than two SDs from Syrian population norm (78.99 ( \pm 2.18$)$ percent) (Nourallah et al., 2005) was $25.6 \%$. The percentage of Class II-1 patients who had overall ratios greater than two SDs from Bolton's norm (91.3 ( \pm 1.91$)$ percent) (Bolton, 1958$)$ was $6.98 \%$, whereas none of Class II-1 patients had overall ratios greater than two SDs from Syrian population norm 
Table 1 Cephalometric measurements and tooth-size ratios of Syrian adolescents with Class II-1 malocclusion.

\begin{tabular}{|c|c|c|c|c|c|c|}
\hline \multirow[t]{2}{*}{ Cephalometric measurements } & \multicolumn{2}{|c|}{$\begin{array}{l}\text { Syrian Males with Class II-1 } \\
\text { Malocclusion }(n=19)\end{array}$} & \multicolumn{2}{|c|}{$\begin{array}{l}\text { Syrian Females with Class II-1 } \\
\text { Malocclusion }(n=24)\end{array}$} & \multicolumn{2}{|c|}{$\begin{array}{l}\text { Syrian adolescents with Class II-1 } \\
\text { Malocclusion }(n=43)\end{array}$} \\
\hline & Mean ( \pm S.D) & $\begin{array}{l}\text { 95\% CIs for mean } \\
\text { Lower, Upper }\end{array}$ & Mean ( \pm S.D) & $\begin{array}{l}\text { 95\% CIs for mean } \\
\text { Lower, Upper }\end{array}$ & Mean ( \pm S.D) & $\begin{array}{l}\text { 95\% CIs for mean } \\
\text { Lower, Upper }\end{array}$ \\
\hline \multicolumn{7}{|l|}{ Skeletal measurements } \\
\hline \multicolumn{7}{|l|}{ Sagittal values } \\
\hline A-NP (mm) & $-0.64( \pm 2.60)$ & $-1.90,0.61$ & $0.53( \pm 2.00)$ & $-0.31,1.38$ & $0.01( \pm 2.33)$ & $-0.70,0.73$ \\
\hline SNA $\left(^{\circ}\right)$ & $79.70( \pm 2.72)$ & $78.39,81.01$ & $81.06( \pm 2.50)$ & $80.00,82.11$ & $80.46( \pm 2.66)$ & $79.64,81.27$ \\
\hline Pog-NP (mm) & $-10.95( \pm 3.85)$ & $-12.81,-9.10$ & $-11.05( \pm 5.34)$ & $-13.31,-8.80$ & $-11.01( \pm 4.69)$ & $-12.45,-9.57$ \\
\hline Cond-A (mm) & $85.84( \pm 5.31)$ & $83.28,88.39$ & $85.25( \pm 3.79)$ & $83.65,86.85$ & $85.51( \pm 4.48)$ & $84.13,86.89$ \\
\hline Cond-Gn (mm) & $108.47( \pm 5.81)$ & $105.67,111.27$ & $107.59( \pm 5.43)$ & $105.30,109.89$ & $107.98( \pm 5.55)$ & $106.27,109.69$ \\
\hline Max-Mand (mm) & $22.64( \pm 4.26)$ & $20.59,24.69$ & $22.34( \pm 4.59)$ & $20.41,24.28$ & $22.47( \pm 4.39)$ & $21.12,23.82$ \\
\hline \multicolumn{7}{|l|}{ Vertical values } \\
\hline ANS-Me (mm) & $68.65( \pm 5.41)$ & $66.04,71.26$ & $68.01( \pm 4.92)$ & $65.94,70.09$ & $68.30( \pm 5.09)$ & $66.73,69.86$ \\
\hline $\mathrm{MP}-\mathrm{FH}\left({ }^{\circ}\right)$ & $28.70( \pm 5.15)$ & $26.21,31.18$ & $30.61( \pm 5.94)$ & $28.11,33.12$ & $29.77( \pm 5.62)$ & $28.04,31.50$ \\
\hline Facial Axis $\left(^{\circ}\right)$ & $-6.35( \pm 5.05)$ & $-8.78,-3.91$ & $-6.18( \pm 4.24)$ & $-7.97,-4.38$ & $-6.25( \pm 4.56)$ & $-7.65,-4.85$ \\
\hline \multicolumn{7}{|l|}{ Dental measurements } \\
\hline $1 \mathrm{U}-\mathrm{AP}(\mathrm{mm})$ & $5.66( \pm 2.07)$ & $4.66,6.65$ & $6.03( \pm 2.06)$ & $5.16,6.90$ & $5.86( \pm 2.05)$ & $5.23,6.49$ \\
\hline 1L-APog (mm) & $4.33( \pm 1.92)$ & $3.40,5.25$ & $5.27( \pm 1.79)$ & $4.51,6.02$ & $4.85( \pm 1.89)$ & $4.27,5.43$ \\
\hline \multicolumn{7}{|l|}{ Soft tissue measurements } \\
\hline NLA $\left(^{\circ}\right)$ & $104.78( \pm 6.32)$ & $101.73,107.82$ & $103.47( \pm 8.27)$ & $99.98,106.96$ & $104.05( \pm 7.42)$ & $101.77,106.33$ \\
\hline UL-NP $\left({ }^{\circ}\right)$ & $9.16( \pm 7.51)$ & $5.54,12.78$ & $12.54( \pm 7.49)$ & $9.38,15.70$ & $11.05( \pm 7.60)$ & $8.71,13.39$ \\
\hline \multicolumn{7}{|l|}{ Airway measurements } \\
\hline $\mathrm{UPh}(\mathrm{mm})$ & $10.57( \pm 3.17)$ & $9.04,12.10$ & $12.24( \pm 3.00)$ & $10.97,13.51$ & $11.50( \pm 3.15)$ & $10.53,12.47$ \\
\hline $\mathrm{LPh}(\mathrm{mm})$ & $10.44( \pm 2.48)$ & $9.25,11.63$ & $11.41( \pm 3.19)$ & $10.06,12.75$ & $10.98( \pm 2.90)$ & $10.09,11.87$ \\
\hline Tooth-size ratios & \multicolumn{2}{|c|}{$\begin{array}{l}\text { Syrian Males with Class II-1 } \\
\text { Malocclusion }(n=19)\end{array}$} & \multicolumn{2}{|c|}{$\begin{array}{l}\text { Syrian Females with Class II-1 } \\
\text { Malocclusion }(n=24)\end{array}$} & \multicolumn{2}{|c|}{$\begin{array}{l}\text { Syrian adolescents with Class II-1 } \\
\text { Malocclusion }(n=43)\end{array}$} \\
\hline Variables & Mean $( \pm$ S.D) & $\begin{array}{l}\text { 95\% CIs for means } \\
\text { Lower, Upper }\end{array}$ & Mean $( \pm$ S.D) & $\begin{array}{l}\text { 95\% CIs for means } \\
\text { Lower, Upper }\end{array}$ & Mean ( \pm S.D) & $\begin{array}{l}\text { 95\% CIs for means } \\
\text { Lower, Upper }\end{array}$ \\
\hline Anterior ratio (\%) & $80.55( \pm 2.95)$ & $79.12,81.97$ & $80.81( \pm 2.60)$ & 79.71, 81.91 & $80.69( \pm 2.73)$ & $79.85,81.53$ \\
\hline Overall ratio (\%) & $92.74( \pm 1.80)$ & $91.87,93.61$ & $92.92( \pm 1.65)$ & $92.23,93.62$ & $92.84( \pm 1.70)$ & $92.32,93.37$ \\
\hline
\end{tabular}

Notes:

CIs, confidence intervals; S.D, standard deviation.

Bold values indicate lower and upper bounds of $95 \%$ confidence intervals for mean.

(92.26 ( \pm 2.06$)$ percent) (Nourallah et al., 2005). Additionally, none of Class II-1 patients had anterior or overall ratios smaller than two SDs from Bolton's norms (Bolton, 1958), and none of Class II-1 patients had anterior or overall ratios smaller than two SDs from Syrian population norms (Nourallah et al., 2005).

\section{DISCUSSION}

Several studies have reported the cephalometric and tooth-size features of individuals of Middle Eastern ethnicity (Al Jundi \& Riba, 2014; Ali, El-Shorbagy \& Elliathy, 2016; Fouda, Hafez \& Al-Awdi, 2017; Mollabashi et al., 2019; ElAbbasy, 2019). Although Syrians 
belong to the Middle Eastern ethnic group, limited data are available pertaining to the craniofacial characteristics of adolescents of Syrian nationality. Therefore, this compound cephalometric and tooth-size study was attempted to establish the dentofacial morphology, upper-airway dimensions, and tooth-size characteristics of Syrian adolescents with both skeletal and dental Class II-1 malocclusion. To our knowledge, this is the first comprehensive study on this topic.

In addition, 95\% confidence intervals (CIs) for the means of cephalometric and tooth-size variables in the present study sample (Class II-1 malocclusion) (Table 1) were compared with $95 \%$ CIs for the means of normative cephalometric and tooth-size variables (Table S2) obtained from two previous studies (Nourallah et al., 2005; Al Sabbagh, 2014) and with 95\% CIs for the means of the corresponding variables in previous Middle Eastern studies on Class II-1 malocclusion (Table S5).

\section{Skeletal components}

In this study, the maxillary anteroposterior position was normal relative to the normative data, while the mandible was posteriorly positioned (CIs of A-NP, SNA, and Pog-NP in Table 1 vs. their corresponding values in Table S2); these findings were in agreement with those of several Middle Eastern studies (Demir, Uysal \& Basciftci, 2005; Saym \& Türkkahraman, 2005; Isik et al., 2006; Mortazavi, Salehi \& Ansari, 2009; Al Jundi \& Riba, 2014) (CIs of A-NP, and Pog-NP in Table 1 vs. their corresponding values in Table S5). However, other Middle Eastern studies have reported different results (Al-Khateeb \& Al-Khateeb, 2009; Ali, 2014); a possible reason for the divergence in findings could be, on the one hand, due to differences in the methods used for the determination of the maxillary and mandibular position (Pancherz, Zieber \& Hoyer, 1997), while on the other hand, the involvement of different nationalities in the various studies may explain the range of results. Furthermore, previous Middle Eastern studies have suggested that the majority of Class II-1 patients may have abnormal development of the mandible, both in terms of size and in terms of position (Saym \& Türkkahraman, 2005; Mortazavi, Salehi \& Ansari, 2009; Al Jundi \& Riba, 2014). In this study, although a shorter absolute mandibular length was observed among Class II-1 subjects, the absolute maxillary length was also shorter when compared with the normative data, resulting in a normal maxillomandibular difference (CIs of Cond-A, Cond-Gn and Max-Mand in Table 1 vs. their corresponding values in Table S2). In the interpretation of such data, the difference between maxillary and mandibular lengths should also be considered because a geometric relationship exists between both measurements (McNamara, 1984). The normal maxillomandibular difference in this study confirms that mandibular length was proportional to the maxillary length. Therefore, the short mandibular and maxillary lengths do not represent a conclusive feature of Class II-1 subjects included in this study rather than a potential difference between this study and the cephalometric control study in estimating the point "condylion." This point was considered by McNamara as "often difficult to find" and used as a measure of the lengths of both jaws; therefore, a slight difference in the estimation of condylion will simply affect the absolute lengths of both jaws but will not impact the maxillomandibular difference (McNamara, 1984). 


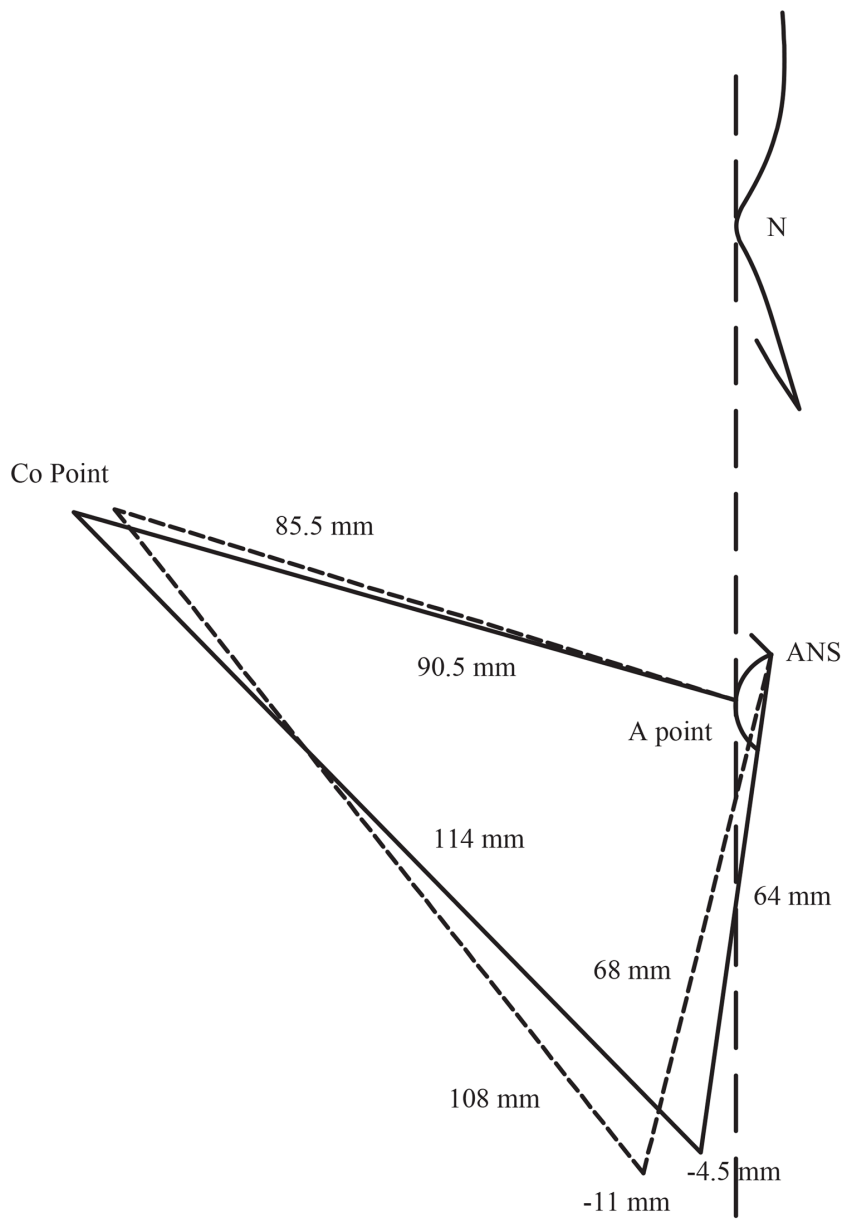

Normal occlusion (males and females)

Class II-1 (males and females)

Figure 2 Comparison between Class II-1 subjects and normal occlusion subjects regarding the skeletal parameters. Full-size $\underset{0}{0}$ DOI: 10.7717 /peerj.9545/fig-2

A prominent feature of subjects with Class II-1 malocclusion in the present study was the hyperdivergent facial pattern. The retruded mandible appeared to be accompanied by an increased mandibular plane angle and opened facial axis in both genders and excessive lower anterior facial height that was clear enough in females (CIs of ANS-Me, MP-FH and Facial Axis in Table 1 vs. their corresponding values in Table S2). A review of the Middle Eastern literature suggests wide agreement with these results (Saym \& Türkkahraman, 2005; Isik et al., 2006; Al-Khateeb \& Al-Khateeb, 2009; Mortazavi, Salehi \& Ansari, 2009; Ali, 2014; Al Jundi \& Riba, 2014) (CIs of MP-FH in Table 1 vs. their corresponding values in Table S5). Therefore, the posterior position of the mandible and, consequently, the inter-maxillary discrepancy of Class II-1 subjects in this study may be seen as a feature of the hyperdivergent facial pattern, as determined by the increased lower anterior facial height and backward rotation of the mandible (Fig. 2). 


\section{Dentoalveolar components}

Dentoalveolar aberrations were represented by protrusive mandibular incisors that were clear enough in females, whereas maxillary incisors were normally positioned in both genders when compared with the normative data (CIs of 1U-AP and 1L-APog in Table 1 vs. their corresponding values in Table S2). These findings contradicted those of certain Middle Eastern studies (Demir, Uysal \& Basciftci, 2005; Ali, 2014). However, other Middle Eastern studies confirmed normally positioned maxillary incisors (Saym \& Türkkahraman, 2005) and more protrusive mandibular incisors existed in Class II-1 malocclusion (Al-Khateeb \& Al-Khateeb, 2009; Mortazavi, Salehi \& Ansari, 2009; Al Jundi \& Riba, 2014) (CIs of $1 \mathrm{U}-\mathrm{AP}$ and $1 \mathrm{~L}-\mathrm{APog}$ in Table 1 vs. their corresponding values in Table S5). The inconsistent findings between this study and other previous studies might be owing to the use of different reference lines for the determination of the incisors position or might be attributed to the variations in the nationality background of the studied samples.

In the present study, the protrusion of mandibular incisors in Class II-1 subjects (especially in females) might be attributed to the dentoalveolar compensatory mechanism in response to the underlying skeletal discrepancy attempting to maintain relatively normal relationships between the dental arches (Solow, 1980). Another explanation might be the relative tooth-size excess observed in the mandibular anterior segment (see below), since the protrusion of mandibular incisors could occur because of space limitations.

\section{Soft tissue components}

The soft tissue parameters of Class II-1 subjects, when compared with the normative data, showed a more obtuse nasolabial angle (CIs of NLA in Table 1 vs. their corresponding values in Table S2). A previous Middle Eastern study found that Class II subjects had a greater value of the nasolabial angle than those with Class I; however, the difference was not significant (Gulsen et al., 2006). Conversely, other Middle Eastern studies suggested different results (Al-Saleem, 2013; Mohammed, Nissan \& Taha, 2013) (CIs of NLA in Table 1 vs. their corresponding values in Table S5). A probable reason for this variability among outcomes might be the differences in the methods used to determine the nasolabial angle (Hwang, Kim \& McNamara, 2000). Moreover, nationality differences may be a possible reason for such variability in soft tissue results.

Since there was no difference in the upper-lip angulation (CIs of UL-NP in Table 1 vs. their corresponding values in Table S2), our findings suggest that the angulation of the lower border of the nose may be a reason for the more obtuse nasolabial angle in Class II-1 subjects. In the present study, it was not possible to investigate the slope of the lower nasal border because there was no normative data available on this variable. Fitzgerald, Nanda \& Currier (1992) established a reliable method of constructing the nasolabial angle to determine the interrelationship between the nose and the upper lip. Further investigations that consider using this method are needed to validate our results.

\section{Upper-airway dimensions}

In the present study, upper-pharyngeal widths when compared with the normative data were smaller in Class II-1 subjects, and lower-pharyngeal widths showed smaller widths 
that were clear enough in males (CIs of UPh and LPh in Table 1 vs. their corresponding values in Table S2). These findings support the results of previous Middle Eastern studies (Ali, 2014; Elwareth Abd Elrazik Yousif, 2015; Gholinia, Habibi \& Amrollahi Boyouki, 2019) (CIs of UPh and LPh in Table 1 vs. their corresponding values in Table S5). In contrast, some Middle Eastern studies denied that a relationship exists between Class II-1 malocclusion and airway dimensions (Abu Allhaija \& Al-Khateeb, 2005; Uslu-Akcam, 2017). An explanation for the contrasting results might be an overlap between etiologic factors, including abnormal skeletal morphology and abnormal upper-airway soft tissue structures (Ferguson et al., 1995). In this study, the observed smaller pharyngeal widths might be attributable to the hyperdivergent facial pattern associated with Class II-1 malocclusion; this corroborates previous results in the Middle Eastern literature (Elwareth Abd Elrazik Yousif, 2015).

McNamara emphasized that an upper-pharyngeal width of $5 \mathrm{~mm}$ or less can be used as an indicator of possible airway obstruction, whereas lower pharyngeal measurements smaller than average values are not remarkable (McNamara, 1984). According to this indicator, there was no prevalence of pharyngeal obstructions in the subjects of this study. However, a more accurate diagnosis can be made only by an otorhinolaryngologist (McNamara, 1984).

\section{Tooth-size characteristics}

Former Middle Eastern studies have indicated that tooth-size disharmonies exist among different groups of malocclusion (Fattahi, Pakshir \& Hedayati, 2006; Mollabashi et al., 2019). In accordance with our results on tooth-size ratios (CIs of anterior ratio and overall ratio in Table 1 vs. their corresponding values in Table S2), some Middle Eastern studies did not find differences in overall ratios between Class II-1 subjects and the normative data (Asiry \& Hashim, 2012), whereas other Middle Eastern studies described an overall ratio for Class II-1 subjects that was smaller (Mollabashi et al., 2019; Shamaa, 2019) or larger (Uysal et al., 2005) compared to that of subjects with normal occlusion. Similarly, variability can be found in the Middle Eastern literature regarding the anterior ratio, whereas a smaller ratio (Fattahi, Pakshir \& Hedayati, 2006) or no differences were detected (Uysal et al., 2005; Asiry \& Hashim, 2012) (CIs of anterior ratio and overall ratio in Table 1 vs. their corresponding values in Table S5). Such divergence in findings may be explained by differences in the nationality background of the samples.

Several studies confirmed that a tooth-size disharmony greater than two SDs, as compared with Bolton's norms, could create clinical difficulties, particularly in the finishing phase of treatment (Crosby \& Alexander, 1989; Wędrychowska-Szulc, Janiszewska-Olszowska \& Stepien, 2010). In contrast, one study suggested that Bolton's SDs may not be a valuable index to use to determine the clinical significance of tooth-size disharmony because of their relatively modest values (Othman \& Harradine, 2006). Therefore, the frequencies of tooth-size discrepancy outside two SDs from Bolton's norms as well as the frequencies of tooth-size discrepancy outside two SDs from Syrian 
population norms were calculated in this study. The percentage of patients with anterior ratios greater than two SDs from Bolton's norm was 39.5\%, while the percentage of patients who had anterior ratios greater than two SDs from Syrian population norm was $25.6 \%$, representing a relative tooth-size excess in the mandibular anterior segment that was great enough to warrant clinical concern. These relatively high percentages of patients with an anterior ratio exceeding two SDs may be explained by the association of a higher percentage of tooth-size disharmonies and sufficiently remarkable malocclusions such as Class II-1 malocclusion. These disharmonies are particularly evident in the anterior segment, since the anterior teeth, especially the incisors, have the greatest incidence of tooth-size variations (Fattahi, Pakshir \& Hedayati, 2006).

\section{Limitations}

As far as limitations of the current study were concerned, consideration must be given to the sample size. Although the sample size estimation showed sufficient sample size for each gender group, the sample size was small; therefore, the results should be interpreted with caution and further studies with larger sample size are warranted. Such studies should also include adolescents from several orthodontic centers, since the data in the present study were recruited from only one private orthodontic practice in Syria. Additionally, there was no concurrent control group in this study. The inclusion of a matched control group in this investigation would have been desirable for a better comparison, although, in the case of normative cephalometric data, requiring the exposure of patients with well-balanced dentofacial relationships to $X$-ray radiation constitutes an ethical issue. As an alternative, already established cephalometric and tooth-size data were used as sources of normative measurements (Nourallah et al., 2005; Al Sabbagh, 2014). Although age could not be a confounding factor in tooth-size analysis, a wider age range was used in the normative cephalometric study than that in this study which could be a confounding factor in the cephalometric analysis. Because no other cephalometric data have been published on Syrian adolescent norms; these published data, therefore, were used as sources of normative measurements.

\section{CONCLUSIONS}

- In this study, cephalometric results showed that a hyperdivergent facial pattern was the main cause of the inter-maxillary discrepancy in Syrian adolescents with Class II-1 malocclusion, while the observed small pharyngeal widths were not clinically significant.

- Tooth-size results revealed that $39.5 \%$ of samples had anterior ratios exceeding two SDs of Bolton's norm and $25.6 \%$ of samples had anterior ratios exceeding two SDs of Syrian population norm, which may be considered as clinically relevant.

- Determining the craniofacial characteristics of Class II-1 malocclusion in the young Syrian population would help orthodontists to establish an effective protocol for long-term stable treatment of Syrian orthodontic patients. 


\section{ADDITIONAL INFORMATION AND DECLARATIONS}

\section{Funding}

The authors received no funding for this work.

\section{Competing Interests}

The authors declare that they have no competing interests.

\section{Author Contributions}

- Alaa Al Ayoubi conceived and designed the experiments, performed the experiments, analyzed the data, prepared figures and/or tables, authored or reviewed drafts of the paper, and approved the final draft.

- Daniel Dalla Torre analyzed the data, authored or reviewed drafts of the paper, and approved the final draft.

- Melinda Madléna conceived and designed the experiments, analyzed the data, authored or reviewed drafts of the paper, and approved the final draft.

\section{Human Ethics}

The following information was supplied relating to ethical approvals (i.e., approving body and any reference numbers):

Ethical approval for the present study was obtained from the Human Investigation

Review Board at the University of Szeged (151/2018-SZTE).

\section{Data Availability}

The following information was supplied regarding data availability:

The raw measurements are available in the Supplemental Files.

\section{Supplemental Information}

Supplemental information for this article can be found online at http://dx.doi.org/10.7717/ peerj.9545\#supplemental-information.

\section{REFERENCES}

Abu Allhaija ES, Al-Khateeb SN. 2005. Uvulo-Glosso-Pharyngeal dimensions in different anteroposterior skeletal patterns. Angle Orthodontist 75:1012-1018 DOI 10.1043/0003-3219(2005)75[1012:UDIDAS]2.0.CO;2.

Al Jundi A, Riba H. 2014. Characteristics of craniofacial complex for class II division 1 malocclusion in Saudi subjects with permanent dentition. Global Journal of Medical Research 14:1-9.

Al Sabbagh R. 2014. Syrian norms of McNamara cephalometric analysis. International Arab Journal of Dentistry 5(3):95-101 DOI 10.12816/0028756.

Al-Khateeb EA, Al-Khateeb SN. 2009. Anteroposterior and vertical components of Class II division 1 and division 2 malocclusion. Angle Orthodontist 79(5):859-866

DOI 10.2319/062208-325.1.

Al-Saleem NR. 2013. Comparison of lip analyses in skeletal class I normal occlusion and class II division 1 Malocclusion. Al-Rafidain Dental Journal 13(2):192-201

DOI 10.33899/rden.2013.84690. 
Alatrach AB, Saleh FK, Osman E. 2014. The prevalence of malocclusion and orthodontic treatment need in a sample of Syrian children. European Scientific Journal 10:230-247.

Albakri FM, Ingle N, Assery MK. 2018. Prevalence of malocclusion among male school children in Riyadh city. Open Access Macedonian Journal of Medical Sciences 6(7):1296-1299 DOI 10.3889/oamjms.2018.207.

Ali AI. 2014. Mcnamara's cephalometric analysis for Iraqi population in Mosul city. International Journal of Enhanced Research in Science Technology \& Engineering 3:287-299.

Ali RSE-D, El-Shorbagy EM, Elliathy MM. 2016. Relationship of interarch tooth-size discrepancy to occlusion. Egyptian Dental Journal 62(1):2979-2988 DOI 10.21608/edj.2016.95079.

Altemus LA. 1955. Horizontal and vertical dentofacial relationships in normal and Class II division I malocclusion in girls 11-15 years. Angle Orthodontist 25:120-137 DOI 10.1043/0003-3219(1955)025<0120:HAVDRI>2.0.CO;2.

Asiry M, Hashim H. 2012. Tooth size ratios in Saudi subjects with Class II, Division 1 malocclusion. Journal of International Oral Health 4:29-34.

Bilgic F, Gelgor IE, Celebi AA. 2015. Malocclusion prevalence and orthodontic treatment need in central Anatolian adolescents compared to European and other nations' adolescents. Dental Press Journal of Orthodontics 20(6):75-81 DOI 10.1590/2177-6709.20.6.075-081.oar.

Bollhalder J, Hänggi MP, Schätzle M, Markic G, Roos M, Peltomäki TA. 2013. Dentofacial and upper airway characteristics of mild and severe class II division 1 subjects. European Journal of Orthodontics 35(4):447-453 DOI 10.1093/ejo/cjs010.

Bolton WA. 1958. Disharmony in tooth size and its relation to the analysis and treatment of malocclusion. Angle Orthodontist 28:113-130 DOI 10.1043/0003-3219(1958)028<0113:DITSAI>2.0.CO;2.

Borzabadi-Farahani A, Borzabadi-Farahani A, Eslamipour F. 2009. Malocclusion and occlusal traits in an urban Iranian population: an epidemiological study of 11-to 14-year-old children. European Journal of Orthodontics 31(5):477-484 DOI 10.1093/ejo/cjp031.

Bugaighis I, Karanth D. 2013. The prevalence of malocclusion in urban Libyan schoolchildren. Journal of Orthodontic Science 2(1):1-6 DOI 10.4103/2278-0203.110325.

Ceylan İ, Oktay H. 1995. A study on the pharyngeal size in different skeletal patterns. American Journal of Orthodontics and Dentofacial Orthopedics 108(1):69-75 DOI 10.1016/S0889-5406(95)70068-4.

Crosby DR, Alexander CG. 1989. The occurrence of tooth size discrepancies among different malocclusion groups. American Journal of Orthodontics and Dentofacial Orthopedics 95(6):457-461 DOI 10.1016/0889-5406(89)90408-3.

Dahlberg G. 1940. Statistical methods for medical and biological students. London: George Alien and Unwin, Ltd.

De Souza RA, De Araújo Magnani MBB, Nouer DF, Romano FL, Passos MR. 2016. Prevalence of malocclusion in a Brazilian schoolchildren population and its relationship with early tooth loss. Brazilian Journal of Oral Sciences 7:1566-1570.

Demir A, Uysal T, Basciftci FA. 2005. Determination of skeletal and dental characteristics of class II malocclusion. Turkish Journal of Orthodontics 18(3):205-214 DOI 10.13076/1300-3550-18-3-205.

DESTATIS. 2018. Geburtenanstieg setzte sich 2016 fort. Available at https://www.destatis.de/DE/ Presse/Pressemitteilungen/2018/03/PD18_115_122.html (accessed 11 September 2019).

Drelich RC. 1948. A cephalometric study of untreated class II, division 1 malocclusion1. Angle Orthodontist 18:70-75 DOI 10.1043/0003-3219(1948)018<0070:ACSOUC>2.0.CO;2. 
El-Mangoury NH, Mostafa YA. 1990. Epidemiologic panorama of dental occlusion. Angle Orthodontist 60:207-214 DOI 10.1043/0003-3219(1990)060<0207:EPODO>2.0.CO;2.

ElAbbasy DO. 2019. Evaluation of the therapeutic effects of Sabbagh Universal Spring compared to Class II elastics in the treatment of Class II division 1 patients. Egyptian Dental Journal 65(4):3053-3067 DOI 10.21608/edj.2019.73984.

Elwareth Abd Elrazik Yousif AA. 2015. Evaluation of upper and lower pharyngeal airway in hypo and hyper divergent Class I, II and III malocclusions in a group of Egyptian patients. Tanta Dental Journal 12(4):265-276 DOI 10.1016/j.tdj.2015.07.001.

Eurostat Database. 2019. Asylum and first time asylum applicants by citizenship, age and sex Annual aggregated data (rounded). Available at https://ec.europa.eu/eurostat/data/database (accessed 7 March 2019).

Fattahi HR, Pakshir HR, Hedayati Z. 2006. Comparison of tooth size discrepancies among different malocclusion groups. European Journal of Orthodontics 28(5):491-495 DOI 10.1093/ejo/cj1012.

Ferguson KA, Ono T, Lowe AA, Ryan CF, Fleetham JA. 1995. The relationship between obesity and craniofacial structure in obstructive sleep apnea. Chest 108(2):375-381

DOI 10.1378/chest.108.2.375.

Fitzgerald JP, Nanda RS, Currier GF. 1992. An evaluation of the nasolabial angle and the relative inclinations of the nose and upper lip. American Journal of Orthodontics and Dentofacial Orthopedics 102(4):328-334 DOI 10.1016/0889-5406(92)70048-F.

Foster TD, Walpole Day AJ. 1974. A survey of malocclusion and the need for orthodontic treatment in a Shropshire school population. British Journal of Orthodontics 1(3):73-78 DOI 10.1179/bjo.1.3.73.

Fouda M, Hafez A, Al-Awdi M. 2017. Soft tissue profile changes in growing patients having class II division 1 malocclusion treated by modified activator with lip bumper. Indian Journal of Orthodontics and Dentofacial Research 3(2):103-106 DOI 10.18231/2455-6785.2017.0021.

Freitas MR, Santos MAC, Freitas KMS, Janson G, Freitas DS, Henriques JFC. 2005. Cephalometric characterization of skeletal Class II, division 1 malocclusion in white Brazilian subjects. Journal of Applied Oral Science 13(2):198-203

DOI 10.1590/S1678-77572005000200020.

Gholinia F, Habibi L, Amrollahi Boyouki M. 2019. Cephalometric evaluation of the upper airway in different skeletal classifications of jaws. Journal of Craniofacial Surgery 30(5):e469-e474 DOI 10.1097/SCS.0000000000005637.

Gulsen A, Okay C, Aslan BI, Uner O, Yavuzer R. 2006. The relationship between craniofacial structures and the nose in Anatolian Turkish adults: A cephalometric evaluation. American Journal of Orthodontics and Dentofacial Orthopedics 130(2):131.e15-132.e25 DOI 10.1016/j.ajodo.2006.01.020.

Gábris K, Márton S, Madléna M. 2006. Prevalence of malocclusions in Hungarian adolescents. European Journal of Orthodontics 28(5):467-470 DOI 10.1093/ejo/cjl027.

Hitchcock HP. 1973. A cephalometric description of Class II, Division 1 malocclusion. American Journal of Orthodontics and Dentofacial Orthopedics 63(4):414-423 DOI 10.1016/0002-9416(73)90146-2.

Hulley SB, Cummings SR, Browner WS, Grady DG, Newman TB. 2013. Designing clinical research. Philadelphia: Wolters Kluwer Health.

Hwang H-S, Kim W-S, McNamara JA. 2000. A comparative study of two methods of quantifying the soft tissue profile. Angle Orthodontist 70:200-207

DOI 10.1043/0003-3219(2000)070<0200:ACSOTM>2.0.CO;2. 
Ishii N, Deguchi T, Hunt NP. 2002. Morphological differences in the craniofacial structure between Japanese and Caucasian girls with Class II Division 1 malocclusions.

European Journal of Orthodontics 24(1):61-67 DOI 10.1093/ejo/24.1.61.

Isik F, Nalbantgil D, Sayinsu K, Arun T. 2006. A comparative study of cephalometric and arch width characteristics of Class II division 1 and division 2 malocclusions. European Journal of Orthodontics 28(2):179-183 DOI 10.1093/ejo/cji096.

Lau JWP, Hägg U. 1999. Cephalometric morphology of Chinese with class II division 1 malocclusion. British Dental Journal 186(4):188-190 DOI 10.1038/sj.bdj.4800059.

Lavelle CLB. 1972. Maxillary and mandibular tooth size in different racial groups and in different occlusal categories. American Journal of Orthodontics 61(1):29-37

DOI 10.1016/0002-9416(72)90173-X.

Lew KK, Foong WC, Loh E. 1993. Malocclusion prevalence in an ethnic Chinese population. Australian Dental Journal 38(6):442-449 DOI 10.1111/j.1834-7819.1993.tb04759.x.

Machado V, Botelho J, Pereira D, Vasques M, Fernandes-Retto P, Proença L, Mendes J-J, Delgado A. 2018. Bolton ratios in Portuguese subjects among different malocclusion groups. Journal of Clinical and Experimental Dentistry 10:e864-e868 DOI 10.4317/jced.54977.

Massler M, Frankel JM. 1951. Prevalence of malocclusion in children aged 14 to 18 years. American Journal of Orthodontics 37(10):751-768 DOI 10.1016/0002-9416(51)90047-4.

McNamara JA Jr, Brust EW, Riolo ML. 1992. Soft tissue evaluation of individuals with an ideal occlusion and a well-balanced face: esthetics and the Treatment of Facial Form. Craniofacial Growth Series. Ann Arbor: Center for Human Growth and Development, The University of Michigan, 115-146.

McNamara JA Jr. 1984. A method of cephalometric evaluation. American Journal of Orthodontics 86(6):449-469 DOI 10.1016/S0002-9416(84)90352-X.

Mergen DC, Jacobs RM. 1970. The size of nasopharynx associated with normal occlusion and class II malocclusion. Angle Orthodontist 40:342-346 DOI 10.1043/0003-3219(1970)040<0342:TSONAW>2.0.CO;2.

Mohammed SA, Nissan LMK, Taha SS. 2013. Soft tissue facial profile analysis of adult iraqis with different classes of malocclusion. Journal of Baghdad College of Dentistry 325(4):1-9 DOI 10.12816/0015083.

Mollabashi V, Soltani MK, Moslemian N, Akhlaghian M, Akbarzadeh M, Samavat H, Abolvardi M. 2019. Comparison of Bolton ratio in normal occlusion and different malocclusion groups in Iranian population. International Orthodontics 17(1):143-150 DOI 10.1016/j.ortho.2019.01.005.

Moorrees CFA, Reed RB. 1964. Correlations among crown diameters of human teeth. Archives of Oral Biology 9(6):685-697 DOI 10.1016/0003-9969(64)90080-9.

Mortazavi M, Salehi P, Ansari G. 2009. Mandibular size and position in a group of 13-15 years old iranian children with class II division 1 malocclusion. Research Journal of Biological Sciences 4:531-536.

Nadim R, Aslam K, Rizwan S. 2014. Frequency of malocclusion among 12-15 years old school children in three sectors of Karachi. Pakistan Oral and Dental Journal 34:510-514.

Nourallah AW, Splieth CH, Schwahn C, Khurdaji M. 2005. Standardizing interarch tooth-size harmony in a Syrian population. Angle Orthodontist 75:996-999

DOI 10.1043/0003-3219(2005)75[996:SITHIA]2.0.CO;2.

Oktay H, Ulukaya E. 2010. Intermaxillary tooth size discrepancies among different malocclusion groups. European Journal of Orthodontics 32(3):307-312 DOI 10.1093/ejo/cjp079. 
Onyeaso CO. 2004. Prevalence of malocclusion among adolescents in Ibadan, Nigeria. American Journal of Orthodontics and Dentofacial Orthopedics 126(5):604-607 DOI 10.1016/j.ajodo.2003.07.012.

Othman SA, Harradine NWT. 2006. Tooth-size discrepancy and Bolton's ratios: a literature review. Journal of Orthodontics 33(1):45-51 DOI 10.1179/146531205225021384.

Pancherz H, Zieber K, Hoyer B. 1997. Cephalometric characteristics of class II division 1 and class II division 2 malocclusions: a comparative study in children. Angle Orthodontist 67:111-120 DOI 10.1043/0003-3219(1997)067<0111:CCOCID>2.3.CO;2.

Perillo L, Masucci C, Ferro F, Apicella D, Baccetti T. 2009. Prevalence of orthodontic treatment need in southern Italian schoolchildren. European Journal of Orthodontics 32(1):49-53 DOI 10.1093/ejo/cjp050.

Riedel RA. 1952. The relation of maxillary structures to cranium in malocclusion and in normal occlusion. Angle Orthodontist 22:142-145 DOI 10.1043/0003-3219(1952)022<0142:TROMST>2.0.CO;2.

Rothstein T, Yoon-Tarlie C. 2000. Dental and facial skeletal characteristics and growth of males and females with class II, division 1 malocclusion between the ages of 10 and 14 (revisited)-Part I: characteristics of size, form, and position. American Journal of Orthodontics and Dentofacial Orthopedics 117(3):320-332 DOI 10.1016/S0889-5406(00)70237-X.

Saleh FK. 1999. Prevalence of malocclusion in a sample of Lebanese schoolchildren: an epidemiological study. Eastern Mediterranean health journal 5:337-343.

Sayın MO, Türkkahraman H. 2005. Cephalometric evaluation of nongrowing females with skeletal and dental Class II, division 1 malocclusion. Angle Orthodontist 75:656-660 DOI 10.1043/0003-3219(2005)75[656:CEONFW]2.0.CO;2.

Seipel CM. 1946. Variation in tooth positon, A metric study of variation and adaptation in the deciduous and permanent dentitions. Svensk tandlakare tidskrift 39:26-29.

Shamaa MS. 2019. Comparison between Class II Division 1 and 2 Malocclusions and normal occlusion regarding tooth size discrepancy and arch dimensions using digital models. Egyptian Dental Journal 65(2):899-908 DOI 10.21608/edj.2015.71985.

Shyagali TR, Singh M, Joshi R, Gupta A, Kshirsagar P, Jha R. 2019. Prevalence of Angle's malocclusion in sensory-deprived and normal school children of age group of 12-16 years in India: a study conducted in 2016-2018. Journal of Oral Health and Oral Epidemiology 8:74-80.

Silva RG, Kang DS. 2001. Prevalence of malocclusion among Latino adolescents. American Journal of Orthodontics and Dentofacial Orthopedics 119(3):313-315 DOI 10.1067/mod.2001.110985.

Silva NN, Lacerda RHW, Silva AWC, Ramos TB. 2015. Assessment of upper airways measurements in patients with mandibular skeletal class II malocclusion. Dental Press Journal of Orthodontics 20(5):86-93 DOI 10.1590/2177-6709.20.5.086-093.oar.

Singh VP, Sharma A. 2014. Epidemiology of malocclusion and assessment of orthodontic treatment need for nepalese children. International Scholarly Research Notices 2014(2):1-4 DOI $10.1155 / 2014 / 768357$.

Solow B. 1980. The dentoalveolar compensatory mechanism: background and clinical implications. British Journal of Orthodontics 7(3):145-161 DOI 10.1179/bjo.7.3.145.

Soni J, Shyagali TR, Bhayya DP, Shah R. 2015. Evaluation of pharyngeal space in different combinations of class II skeletal malocclusion. Acta Informatica Medica 23(5):285-289 DOI 10.5455/aim.2015.23.285-289.

Sosa FA, Graber TM, Muller TP. 1982. Postpharyngeal lymphoid tissue in angle class I and Class II malocclusions. American Journal of Orthodontics 81(4):299-309

DOI 10.1016/0002-9416(82)90216-0. 
Tausche E, Luck O, Harzer W. 2004. Prevalence of malocclusions in the early mixed dentition and orthodontic treatment need. European Journal of Orthodontics 26(3):237-244 DOI 10.1093/ejo/26.3.237.

Thilander B, Myrberg N. 1973. The prevalence of malocclusion in Swedish schoolchildren. European Journal of Oral Sciences 81(1):12-20 DOI 10.1111/j.1600-0722.1973.tb01489.x.

Thilander B, Pena L, Infante C, Parada SS, De Mayorga C. 2001. Prevalence of malocclusion and orthodontic treatment need in children and adolescents in Bogota, Colombia: an epidemiological study related to different stages of dental development. European Journal of Orthodontics 23(2):153-168 DOI 10.1093/ejo/23.2.153.

United Nations Population Division. 2019. International migrant stock 2019, graph: Twenty countries or areas of origin with the largest diaspora populations (millions). Available at https://www.un.org/en/development/desa/population/migration/data/estimates2/ estimatesgraphs.asp?3g3 (accessed 27 September 2019).

Uslu-Akcam O. 2017. Pharyngeal airway dimensions in skeletal class II: a cephalometric growth study. Imaging Science in Dentistry 47(1):1-9 DOI 10.5624/isd.2017.47.1.1.

Uysal T, Sari Z, Basciftci FA, Memili B. 2005. Intermaxillary tooth size discrepancy and malocclusion: is there a relation? Angle Orthodontist 75:208-213

DOI 10.1043/0003-3219(2005)075<0204:ITSDAM>2.0.CO;2.

Wędrychowska-Szulc B, Janiszewska-Olszowska J, Stepień P. 2010. Overall and anterior Bolton ratio in Class I, II, and III orthodontic patients. European Journal of Orthodontics 32(3):313-318 DOI 10.1093/ejo/cjp114. 


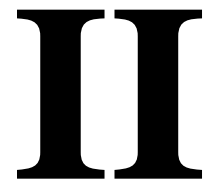




\title{
Dentoskeletal and tooth-size differences between Syrian and Hungarian adolescents with Class II division 1 malocclusion: a retrospective study
}

\author{
Alaa Al Ayoubi* (i), Alireza Khandan Dezfully and Melinda Madléna* (i)
}

\begin{abstract}
Objectives: Malocclusion features differ across various populations and ethnicities. At this time, no data are available regarding the dentofacial differences between Syrian and European adolescents with Class II division 1 malocclusion, which is one of the most frequently treated pathologies in orthodontic practice. The present combined cephalometric and tooth-size study aimed to compare the dentoskeletal and tooth-size characteristics of Syrian and Hungarian adolescents with Class II division 1 malocclusion.

Results: Class II division 1 malocclusion in Hungarian adolescents was a sagittal discrepancy, while in Syrian adolescents, it was a result of excessive vertical development. Syrian adolescents had a significantly excessive vertical development when compared with Hungarian adolescents, regardless of $\operatorname{sex}(p<0.01)$. Hungarian boys had significantly more protruded maxillae $(p<0.001)$ and less retruded mandibles $(p<0.01)$ when compared with Syrian boys, while Hungarian girls had significantly shorter mandibles relative to those of Syrian girls $(p<0.01)$. Syrian girls had significantly more protrusive lower incisors $(p<0.001)$, accompanied by significantly larger anterior tooth-size ratios when compared to Hungarian girls $(p<0.001)$. In conclusion, these findings underscore the importance of considering ethnic differences during orthodontic diagnosis and may have implications for optimizing orthodontic treatments in Syrian and Hungarian adolescents with Class II division 1 malocclusion.
\end{abstract}

Keywords: Ethnic differences, Dentoskeletal structure, Tooth size, Class II division 1 malocclusion

\section{Introduction}

Although several studies have reported ethnic differences in dentoskeletal structure and tooth-size characteristics [1-8], limited studies have investigated these differences in Class II division 1 (Class II/1) malocclusion [9-11]. With prevalences of $16 \%$ and $23.5 \%$ in Syrian and Hungarian adolescents, respectively $[12,13]$, this is one of

*Correspondence: alaa.alayoubi@outlook.com; madlenamelinda784@gmail. com

Department of Orthodontics and Pediatric Dentistry, Faculty of Dentistry,

University of Szeged, Tisza Lajos körút 64-66, Szeged 6720, Hungary the most frequently seen malocclusions in orthodontic practice.

Various factors cause Class II/1 malocclusion. However, conflicting results, possibly due to ethnic variations, have prevented their general characterization [9-11]. Likewise, tooth-size ratios show ethnic differences $[4$, 5]. In view of recent migration trends, especially from the Middle-East toward Europe, these findings underscore the need for updated comparisons of dentoskeletal and tooth-size characteristics across ethnicities [14]. Although some research has considered some dentoskeletal and tooth-size characteristics of Syrian populations $[15,16]$ or Hungarian populations $[17,18]$, no study has

(c) The Author(s) 2020. This article is licensed under a Creative Commons Attribution 4.0 International License, which permits use, sharing, adaptation, distribution and reproduction in any medium or format, as long as you give appropriate credit to the original author(s) and the source, provide a link to the Creative Commons licence, and indicate if changes were made. The images or other third party material in this article are included in the article's Creative Commons licence, unless indicated otherwise in a credit line to the material. If material is not included in the article's Creative Commons licence and your intended use is not permitted by statutory regulation or exceeds the permitted use, you will need to obtain permission directly from the copyright holder. To view a copy of this licence, visit http://creativeco mmons.org/licenses/by/4.0/. The Creative Commons Public Domain Dedication waiver (http://creativecommons.org/publicdomain/ zero/1.0/) applies to the data made available in this article, unless otherwise stated in a credit line to the data. 
compared these characteristics between Syrian and European (Hungarian) adolescents.

Despite the evaluation of Class II/1 malocclusion in multiple studies, the following factors limit their results:

- The influence of skeletal age variations on results' reliability has been neglected, since most Class II/1 malocclusion studies grouped patients by their chronological age [9-11, 19-23].

- While most studies selected patients with Class II/1 malocclusion based on their dental relationships (molar and/or incisor relationships) [9, 11, 20, 21, 23-25], these patients might have had either Class I or Class II skeletal pattern; studies on both skeletal and dental Class II/1 malocclusion are lacking [10, 22, 26].

- The dentoskeletal structure of individuals with Class II/1 malocclusion was analyzed during childhood [10, 11], adulthood [26], or by including subjects across a wide age-range-early childhood to adulthood [19-21]. However, most orthodontic patients seek treatment during adolescence, during which all treatment options and techniques are available.

- Limited studies have included cephalometric and tooth-size measurements in the same investigation [1]. This combination could comprehensively diagnose the malocclusion and elucidate the complex relationship between its components.

\section{Objective}

This combined cephalometric and tooth-size study aimed to compare the skeletal morphology, dental position, and tooth size of skeletal age- and sex-matched Syrian and Hungarian adolescents with skeletal and dental Class II/1 malocclusion.

\section{Main text}

\section{Materials and methods}

\section{Subjects}

The sample size assumed a bilateral two-sample $t$ test for assessment. According to previous similar dentoskeletal and tooth-size studies [5, 27], effect sizes were estimated from the SNGoMe angle $5.80^{\circ}\left( \pm 5.78^{\circ}\right)$ [27], and the upper central-incisor width $0.54( \pm 0.52) \mathrm{mm}[5]$, respectively. With a significance level alpha $=0.05$ (two-sided) and $80 \%$ power, the required sample size was calculated to detect standardized effect sizes of $1.00\left(5.80 / 5.78^{\circ}\right)$ and $1.03(0.54 / 0.52 \mathrm{~mm})$ for dentoskeletal and toothsize comparisons, respectively. Sample size calculation showed that 17 patients were required for each sex subgroup in each ethnic group [28]; lateral cephalograms and dental casts of 86 untreated patients with skeletal and dental Class II/1 malocclusion were thus included in this study. The study sample comprised two groups based on ethnicity-group 1, 43 Syrian patients selected from a private orthodontic office in Damascus, Syria; and group 2, 43 Hungarian patients selected from the Department of Orthodontics and Pediatric Dentistry, Faculty of Dentistry, University of Szeged, Hungary. Both groups included 24 girls and 19 boys. Each patient in group 1 was matched with a patient in group 2 by sex and skeletal age. To eradicate bias caused by growth variation, skeletal age was assessed from lateral cephalograms according to the method developed by Baccetti et al. [29]. Age and sex distributions of the study sample are summarized in Table 1.

The inclusion criteria were as follows:

- Age, 12-17 years.

- Syrian ethnicity for group 1; Hungarian ethnicity for group 2.

- Overjet $>4 \mathrm{~mm}$ without upper incisor retroclination (U1/NA angle $\geq 22^{\circ}$ ).

- Half-unit or greater bilateral distal occlusion with permanent dentition.

- ANB angle $>4^{\circ}$ with a convex facial profile.

- No extractions, interproximal restorations, or conditions affecting the mesio-distal teeth diameter.

The exclusion criteria were patients with history of orthodontic treatment, trauma, or craniofacial syndromes. The Human Investigation Review Board at the University of Szeged (151/2018-SZTE) approved this

Table 1 Age and sex distributions of the study groups

\begin{tabular}{|c|c|c|c|c|c|c|c|}
\hline & \multicolumn{3}{|l|}{ Boys } & \multicolumn{3}{|l|}{ Girls } & \multirow[t]{2}{*}{ Total } \\
\hline & Mean age \pm S.D (y) & Age range $(y)$ & $\begin{array}{l}\text { Sample size } \\
\text { (n) }\end{array}$ & Mean age \pm S.D (y) & Age range (y) & $\begin{array}{l}\text { Sample size } \\
\text { (n) }\end{array}$ & \\
\hline Syrians & $14.1 \pm 1.7$ & $11.7-17.3$ & 19 & $14.6 \pm 1.4$ & $11.9-17.1$ & 24 & 43 \\
\hline Hungarians & $14.0 \pm 2.0$ & $11.4-17.6$ & 19 & $14.6 \pm 1.8$ & $11.3-17.7$ & 24 & 43 \\
\hline Total & & & 38 & & & 48 & 86 \\
\hline
\end{tabular}


retrospective cross-sectional study. The participants or their parent/legal guardian provided written informed consent to participate in this study.

\section{Cephalometric measurements}

Pretreatment lateral cephalograms were obtained for each patient in both ethnic groups using the same protocol (head in natural position and teeth in maximal intercuspation). Magnification was corrected to 1:1 since the cephalograms were acquired with two different machines. The cephalometric measurements used herein were derived from the analyses developed by Jarabak, Steiner, and the University of Bonn [30-32]. Definitions of the cephalometric measurements are presented in Additional file 1: Table S1. Landmarks and reference lines are shown in Additional file 2: Figure S1. A special orthodontic software (OnyxCeph $3^{\mathrm{TM}}$, Image Instruments $\mathrm{GmbH}$, Chemnitz, Germany) was used by one investigator to digitize and analyze all lateral cephalograms.

\section{Dental-cast measurements}

The teeth in both arches-from the right first permanent molar to the left first permanent molar-were measured at the largest mesio-distal dimension [33], to the nearest $0.01-\mathrm{mm}$, by one investigator using a universal digital caliper (MIB Messzeuge GmbH, Spangenberg, Germany). Bolton's overall ratio ( $\sum$ widths of the mandibular 6-6/ Ewidths of the maxillary $6-6 \times 100$ ) [34] and Bolton's anterior ratio ( $\sum$ widths of the mandibular $3-3 /$ Ewidths of the maxillary $3-3 \times 100$ ) [34] were calculated and used in statistical analyses.

\section{Method error}

To establish intra-examiner reliability, measurements of 20 randomly selected cephalograms and casts were replicated several weeks later by the same investigator. Dahlberg's formula [35] showed random errors $\leq 0.40 \mathrm{~mm}$ and $\leq 0.44^{\circ}$ for linear and angular cephalometric variables, respectively, and $\leq 0.17 \mathrm{~mm}$ for tooth-size measurements. Paired sample $t$-tests showed no systematic error $(\mathrm{p}>0.05)$. Intraclass correlation coefficients were $>0.95$.

To establish inter-examiner reliability, measurements of 20 randomly selected cephalograms and casts were replicated again by another investigator. Random errors were $\leq 0.46 \mathrm{~mm}$ and $\leq 0.48^{\circ}$ for linear and angular cephalometric variables, respectively, and $\leq 0.33 \mathrm{~mm}$ for tooth-size measurements. Systematic error was absent $(p>0.05)$. Intraclass correlation coefficients were $>0.93$.

\section{Statistical analyses}

Descriptive statistics of each variable were calculated using SPSS software 24.0 (SPSS Inc., Chicago, USA). Intergroup comparisons were performed using $t$ - or
Mann-Whitney $U$-tests, depending on data normality (according to Shapiro-Wilk's test). For normally-distributed data, two-sample or Welch's $t$-tests were used depending on equality of variance (according to $F$-test). The level of statistical significance was set at 0.05 .

\section{Results}

Results for sex-based comparisons between the two ethnic groups are presented in Table 2.

Results for overall comparisons between the two ethnic groups are presented in Additional file 3: Table S2.

\section{Cephalometric comparisons}

Sagittal comparisons revealed that Hungarian boys had significantly more protruded maxillae (SNA) than their Syrian counterparts $(p<0.001)$, while Syrian boys had significantly more retruded mandibles (SNB) $(p<0.01)$. Hungarian girls had significantly smaller mandibular lengths $(\mathrm{Go}-\mathrm{Gn})$ than their Syrian counterparts $(p<0.01)$ (Fig. 1).

Vertical measurements (ArGoMe, $\sum$ Bjork, SN/GoMe, and S-Go:N-Me) showed significant differences $(p<0.01)$ between Syrian and Hungarian adolescents, regardless of sex, indicating a hyperdivergent facial pattern in Syrian ethnicity (Additional file 3: Table S2).

Dental measurement results revealed that Syrian girls had significantly more protruded lower incisors (L1/ NB and L1-NB) $(p<0.001)$ than Hungarian girls. These observations did not extend to the male populations (Table 2).

\section{Tooth-size comparisons}

Syrian girls had significantly greater anterior tooth-size ratios than Hungarian girls $(p<0.001)$. Syrian and Hungarian boys showed no such difference (Table 2).

\section{Discussion}

This study evaluated the effects of ethnic variations on dentoskeletal and tooth-size characteristics of Syrians and Hungarians adolescents with Class II/1 malocclusion. As most dentoskeletal variations can be ascribed to sex, age (maturity stage), and ethnicity [9], and most tooth-size variations can be ascribed to sex and ethnicity $[4,5]$, this study compared sex- and skeletal age-matched individuals to yield clear conclusions on the impact of ethnicity on dentoskeletal and tooth-size characteristics.

Skeletal comparisons showed that sagittal measurements significantly differed between the two groups-Hungarian boys had more protruded maxillae compared to Syrian boys, while Hungarian girls had significantly shorter mandibles than Syrian girls (Fig. 1). These observations in Hungarian adolescents support those of a previous study [19], which found 
Table 2 Sex-based comparison of cephalometric measurements and tooth-size ratios between the two ethnic groups

\begin{tabular}{|c|c|c|c|c|c|c|c|c|c|c|}
\hline & \multicolumn{5}{|l|}{ Boys } & \multicolumn{5}{|l|}{ Girls } \\
\hline & \multirow[t]{2}{*}{$\begin{array}{l}\text { Syrians } \\
(n=19) \\
\text { Mean } \pm \text { S.D }\end{array}$} & \multirow[t]{2}{*}{$\begin{array}{l}\text { Hungarians } \\
(n=19) \\
\text { Mean } \pm \text { S.D }\end{array}$} & \multicolumn{2}{|c|}{$\begin{array}{l}95 \% \mathrm{Cl} \\
\text { of Mean } \\
\text { difference }\end{array}$} & \multirow[t]{2}{*}{$p$-value } & \multirow[t]{2}{*}{$\begin{array}{l}\text { Syrians } \\
(n=24) \\
\text { mean } \pm \text { S.D }\end{array}$} & \multirow[t]{2}{*}{$\begin{array}{l}\text { Hungarians } \\
(n=24) \\
\text { Mean } \pm \text { S.D }\end{array}$} & \multicolumn{2}{|c|}{$\begin{array}{l}95 \% \mathrm{Cl} \\
\text { of Mean } \\
\text { difference }\end{array}$} & \multirow[t]{2}{*}{$p$-value } \\
\hline & & & $\mathbf{L}$ & $U$ & & & & $\mathbf{L}$ & $U$ & \\
\hline \multicolumn{11}{|c|}{ Cephalometric measurements $\partial$} \\
\hline \multicolumn{11}{|c|}{ Skeletal measurements } \\
\hline \multicolumn{11}{|l|}{ Sagittal values } \\
\hline SNA $\left(^{\circ}\right)$ & $79.70 \pm 2.72$ & $83.43 \pm 2.79$ & -5.54 & -1.91 & $<0.001$ & $81.06 \pm 2.50$ & $80.69 \pm 3.49$ & -1.40 & 2.13 & 0.679 \\
\hline SNB $\left(^{\circ}\right)$ & $73.81 \pm 2.93$ & $76.73 \pm 2.82$ & -4.81 & -1.03 & 0.003 & $74.05 \pm 2.85$ & $74.24 \pm 3.62$ & -2.09 & 1.70 & 0.840 \\
\hline ANB $\left(^{\circ}\right)$ & $5.89 \pm 1.46$ & $6.70 \pm 1.19$ & -1.69 & 0.06 & 0.068 & $7.01 \pm 1.75$ & $6.45 \pm 1.56$ & -0.41 & 1.52 & 0.249 \\
\hline ANS-PNS (mm) & $56.44 \pm 4.95$ & $56.68 \pm 3.12$ & -2.97 & 2.49 & 0.859 & $55.00 \pm 4.04$ & $53.39 \pm 3.15$ & -0.50 & 3.71 & 0.132 \\
\hline Go-Gn (mm) & $73.13 \pm 6.18$ & $71.38 \pm 5.05$ & -1.96 & 5.47 & 0.345 & $71.93 \pm 4.58$ & $67.77 \pm 4.50$ & 1.52 & 6.79 & 0.003 \\
\hline \multicolumn{11}{|l|}{ Vertical values } \\
\hline $\operatorname{ArGoMe}\left({ }^{\circ}\right)$ & $124.08 \pm 7.88$ & $119.11 \pm 6.25$ & 0.30 & 9.66 & 0.038 & $125.29 \pm 9.62$ & $120.18 \pm 6.67$ & 0.30 & 9.92 & 0.038 \\
\hline$\sum$ Bjork $\left(^{\circ}\right)$ & $398.33 \pm 5.75$ & $392.16 \pm 5.85$ & 2.35 & 9.99 & 0.002 & $400.14 \pm 6.43$ & $394.53 \pm 6.75$ & 1.78 & 9.44 & 0.005 \\
\hline $\operatorname{Ar}-\mathrm{Go}(\mathrm{mm})$ & $41.56 \pm 5.11$ & $44.48 \pm 4.70$ & -6.15 & 0.30 & 0.074 & $42.01 \pm 4.81$ & $39.98 \pm 4.17$ & -0.58 & 4.65 & 0.124 \\
\hline SN/GoMe $\left(^{\circ}\right)$ & $38.33 \pm 5.76$ & $32.16 \pm 5.85$ & 2.35 & 9.99 & 0.002 & $40.14 \pm 6.43$ & $34.53 \pm 6.75$ & 1.78 & 9.44 & 0.005 \\
\hline S-Go:N-Me (\%) & $61.64 \pm 4.09$ & $66.71 \pm 4.51$ & -7.90 & -2.24 & 0.001 & $60.62 \pm 4.69$ & $64.47 \pm 5.42$ & -6.80 & -0.90 & 0.012 \\
\hline \multicolumn{11}{|c|}{ Dental measurements } \\
\hline U1/NA $\left(^{\circ}\right)$ & $26.97 \pm 4.18$ & $26.98 \pm 3.71$ & -2.62 & 2.58 & 0.989 & $26.44 \pm 2.60$ & $28.16 \pm 4.32$ & -3.81 & 0.36 & 0.102 \\
\hline L1/NB $\left(^{\circ}\right)$ & $29.37 \pm 5.56$ & $28.80 \pm 5.23$ & -2.99 & 4.11 & 0.750 & $35.45 \pm 4.34$ & $27.50 \pm 6.05$ & 4.89 & 11.01 & $<0.001$ \\
\hline U1-NA (mm) & $5.86 \pm 2.06$ & $4.90 \pm 2.11$ & -0.42 & 2.33 & 0.166 & $6.21 \pm 2.15$ & $5.39 \pm 2.29$ & -0.47 & 2.11 & 0.208 \\
\hline L1-NB (mm) & $8.22 \pm 2.03$ & $6.88 \pm 2.08$ & -0.01 & 2.69 & 0.052 & $9.73 \pm 1.96$ & $5.52 \pm 1.88$ & 3.09 & 5.32 & $<0.001$ \\
\hline \multicolumn{11}{|l|}{ Tooth-size ratios $\partial$} \\
\hline Anterior ratio (\%) & $80.55 \pm 2.95$ & $79.42 \pm 2.08$ & -0.57 & 2.81 & 0.186 & $80.81 \pm 2.60$ & $77.89 \pm 2.42$ & 1.46 & 4.38 & $<0.001$ \\
\hline Overall ratio (\%) & $92.74 \pm 1.80$ & $92.79 \pm 2.33$ & -1.42 & 1.32 & 0.941 & $92.92 \pm 1.65$ & $91.87 \pm 1.98$ & 0.00 & 2.11 & 0.051 \\
\hline
\end{tabular}

Italic values indicate significance of $p$ value $(p<0.05)$

$\partial t$-tests for independent variables

S.D Standard deviation, $C /$ Confidence interval

Class II/1 Caucasian boys with maxillary protrusion and Class II/1 Caucasian girls with shorter-than-average mandibular length. Although Syrian adolescents had relatively normal maxillary position and mandibular length as compared with Hungarian adolescents, their mandibles were posteriorly positioned. This was evident in Syrian boys with significantly smaller SNB angles than Hungarian boys who had relatively normal mandibular position. In contrast, Syrian girls also had restricted mandibles; however, the diminished mandibular sizes of Hungarian girls were pronounced enough to cause a non-significant difference in SNB measurements between the two female populations. NonCaucasian studies reported similar findings of normal maxillary position and retruded mandible in Class II/1 Syrian subjects [20, 22, 23, 26]. Contrarily, some Caucasian studies reported varying findings with normally positioned mandibles and protruded maxillae [24, 25].
The involvement of different ethnicities across various studies may explain the inconsistent findings.

Many authors have recognized the importance of excessive vertical development in the determination of mandibular position $[10,20,26]$. Thus, retruded mandibles of Syrian adolescents in this study can be explained with respect to the vertical plane: Syrian adolescents, in comparison to Hungarian adolescents, regardless of sex, had hyperdivergent facial patterns (Fig. 1). This finding agrees with those of other studies that compared nonCaucasian and Caucasian Class II patients [9, 10, 27].

The position of dentition, relative to the skeletal structure, is another important aspect of Class II/1 malocclusion. The only significant difference in the dental position found in this study was related to the lower incisors and was evident among girls. Syrian girls had more protrusive lower incisors than Hungarian girls. Status on the position of lower incisors in patients with Class II/1 malocclusion remains unclear. Most non-Caucasian studies 

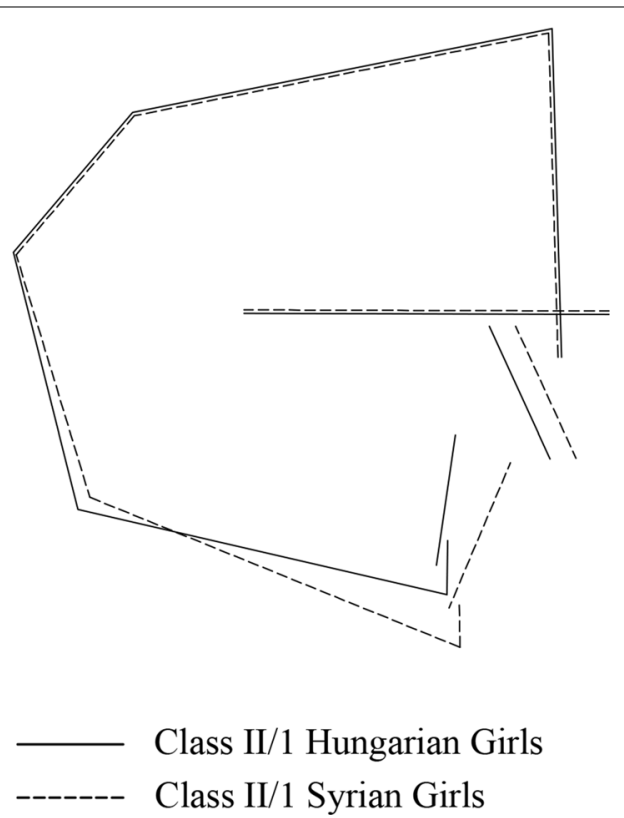
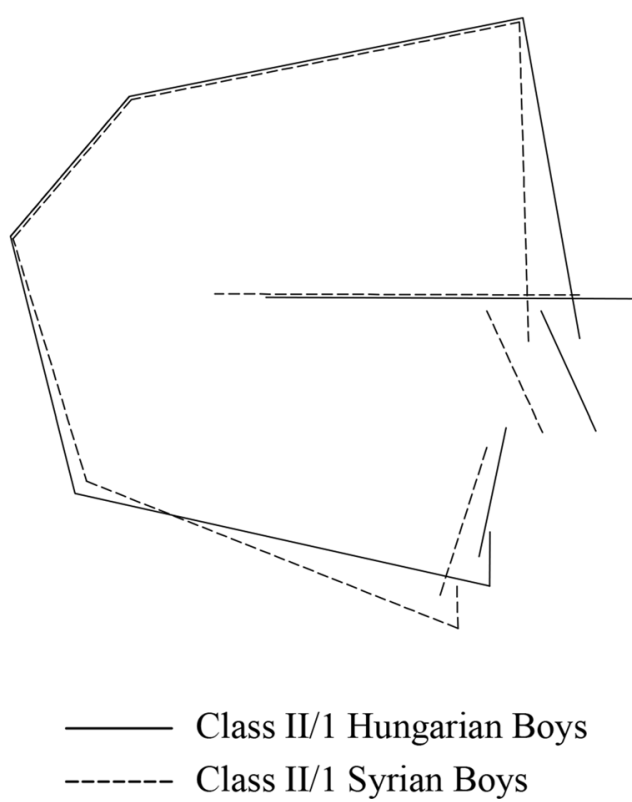

Fig. 1 Sex-based comparisons between Syrian and Hungarian adolescents with Class II/1 malocclusion

have reported protruded lower incisors [20-22, 26], and two comparative studies $[9,10]$ support ethnic variations in lower incisor position between non-Caucasian and Caucasian populations. Since a tooth-size excess with space limitation might cause incisor protrusion, the larger anterior tooth-size ratios of Syrian girls relative to Hungarian girls might further account for their lower incisor protrusion. This is because the large anterior tooth-size ratios of Syrian girls reflect a relative toothsize excess in the lower anterior region. The significant difference in anterior tooth-size ratio between Syrian and Hungarian girls can be attributed to ethnic variations $[4$, 5].

\section{Clinical implications}

First, because Class II/1 malocclusion in Hungarian adolescents represents sagittal discrepancy (protruded maxillae in boys; short mandibles in girls), treatment strategies should aim to inhibit maxillary growth using extra-oral forces in Hungarian boys and enhance mandibular growth using functional appliances in Hungarian girls. Second, since Syrian adolescents had considerable vertical tendencies and most orthodontic treatment mechanics tend to open the bite, greater care should be exercised to control the vertical dimension when treating Syrian adolescents compared with Hungarian adolescents. Treatment strategies for Class II/1 Syrian adolescents should aim to alter the extent and direction of vertical facial growth and prevent posterior mandibular rotation. Finally, Class II/1 Syrian girls exhibited more protrusive lower incisors with relative tooth-size excess in the lower anterior segment, which affects treatment objectives regarding the optimal final position of these teeth. Therefore, a more interproximal reduction might be a better indication for Syrian girls than Hungarian girls, if the treatment decision is to decrease protrusion. Contrarily, protruded lower incisors, more than the standard levels, might be acceptable outcomes in Syrian girls.

\section{Conclusions}

Class II/1 treatment strategies for Hungarian adolescents are not applicable to Syrian adolescents, because.

- Class II/1 malocclusion reflects sagittal discrepancy in Hungarian adolescents (protruded maxillae in boys; short mandibles in girls), while it was caused by excessive vertical growth among Syrian adolescents, regardless of sex.

- Class II/1 Syrian girls have more protrusive lower incisors with a relative tooth-size excess in the lower anterior region compared with Class II/1 Hungarian girls.

Thus, even among patients with the same malocclusion type, dentoskeletal and tooth-size characteristics can vary with ethnicity. Hence, orthodontists should 
be aware of this variation to optimize their differential diagnosis and treatment planning.

\section{Limitations}

Although sample size estimation showed sufficient sample sizes, they were relatively small. This was the major drawback of the present study; therefore, the results should be interpreted with caution, and additional studies with larger sample sizes are warranted.

\section{Supplementary information}

Supplementary information accompanies this paper at https://doi. org/10.1186/s13104-020-05115-0.

Additional file 1: Table S1. Definitions of the cephalometric measurements used in this study.

Additional file 2: Figure S1. Landmarks and reference lines used in this study.

Additional file 3: Table S2. Overall comparison of cephalometric measurements and tooth-size ratios between the two ethnic groups.

\section{Abbreviation}

Class II/1: Class II division 1

\section{Acknowledgements}

Not applicable.

\section{Authors' contributions}

AA contributed to the planning, data acquisition, analysis of data, interpretation of the results and writing of the manuscript. AK contributed to analysis of data, interpretation of the results and writing of the manuscript. MM contributed to the planning, analysis of data, interpretation of the results and writing of the manuscript. All authors read and approved the final manuscript.

\section{Funding}

Open access funding was provided by the University of Szeged (SZTE).

\section{Availability of data and materials}

The datasets generated and analyzed during the current study are available from the corresponding authors on reasonable request.

\section{Ethics approval and consent to participate}

The present study was approved by the Human Investigation Review Board at the University of Szeged (151/2018-SZTE). Written informed consent to participate in this study was provided by the participants or their parent/legal guardian.

\section{Consent for publication}

Not applicable.

\section{Competing interests}

The authors declare that they have no competing interests.

Received: 17 April 2020 Accepted: 26 May 2020

Published online: 03 June 2020

\section{References}

1. Vela E, Taylor RW, Campbell PM, Buschang PH. Differences in craniofacial and dental characteristics of adolescent Mexican Americans and European Americans. Am J Orthod Dentofacial Orthop. 2011;140(6):839-47.
2. Abbassy MA, Horiuchi M, Harouny NE, Kanno Z, Ono T. Comparative cephalometric study of Class I malocclusion in Egyptian and Japanese adult females. Orthod Waves. 2012;71(2):59-65.

3. Trivedi K, Singh S, Shivamurthy DM, Doshi J, Shyagali T, Patel B. Analysis of cephalometrics for orthognathic surgery: determination of norms applicable to Rajasthani population. Natl J Maxillofac Surg. 2010;1 (2):102-7.

4. Kumar TP, Chitra P. Determination of bolton norms for Indian population sample. Orthod J Nepal. 2017;7(1):33-6.

5. Lavelle CLB. Maxillary and mandibular tooth size in different racial groups and in different occlusal categories. Am J Orthod. 1972;61(1):29-37.

6. Al Taki A, Abuhijleh E, Haider K. Dentofacial cephalometric values for emirati adults with normal occlusion and well-balanced faces. Smile Dent J. 2010:5(4):6-10.

7. Abbassy MA, Abushal A. Differences in dentofacial characteristics of Class I malocclusion between Saudi and Japanese adult females. J Orthod Sci. 2015;4(3):86-91.

8. Afifi A, Taha M, Nassar E. Saudian norms of Mc Namara's cephalometric analysis. Egypt Orthod J. 2008;33:41-9.

9. Phelan T, Buschang PH, Behrents RG, Wintergerst AM, Ceen RF, Hernandez A. Variation in Class II malocclusion: comparison of Mexican mestizos and American whites. Am J Orthod Dentofacial Orthop. 2004;125(4):418-25.

10. Ishii N, Deguchi T, Hunt NP. Morphological differences in the craniofacial structure between Japanese and Caucasian girls with Class II division 1 malocclusions. Eur J Orthod. 2002;24(1):61-7.

11. Rana N, Qu YY, Wei Y, Liu L. Comparison of cephalometric hard and soft tissues of adolescents with angle Class II division 1 malocclusion between Northern Chinese population and Northern Indian Population. Chin J Dent Res Off J Sci Sect Chin Stomatol Assoc CSA. 2017;20(1):33-42.

12. Alatrach $A B$, Saleh FK, Osman E. The prevalence of malocclusion and orthodontic treatment need in a sample of Syrian children. Eur Sci J. 2014;10(30):230-47.

13. Gábris K, Márton S, Madléna M. Prevalence of malocclusions in Hungarian adolescents. Eur J Orthod. 2006;28(5):467-70.

14. Abuhijleh E, Al Taki A, Rahhal A. The cephalometric norms of various ethnicities and their significance. Acta Sci Dent Sci. 2019;3(8):21-2.

15. Nourallah AW, Splieth CH, Schwahn C, Khurdaji M. Standardizing interarch tooth-size harmony in a Syrian population. Angle Orthod. 2005;75(6):996-9.

16. Al Sabbagh R. Syrian norms of menamara cephalometric analysis. Int Arab J Dent. 2014;392(3561):1-7.

17. Csiki I, Jianu R, Stratul S-I, Vegh A. Are the ricketts norms adequate for middle European adolescents? Timisoara Med J. 2008;58(1-2):74-7.

18. Gurdán Z, Marada G, Herényi G, Nagy Á. Examining tooth-size discrepancies in regard to treatment, treatment planning and completion. Open J Dent Oral Med. 2014;2(3):43-6.

19. Elsasser WA, Wylie WL. The craniofacial morphology of mandibular retrusion. Am J Phys Anthropol. 1948;6(4):461-74

20. Isik F, Nalbantgil D, Sayinsu K, Arun T. A comparative study of cephalometric and arch width characteristics of Class II division 1 and division 2 malocclusions. Eur J Orthod. 2006;28(2):179-83.

21. Al-Khateeb EA, Al-Khateeb SN. Anteroposterior and vertical components of Class II division 1 and division 2 malocclusion. Angle Orthod. 2009;79(5):859-66.

22. de Freitas MR, dos Santos MAC, de Freitas KMS, Janson G, de Freitas DS, Henriques JFC. Cephalometric characterization of skeletal Class II, division 1 malocclusion in white Brazilian subjects. J Appl Oral Sci. 2005;13(2):198-203.

23. Demir A, Uysal T, Basciftci FA. Determination of skeletal and dental characteristics of Class II malocclusion. Turk J Orthod. 2005;18(3):205-14.

24. Altemus LA. Horizontal and vertical dentofacial relationships in normal and Class II division I malocclusion in girls 11-15 years. Angle Orthod. 1955;25(3):120-37.

25. Rothstein T, Yoon-Tarlie C. Dental and facial skeletal characteristics and growth of males and females with Class II, division 1 malocclusion between the ages of 10 and 14 (revisited)_Part I: characteristics of size, form, and position. Am J Orthod Dentofacial Orthop. 2000;117(3):320-32.

26. Sayın MO, Türkkahraman $\mathrm{H}$. Cephalometric evaluation of nongrowing females with skeletal and dental Class II, division 1 malocclusion. Angle Orthod. 2005;75(4):656-60. 
27. Oh E, Ahn S-J, Sonnesen L. Ethnic differences in craniofacial and upper spine morphology in children with skeletal Class II malocclusion. Angle Orthod. 2018;88(3):283-91.

28. Hulley SB, Cummings SR, Browner WS, Grady DG, Newman TB. Designing clinical research. Wolters Kluwer Health; 2013.

29. Baccetti T, Franchi L, McNamara JA Jr. An improved version of the cervical vertebral maturation (CVM) method for the assessment of mandibular growth. Angle Orthod. 2002;72(4):316-23.

30. Jarabak JR, Fizzell JA. Technique and treatment with light-wire edgewise appliances, ed. 2, St. 1972.

31. Steiner CC. Cephalometrics for you and me. Am J Orthod. 1953;39(10):729-55.

32. Bhatia SN, Leighton BC. Manual of facial growth: a computer analysis of longitudinal cephalometric growth data. Oxford: Oxford University Press, Inc.; 1993.
33. Moorrees CFA, Reed RB. Correlations among crown diameters of human teeth. Arch Oral Biol. 1964;9(6):685-97.

34. Bolton WA. Disharmony in tooth size and its relation to the analysis and treatment of malocclusion. Angle Orthod. 1958;28(3):113-30.

35. Dahlberg G. Statistical methods for medical and biological students. London: George Alien and Unwin Ltd; 1940.

\section{Publisher's Note}

Springer Nature remains neutral with regard to jurisdictional claims in published maps and institutional affiliations.
Ready to submit your research? Choose BMC and benefit from:

- fast, convenient online submission

- thorough peer review by experienced researchers in your field

- rapid publication on acceptance

- support for research data, including large and complex data types

- gold Open Access which fosters wider collaboration and increased citations

- maximum visibility for your research: over 100M website views per year

At BMC, research is always in progress.

Learn more biomedcentral.com/submissions 
III. Accepted article/In press 